\title{
INLET METERING PUMP ANALYSIS AND EXPERIMENTAL EVALUATION WITH APPLICATION FOR FLOW CONTROL
}

\author{
A Dissertation \\ presented to \\ the Faculty of the Graduate School \\ at the University of Missouri-Columbia \\ In Partial Fulfillment \\ of the Requirements for the Degree \\ Doctor of Philosophy \\ by \\ HASAN H. ALI \\ Dr. Roger Fales, Dissertation Supervisor \\ December 2017
}


The undersigned, appointed by the dean of the Graduate School, have examined the dissertation entitled

\section{INLET METERING PUMP ANALYSIS AND EXPERIMENTAL EVALUATION WITH APPLICATION FOR FLOW CONTROL}

presented by Hasan Hamad Ali, a candidate for the degree of doctor of philosophy, and hereby certify that, in their opinion, it is worthy of acceptance.

Professor Roger Fales

Professor Noah Manring

Professor Craig Kluever

Professor Steven Borgelt

Professor Stephen Montgomery-Smith 


\section{ACKNOWLEDGEMENTS}

I would like to express my sincere gratitude to Dr. Roger Fales for his effort and contribution to my research. The completion of my Ph.D. degree would not have been possible without his guidance and assistance.

I would also like to thank Dr. Noah Manring, Dr. Craig Kluever, Dr. Steven Borgelt, and Dr. Stephen Montgomery-Smith for taking the time to serve on my dissertation committee. I am appreciative of their ongoing support throughout this work.

I would also like to take the opportunity to thank our partners at Caterpillar: Jeff Kuehn, Jeremy Peterson, Viral Mehta, Hongliu Du, and Randy Harlow for both the financial support and collective engineering experience that they contributed to this project. I am honored to have collaborated with this team of engineers. I am also grateful for the prototype they were able to provide.

I would like to thank the faculty of the Mechanical and Aerospace department at MU for helping me to excel in my field of interest.

Finally, I take this opportunity to express the profound gratitude to my family for their love and continuous support. 


\section{TABLES OF CONTENTS}

ACKNOWLEDGEMENTS .................................................................................. ii

LIST OF FIGURES ................................................................................... vii

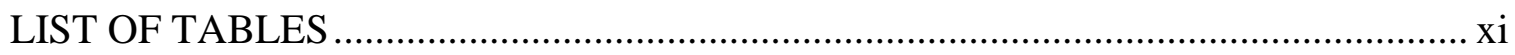

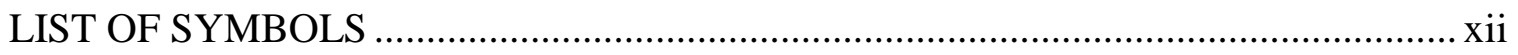

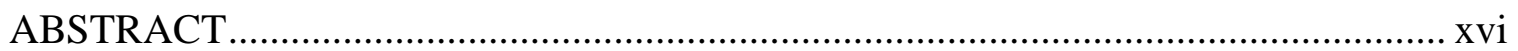

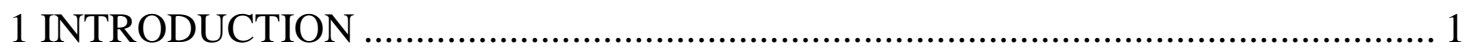

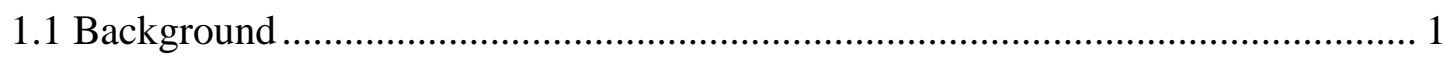

1.2 System Description ...................................................................................... 3

1.3 Velocity Control System................................................................................ 4

1.4 Contribution of the Present Work ……………………...................................... 7

1.5 Dissertation Outline ..........................................................................................

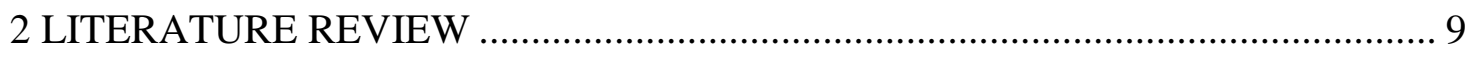

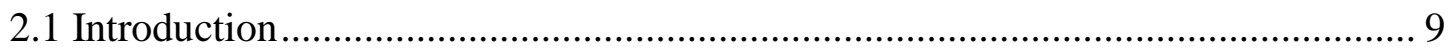

2.2 Variable Displacement Pump ................................................................... 9

2.3 Fixed Displacement Pump …………………………................................. 15

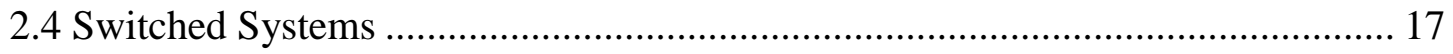

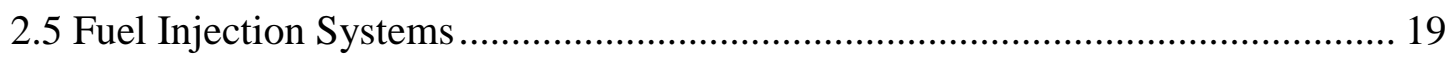

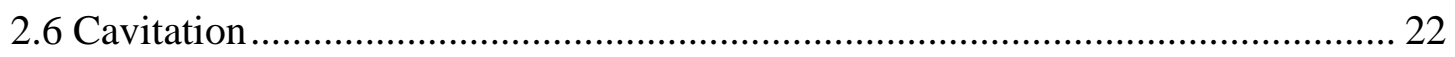


2.7 Literature Review Summary

3 INLET-METERED PUMP EFFICIENCY ........................................................ 25

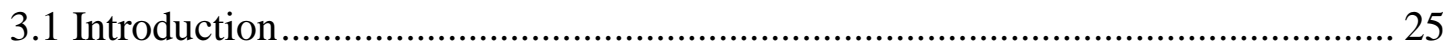

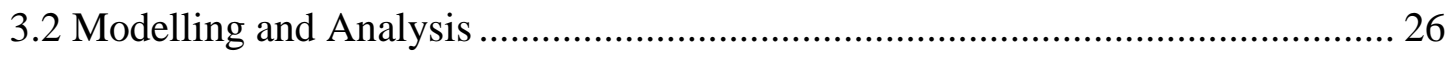

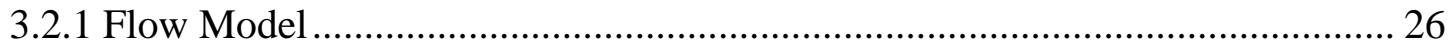

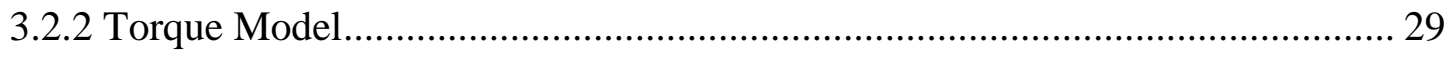

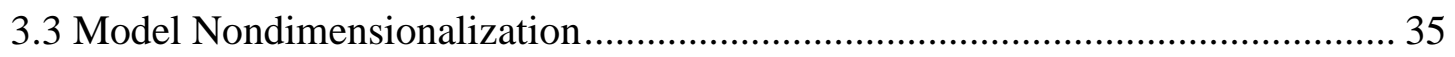

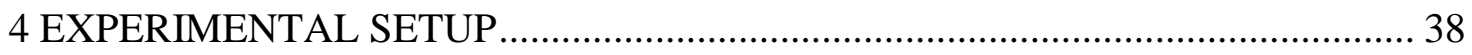

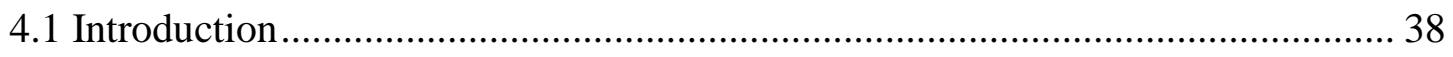

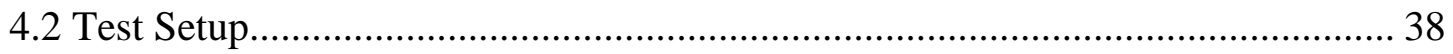

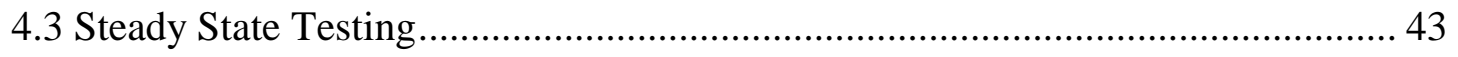

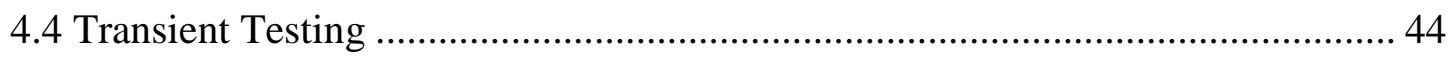

4.5 Inlet-Metering Valve and Pump Components ............................................ 44

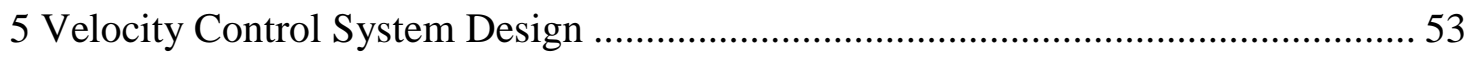

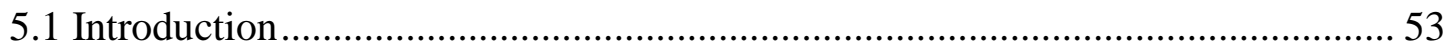

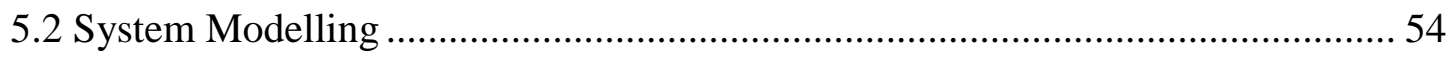

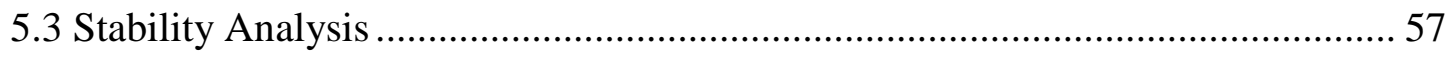

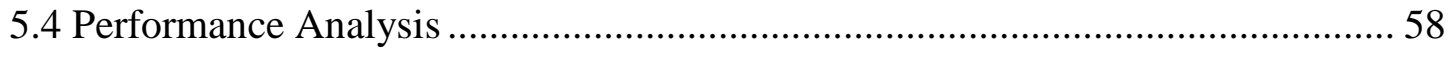

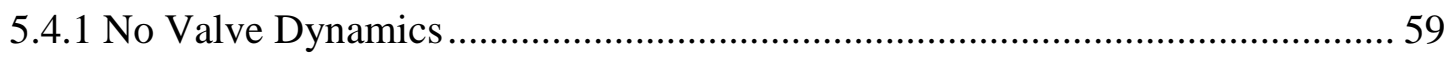


5.4.1.1 Proportional controller design

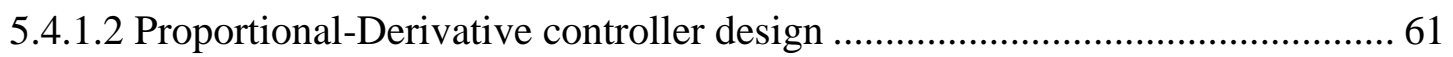

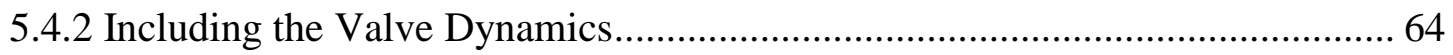

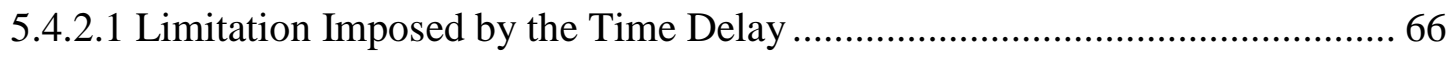

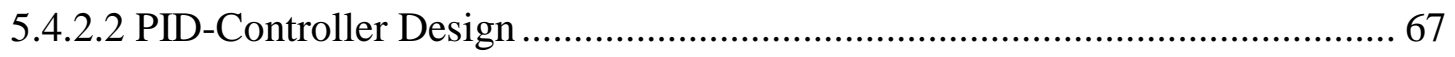

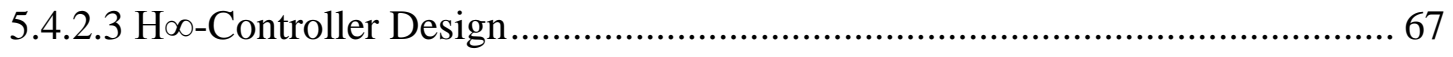

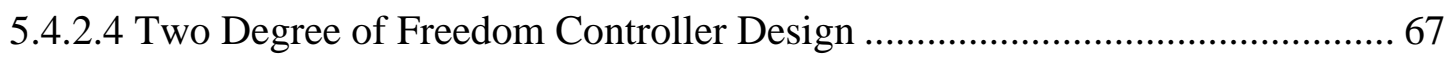

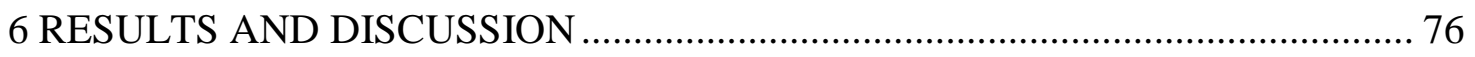

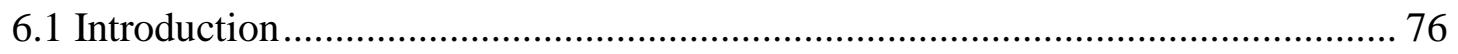

6.2 Determination of the Coefficients in Eqs. (3.29) and (3.31) ............................. 76

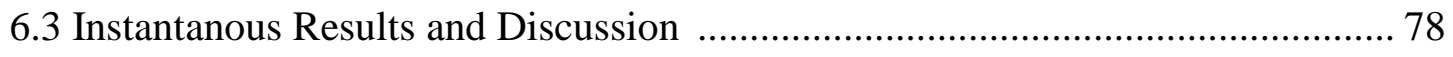

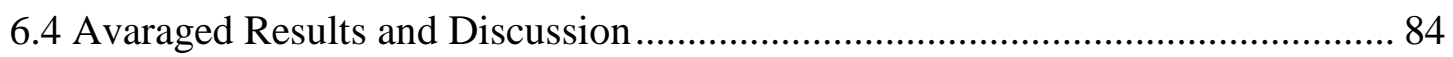

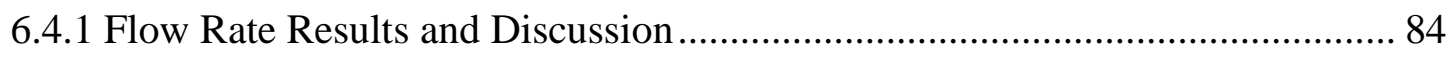

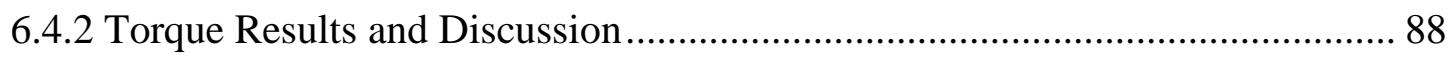

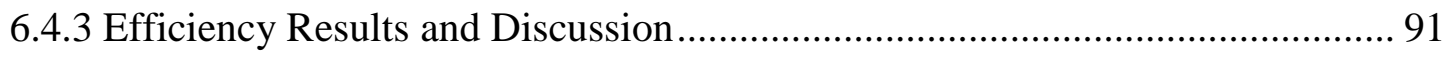

6.5 Velocity Control System Design Results and Discussion ................................ 95

6.5.1 No Valve Dynamics Results and Discussion.............................................. 95

5.4.1 Including the Valve Dynamics Results and Discussion .............................. 100 


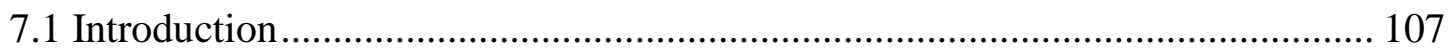

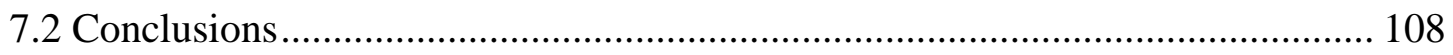

7.3 Recommendations for Future Work.......................................................... 110

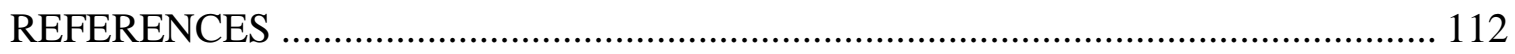

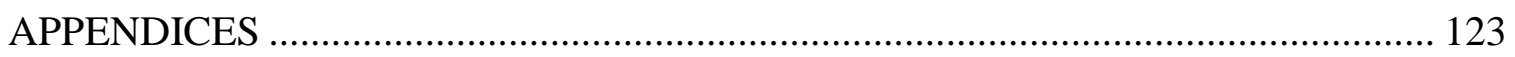

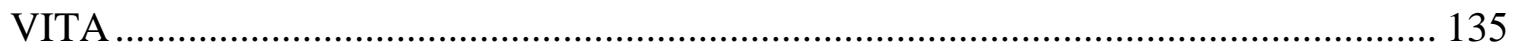




\section{LIST OF FIGURES}

Figure Page

Figure 1.1. A Schematic of Hydrostatic Transmission .............................................. 2

Figure 1.2. Variable Displacement Pump .............................................................. 3

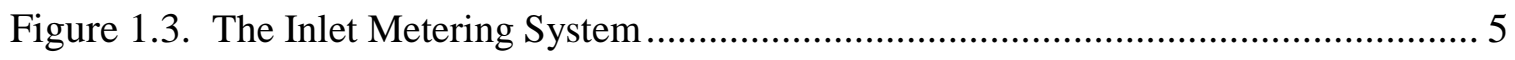

Figure 1.4. The Inlet Metering velocity control System ......................................... 6

Figure 3.1. Inlet Metering Valve and Fixed Displacement Single Piston Pump System 25

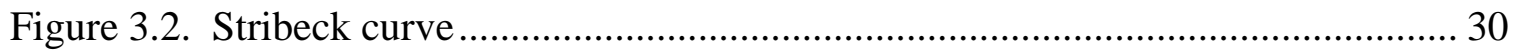

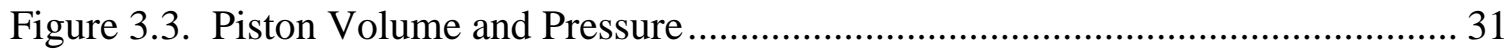

Figure 4.1. Inlet metering pump testing circuit diagram ...................................... 40

Figure 4.2. Inlet metering system experimental setup ........................................... 42

Figure 4.3. Installed Pump Connected to the Torque sensor housing and hoses............ 43

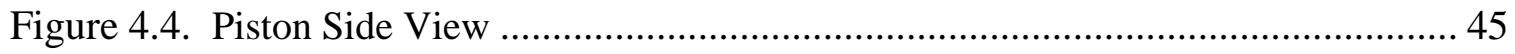

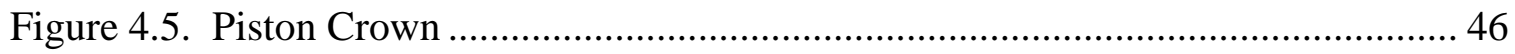

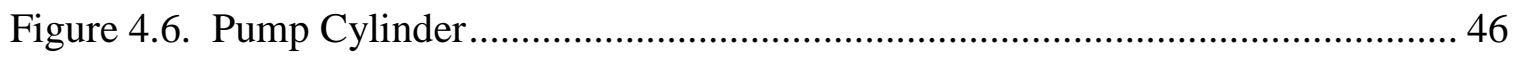

Figure 4.7. Cylinder Head with Inlet Check on the Side and Discharge Check Valve

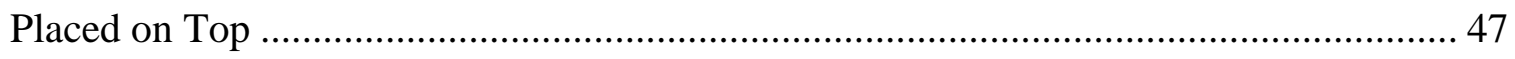

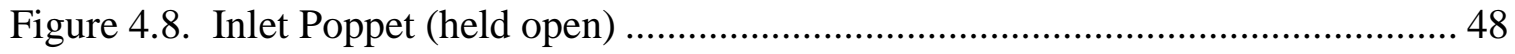

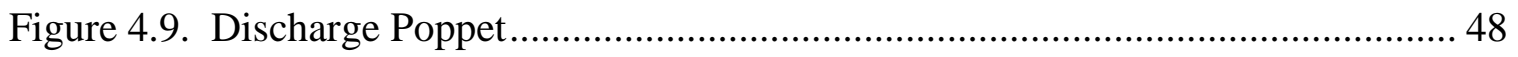

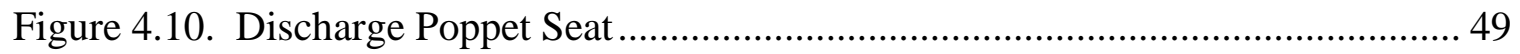

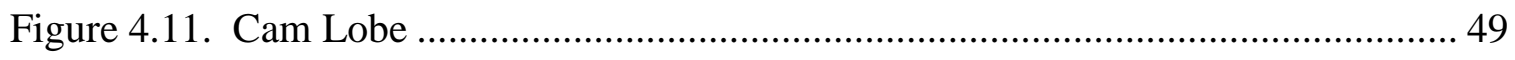

Figure 4.12. Journal Bearing Insert in the Pump Housing End Cap ................................ 50

Figure 4.13. Inlet Metering Valve Sub Assembly .................................................... 51

Figure 4.14. Inlet Metering Valve disassembled.................................................. 52 
Figure 4.15. Case drain for lubrication flow 52

Figure 5.1. Velocity Control System for a Linear Actuator ...................................... 53

Figure 5.2. Block Diagram of the Open Loop System ............................................. 59

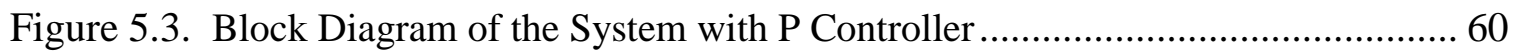

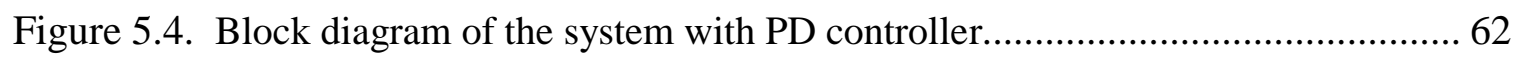

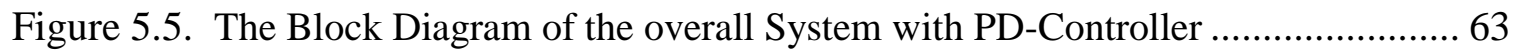

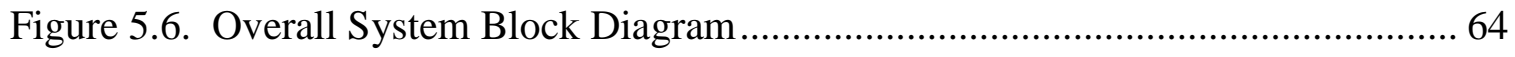

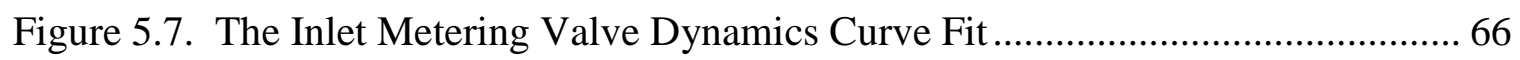

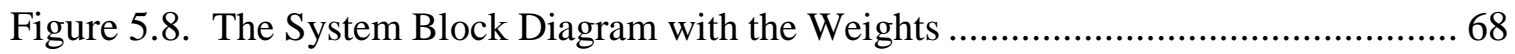

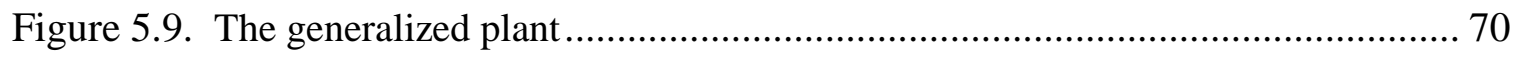

Figure 5.10. The frequency response of the performance weight, $S$, and $S . G_{d \ldots \ldots \ldots \ldots . . .} 71$

Figure 5.11. The frequency response of the Control Effort weight, S.K, and S.K.G $G_{d \ldots \ldots .} 71$

Figure 5.12. Two degrees of freedom controller .................................................. 72

Figure 6.1. Comparison of IMP flow rate projections with actual data for 2500RPM, 2

MPa inlet pressure, $25 \mathrm{MPa}$ discharge Pressure and a step input signal ....................... 79

Figure 6.2. Comparison of IMP torque projections with actual data for 2500RPM, $2 \mathrm{MPa}$ inlet pressure, $25 \mathrm{MPa}$ discharge Pressure and a step input signal ............................... 80

Figure 6.3. Comparison of IMP efficiency projections with actual data for 2500RPM, 2 MPa inlet pressure, $25 \mathrm{MPa}$ discharge Pressure and a step input signal ....................... 81

Figure 6.4. Comparison of IMP flow rate projections with actual data for chirp input

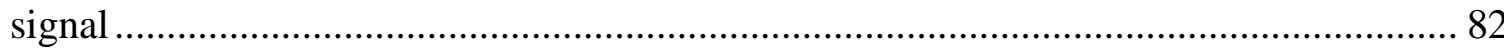

Figure 6.5. Comparison of IMP torque projections with actual data for chirp input signal 83 
Figure 6.6. Comparison of IMP efficiency projections with actual data for chirp input signal.......

Figure 6.7. Non-dimensional pump discharge flow vs. non-dimensional valve opening for $2 \mathrm{MPa}$ inlet pressure and $25 \mathrm{MPa}$ discharge pressure where the solid lines represent the model and the markers represent the data 85

Figure 6.8. Non-dimensional pump discharge flow vs. non-dimensional pump speed for $2 \mathrm{MPa}$ inlet pressure and $25 \mathrm{MPa}$ discharge pressure where the solid lines represent the model and the markers represent the data. 86 Figure 6.9. Non-dimensional pump discharge flow vs. non-dimensional valve opening for $2 \mathrm{MPa}$ inlet pressure and $2500 \mathrm{RPM}$ speed where the solid lines represent the model and the markers represent the data. 87 Figure 6.10. Non-dimensional pump discharge flow vs. non-dimensional valve opening for $25 \mathrm{MPa}$ discharge pressure and $1000 \mathrm{RPM}$ speed where the solid lines represent the model and the markers represent the data 88

Figure 6.11. Non-dimensional torque vs. non-dimensional valve opening for $25 \mathrm{MPa}$ discharge pressure and $2 \mathrm{MPa}$ inlet pressure where the solid lines represent the model due to Eq. (31) and the markers represent the data.

Figure 6.12. Non-dimensional torque vs. non-dimensional valve opening for $25 \mathrm{MPa}$ discharge pressure and $2 \mathrm{MPa}$ inlet pressure solid lines represent the model due to Eq. (31) and the markers represent the data

Figure 6.13. Non-dimensional Torque vs. non-dimensional valve opening for 2500 RPM discharge pressure and $2 \mathrm{MPa}$ inlet pressure where the solid lines represent the model and the markers represent the data 
Figure 6.14. Overall pump efficiency vs. valve non-dimensional area for an inlet pressure of $2 \mathrm{MPa}$, pump shaft speed of $2500 \mathrm{RPM}$, and listed discharge pressures 92

Figure 6.15. Overall pump efficiency vs. valve non-dimensional area for $2 \mathrm{MPa}$ inlet pressure and $25 \mathrm{MPa}$ discharge pressure 93 Figure 6.16. Overall pump efficiency vs. non-dimensional valve opening for $25 \mathrm{MPa}$ discharge pressure and 1000 RPM 94 Figure 6.17. Cylinder velocity vs. time with a step disturbance force and no controller 88 Figure 6.18. Pressure vs. time with a step disturbance force and no controller. 97 Figure 6.19. Cylinder velocity vs. time with PD controller and a step disturbance force .... 98 Figure 6.20. Pressure vs. time with PD controller and a step disturbance force. 99 Figure 6.21. Non-dimensional valve opening area vs. time with PD controller and a sinusoidal disturbance force. 100

Figure 6.22. Velocity time response for the system with a fast valve with PD controller . 102 Figure 6.23. The frequency response of the PID and the $\mathrm{H}_{\infty}$ controllers 103 Figure 6.24. The velocity time response for open-loop and closed-loop with PID controller 103 Figure 6.25. The velocity time response with PID controller for different values of the controller gains. 104 Figure 6.26. The velocity time response with PID and $\mathrm{H}_{\infty}$ controllers. 104 Figure 6.27. The velocity time response with $\mathrm{H}_{\infty}$ controller and TDOF controller 105 


\section{LIST OF TABLES}

Table $\quad$ Page

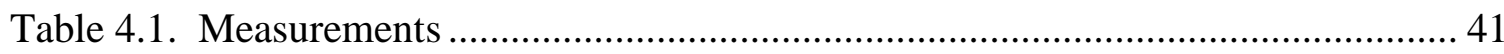

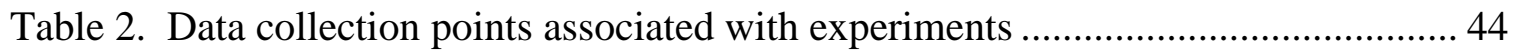

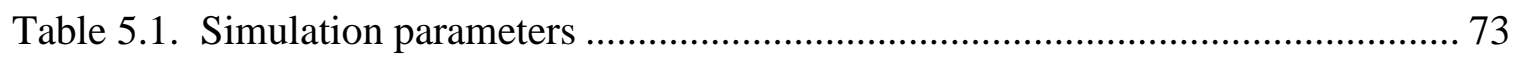

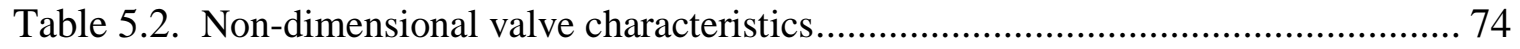

Table 5.3. Performance weight parameters ................................................................. 75

Table 6. The parameters of the feedback part of the TDOF controller (Eq. (5.38))............ 75

Table 7. Inlet metering pump flow and torque coefficients ...................................... 78 


\section{NOMENCLATURE}

A Static Friction Coefficient

$A_{A} \quad$ Actuator Cross Sectional Area

$A_{p} \quad$ Cross-Sectional Area of the Piston Pump

$A_{\mathrm{v}} \quad$ Valve Opening Area

$a \quad$ Maximum Low Frequency Error

B Boundary Lubrication Decay Rate Coefficient

C Hydrodynamic Lubrication Coefficient

e Steady State Error

F Disturbance Force

$F_{o} \quad$ Spring Preload

G Plant Transfer Function

$G_{v} \quad$ Valve Transfer Function

$K \quad \mathrm{H}_{\infty}$ Controller Transfer Function

$k \quad$ Spring Stiffness Coefficient

$k_{0} \quad$ Fluid Compression Coefficient

$k_{1} \quad$ Low Reynolds Number Leakage

$k_{2} \quad$ High Reynolds Number Leakage

$K_{d} \quad$ Derivative Controller Gain

$K_{p} \quad$ Proportional Controller Gain

$l \quad$ Width of the Camshaft Journal Bearing

$m \quad$ Mass of the Working Fluid within the Piston Volume

$\Pi \quad$ Hydraulic Power 


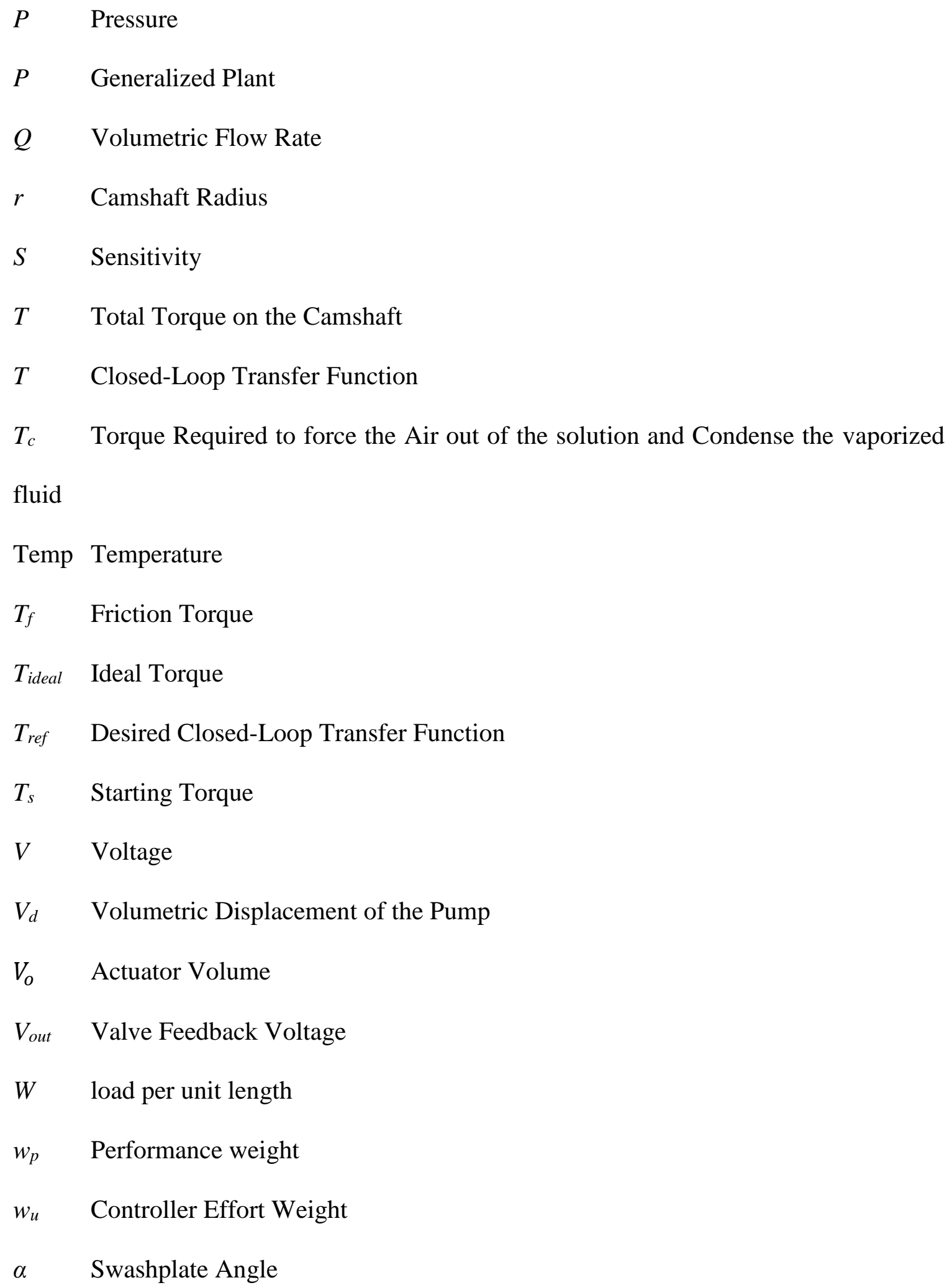




$\begin{array}{ll}\beta & \text { Fluid Bulk Modulus } \\ \eta & \text { Overall Pump Efficiency } \\ \eta_{a} & \text { Actuator Efficiency } \\ \mu & \text { Fluid Viscosity } \\ \mu s & \text { Friction Coefficient } \\ \tau_{l a g} & \text { Lag Time Constant } \\ \tau_{l a g} & \text { Lag Time Constant } \\ \omega & \text { Pump Shaft Speed } \\ \omega_{I} & \text { Zero Location of the Integral Controller } \\ \omega_{n} & \text { Natural Frequency } \\ \xi_{1} & \text { Bandwidth Frequency } \\ \xi_{2} & \text { None Constant } \\ & \text { Parameter for thermodynamic fluid properties } \\ \xi_{b} & \text { Nondimensional Group } \\ & \end{array}$

\section{SUBSCRIPTS}

$\begin{array}{ll}A & \text { Port A of the actuator } \\ B & \text { Port B of the actuator } \\ d & \text { Discharge } \\ i & \text { inlet } \\ l & \text { Leakage } \\ r & \text { Reference Conditions }\end{array}$




\section{SUPERSCRIPTS}

$\wedge \quad$ Nondimensional Quantity

- $\quad$ Averaged Quantity 


\begin{abstract}
Axial piston pumps with variable volumetric displacement are often used to control flow and pressure in hydraulic systems. The displacement control mechanism in these pumps occupies significant space and accounts for significant cost in the pump design. Fixed displacement pumps have lower cost and a more compact design but suffer from significant energy consumption disadvantage due to the need for flow and pressure control by throttling flow and bypassing unused flow to pressures below the discharge pressure. An inlet metering valve (IMV) controlled pump marks a recent development in pumping technology for hydraulic systems. In this design, an inlet metering valve restricts inlet flow reducing inlet pressure so that the specific volume of the fluid is increased as it enters a fixed displacement pump. By altering the specific volume of the working fluid, the inlet metering valve permits precise control over the pump discharge flow. This study presents a theoretical model for inlet metering pump efficiency. The work considers additional sources of energy loss unique to the inlet metering system. Experimental results associated with inlet metering pump efficiency are presented. A comparison of the theoretical model and the experimental results is also included. It is determined that the current efficiency model accurately predicts efficiencies determined using experimental data. In addition, a velocity control system is considered which utilizes the inlet metering valve controlled pump. The stability and the performance of the velocity control system were studied for the open-loop and the closed-loop with a PID, $\mathrm{H}_{\infty}$, and a two degrees of freedom controllers. The simulation showed that the velocity control system is stable and has good performance characteristics.
\end{abstract}




\section{CHAPTER 1}

\section{INTRODUCTION}

\subsection{Background}

Several methods are used to transmit power from the place where it is generated to the place where it is needed. One of these methods is the hydrostatic transmission shown in Fig.1.1. In this method, a high-pressure hydraulic fluid is used to transmit the power. High power density, flexibility, small size, in addition to the ability to continuously change the amount of transmitted power are the advantages of the hydraulic systems. When a single pump is used for a range of duties, it should be sized to meet the greatest output demands. This means that the pump will be oversized and will operate inefficiently for the other conditions. For this reason, controlling the discharge flow rate results in reducing the energy losses and increasing the system life. Discharge flow rate can be controlled by using a variable displacement pump (Fig.1.2). In variable displacement pumps, a swash plate is used to adjust the flow delivered by the pump by controlling the angle of the swash plate. Variable displacement pumps are expensive and complicated. Another way to regulate the flow is by using a fixed displacement pump and unloading valve that is placed downstream from the pump to throttle or recirculate the excess flow. In this technique, a significant amount of hydraulic energy is lost as heat which increases the fluid temperature and reduces the system efficiency [1]. To avoid the valve losses, a variable speed drive could be used as a means of controlling the flow rate. However, variable speed drives usually have a slower response than valve controlled systems especially for large systems where the inertia effect is high. Also, using

continuously variable speed drive could result in an excessive vibration level, and the likelihood of operation under the resonance condition is greatly increased [2]. In recent years, new methods 
for achieving flow control have been developed such as with the use of high-speed switching valves [7-8]. Switched hydraulic systems require high-speed valves. In the present study, an inlet metering valve is placed upstream from a fixed displacement piston pump is used to control the pump flow rate. The next section will provide a detailed description of this system.

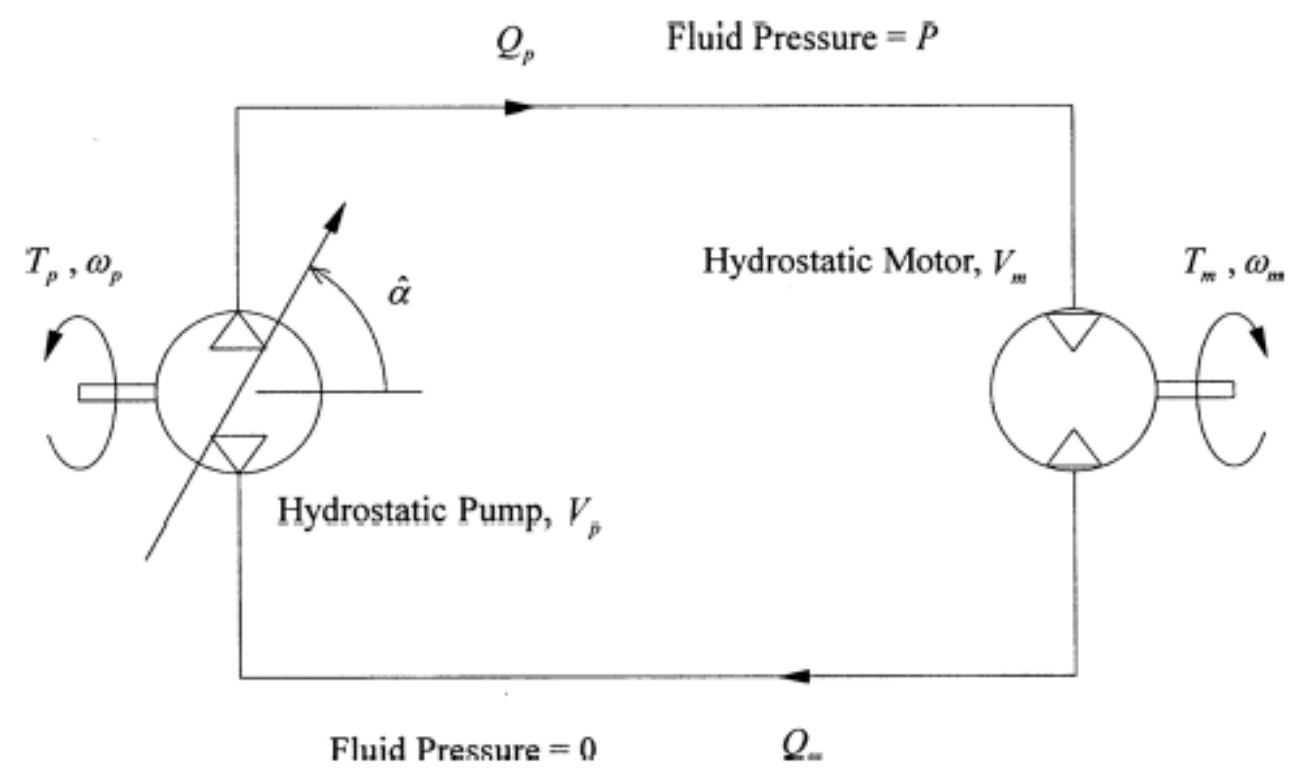

Fig.1.1: A schematic of hydrostatic transmission [35] 


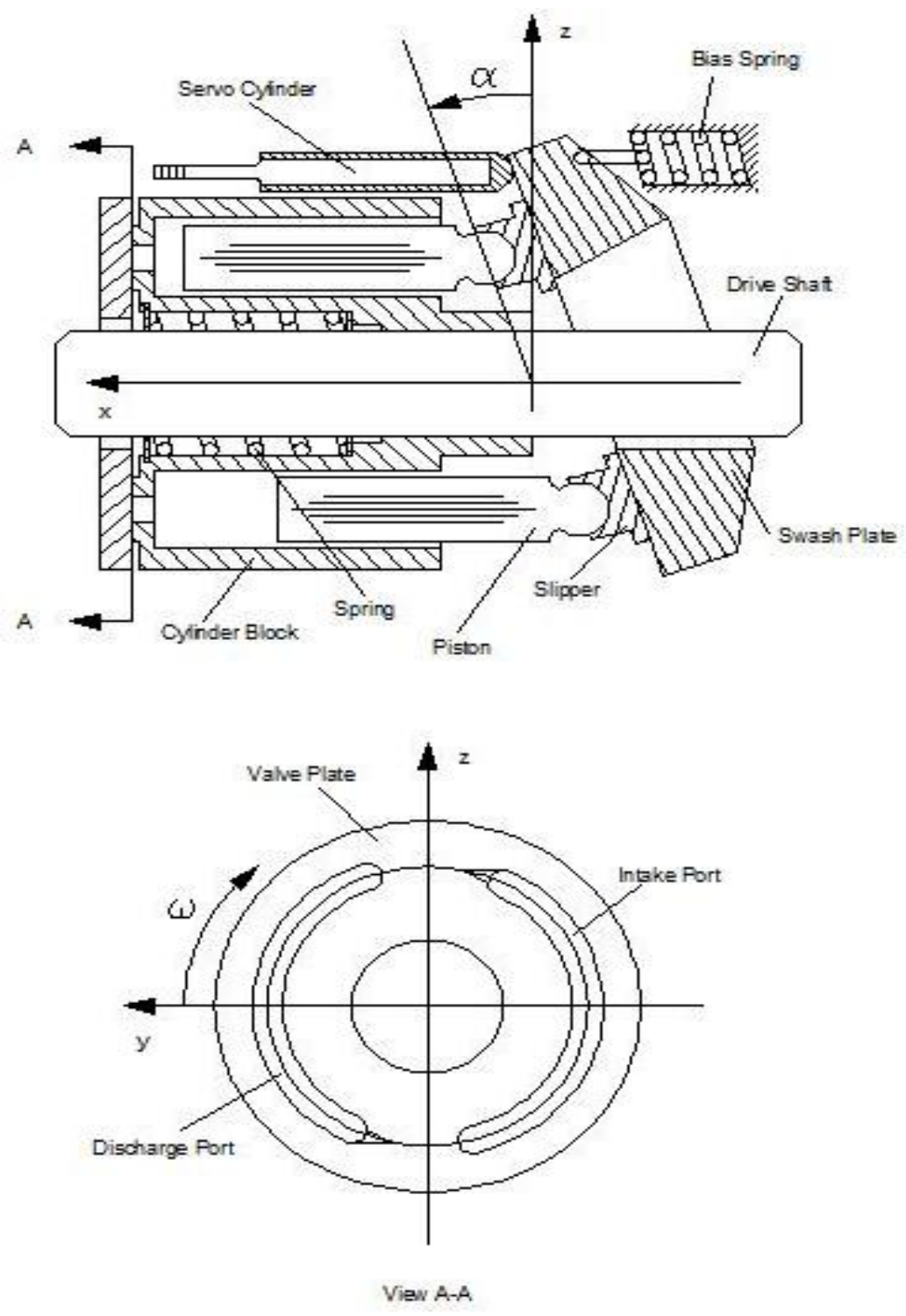

Figure 1.2. Variable Displacement Pump [29].

\subsection{System description}

The inlet metering pump system is shown in Fig. 1.3. This system includes a charge pump, an inlet metering valve, and a fixed displacement piston pump with check valves at the inlet and the outlet. A spring is used to hold the piston down so that it follows the motion of the cam profile. The piston pump requires check valves at both the inlet and outlet for operation. The charge pump supplies fluid at a constant inlet pressure. There is a pressure drop across the inlet valve and an 
increase in volume in the space between the valve and the pump piston as the piston moves downward. This increase in volume results in some combination of partial vaporization of the oil and dissolved air coming out of solution with the oil.

As the pump operates, the volume trapped between the inlet valve and the piston increases and the fluid pressure, $\mathrm{P}$, decreases causing the check valve to open. In the volume between the inlet valve and the piston, the fluid partially vaporizes or dissolved air to comes out of the solution effectively increasing the specific volume of the fluid. Fluid accumulates upstream from the first check valve. As the line upstream from the check valve is filled, the check valve opens and the piston volume fills with the liquid/gas/vapor mixture. This occurs when the piston is in the bottom dead center position. As the camshaft rotates, it forces the piston head upwards. The size of the internal piston volume decreases, which results in an elevated pressure and closing of the inlet check valve. The increased pressure condenses the fluid and forces the trapped air back into solution. After the fluid pressure reaches a pressure of $P_{d}$ the second check valve opens and the fluid travels downstream at a flow rate of $Q_{\mathrm{d}}$. Then the second check valve closes as the cylinder pressure decreases when the piston moves downward and the process continues with new fluid entering the control volume.

\subsection{Velocity control system}

The velocity control system for a linear actuator that utilizes an inlet metering system is shown in Figure 1.4. The system consists of an inlet metering system, a four-way directional valve, and a linear actuator. The four-way directional valve is always wide open to one of the actuator ports. It is used to guide the flow of the inlet metered pump (IMP) to one of the actuator ports, as required, according to the desired direction of the velocity of the hydraulic cylinder. The flow from the other port of the actuator is returned to the tank through the four-way directional valve. 


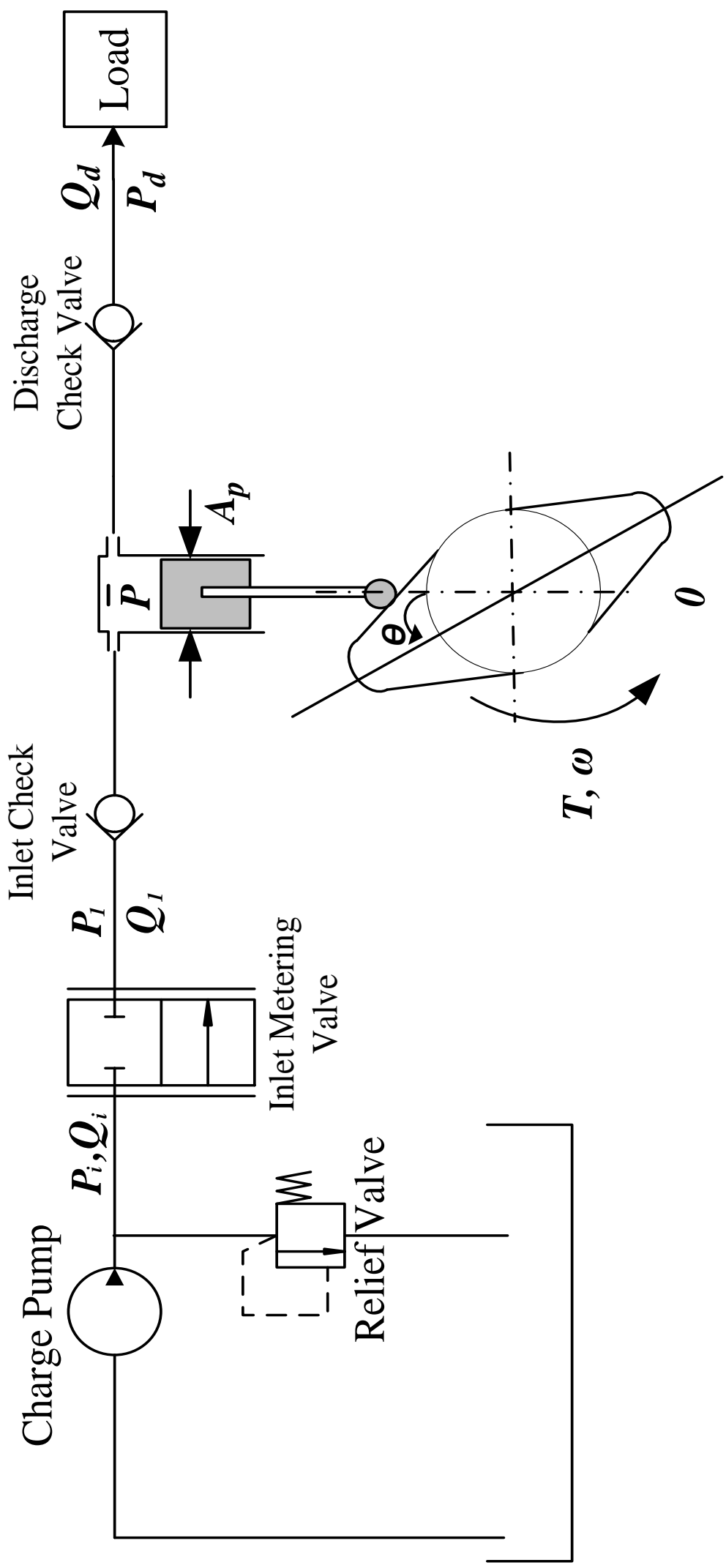

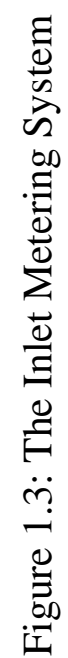




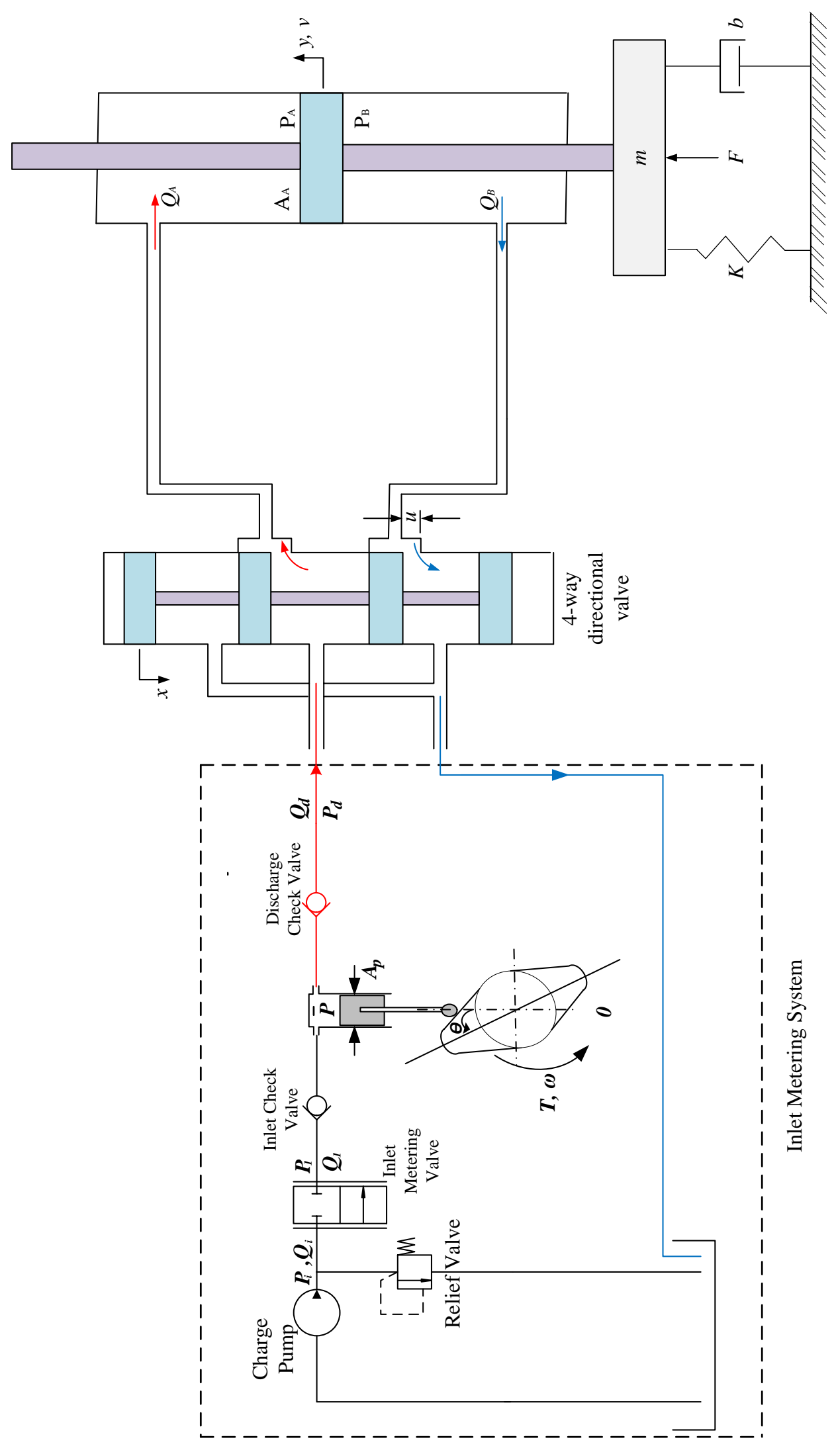

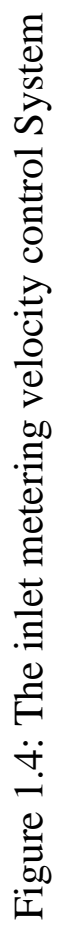




\subsection{Contributions of the present work}

The main objective of this work is to make an assessment of the feasibility of using an inlet metering pump within standard hydraulic circuits to replace axial piston pumps by conducting tests and analysis of performance and efficiency. The specific objectives are as follows:

1. Create a model of the inlet metered pump to determine its theoretical performance and to understand the physical phenomena involved in the pump dynamics and performance.

2. Test the inlet metered pump in the lab to determine the performance of the pump in terms of efficiency and to validate the model.

3. Analyze test data and model so that we can make conclusions about the performance of the pump and feasibility of using the pump in hydraulic systems.

4. Disassemble the pump after testing to search for any signs of significant wear possibly due to cavitation.

5. Make recommendations about the future use of the inlet metering system concept.

6. Design a velocity control system that utilizes the inlet metering system.

\subsection{Dissertation outline}

This dissertation is divided into seven chapters. Chapter one presents a background on flow control techniques and a description of the inlet metering system with an application on the hydraulic control systems. In chapter two, works carried out by other researchers on the flow control methods are reviewed and discussed. The analysis and modeling of the inlet metered pump flow, torque and efficiency are developed in chapter three. This chapter also presents the way of nondimensionalization of the model. The experimental setup details and the test conditions are described in chapter four. Chapter five presents the design of the inlet metering velocity control system. Open-loop and closed-loop analysis are also discussed in this chapter. The validation of 
the model and the results from the experimental and theoretical analysis are presented in chapter six. Finally, a list of conclusions from this work followed by some recommendations for future work is presented in chapter seven. 


\section{CHAPTER 2}

\section{LITERATURE REVIEW}

\subsection{Introduction}

This chapter aimed at providing an overview of the available literature that is relevant to this study. It reviews various ways that are used to control the flow rate of a pump using variable and fixed displacement pumps. Due to the similarity between the inlet metering system and the fuel injection system in the diesel engines, a review of the published studies for the diesel injector system will also be presented in this section. A review of available literature on cavitation phenomenon is also presented in this chapter to provide a good understanding of this phenomenon that might be associated with the inlet metering systems. The chapter ends with a summary of the reviewed literature.

\subsection{Variable displacement pumps}

Many investigations have been done to design and analyze the variable displacement machines. Displacement controlled systems are energy efficient [3]. Wilson [4] developed a model for volumetric and torque efficiencies. His model included viscous torque and low Reynolds number leakage equations. The high Reynolds number leakage was taken into account by the model developed by Schlosser [5]. In order to extend the previous model to include the variable displacement machines, Thoma [6] developed a model introducing the frictional coefficient. Equations for the swash plate dynamic were derived and written in a linearized form in the model developed by Aker and Zeiger [7]. The effect of oil entrapment behind the valve plate was studied by Aker and Zeiger [8]. They discussed the effect of swashplate angle, pump speed, and discharge pressure, in addition to the entrapment angle on instantaneous pressure and torque by solving the 
dynamical equations of motion. In their analysis, they divided the pressure distribution into six regions depending on the angular position of the piston. Their results showed that the peak pressures vary as the pump angular speed or the swashplate angle varies. The entrapment angle was shown to have no effect on the peak pressure, but it affects the pressure recovery time and the torque.

Kaliafetis and Th. Costopoulos [9] studied the characteristics of a standard variable displacement axial piston pump with a pressure regulator. They derived the governing equations for the system and used computer simulation to determine the parameters that affect the pump operating pressure. Their results were compared with the manufacturer's curve and showed good agreement. They concluded that the outlet pressure is mainly affected by the control valve position which affects the piston pressure and on the pistons areas.

Closed form equations that may be used for a variable displacement design were provided in a study developed by Manring and Johnson [10]. They discussed the effect of changing the volume of the actuator and the hose, the controller flow gain, and the leakage. In their model, they assumed that the inertia and damping of the swash plate are negligible compared to the stiffness of the control actuator.

The damping mechanism on the swashplate that is caused by the piston pressure was studied by Zhang et al. [11] by assuming a pressure profile for a variable swashplate angle. A linearized model of the hydrostatic transmission with details of the pump dynamics was developed by Manring, N.D. and Luecke, G.R [12] which does not need to use experimental data -- the modeling parameters may be determined from the geometry of the transmission. A third order system was produced from the dynamics of the pump, the motor, and the hose. The stability of the system was discussed using the Routh-Hurwitz criterion. 
The forces and moments exerted on the swash-plate of an axial piston pump were studied by Manring $[13,14]$. He derived equations for the forces needed to control the swashplate motion and the pressure carryover angle. For a proper operation of the pump, these forces should be overcome by the controller. An equation for the instantaneous torque on the pump shaft was derived in terms of pump geometry, piston accelerations. The average torque was shown to be a function of the pressure carryover angle.

Manring [15] studied the idealized and the actual flow ripple of a swash-plate axial piston pump. The idealized case was performed by neglecting the leakage flow and the fluid compressibility that were taken into account in the actual case. The ripple height and the ripple frequency were studied for pumps with odd and even number of pistons. He stated that the pumps designed with even and odd number of pistons have almost the same flow ripple.

Shi and Manring [16] used the principles of tribology to derive an expression for the effective coefficient of friction by using the Stribeck curve to develop a model for the torque efficiency. They compared this model with traditional models. The comparison showed an improvement in their model over the previous ones.

The effect of the valve plate design and the optimal timing on the pump efficiency, the noise, the pressure ripple, and the forces exerted on the swash-plate was addressed by several researchers [17-23]. They stated that the pump volumetric efficiency is affected by the valve plate design and the optimal timing. The results showed that the optimal timing, which is not symmetric for the inlet and the discharge, can eliminate the dynamic pressure ripples and reduces the noise.

Lee and Hong [24] performed a study on the effect of coating the cylinder barrel of a bent axis piston pump with $\mathrm{CrSiN}$ on the torque efficiency of the pump that is used for an electro- 
hydraulic actuator. The pump in these systems exhibits unsteady conditions because it operates only when error compensation is needed. These unsteady conditions cause wear on the valve plate. Their results showed that the coated cylinder barrel has much lower friction coefficient compared to the original cylinder. The friction coefficient of the coated cylinder was shown to be independent of the normal load while it is proportional to the normal load in case of the original cylinder. An improvement of 1.3 percent in the torque efficiency was achieved by coating the cylinder barrel.

Josep M. Bergada et al. [25] experimentally measured the gap between the barrel and the plate of an axial piston pump. The thickness of the film between the barrel and the plate was shown to be decreasing as the temperature or pressure increases. Significant leakage was shown to occur in the barrel-plate clearance. The experiments showed that mixed lubrication is presented in most of the studied cases especially at high temperature. The barrel dynamics exhibit two main frequencies; the first one is a result of the torque resulting as the piston passes the pressure kidney port while the second one is resulting from the contact between the metals.

A scale-independent design strategy was reported by Scott and Andrew [26]. They used Buckingham theory to define dimensionless parameter groups and substituted the groups into the dynamic equation for developing a dimensionless model that uses a successful market pumps design to find information that is independent of the product dimensions. Eight different pumps were used to generate the data required for this model. The limited amount of data limits the amount of design information that can be covered by this method.

A nonlinear pressure control model of a self-supplied variable displacement axial piston pump was introduced by W.Kemmetmuller et al. [27]. They derived a two degree of freedom nonlinear model with feedback and feedforward control in addition to a load estimator in order to 
achieve a solution for the unknown variable load. Lyapunov's theory was used in their model to determine the system stability. Their results proved the robustness of the control model.

A study that performed by Zhiru et al. [28] examined the flow ripple generated in an axial piston pump in a similar way that was done by Manring [15] but for conical barrel design. They concluded that the flow ripple depends on the swashplate angle and the conical barrel angle. The conical barrel pump was shown to have a slight increase in the output flow and decrease in the inertia compared the cylindrical barrel pump under the same operating conditions. The frequency analysis showed an additional order which caused undesired noise and vibration.

A comprehensive experimental and simulation study of a swash plate dynamics was done by Maiti and Narayan [29]. The torque on the swash plate that results from the piston, the return spring, the control piston and the viscous damping has been included in the model. The model the linearized for the piston torque for simplification purposes. The results showed that the pump has a slow response at extreme positions of the swash plate. In addition, the returning spring characteristics have a significant effect on the dynamic behavior.

Coombs [30] studied the efficiency of hydrostatic efficiency for variable displacement pump with variable displacement motor. His work shows that maximum efficiency can be achieved even when the motor does not operate at the maximum possible displacement. He compared the efficiency in his model with the efficiency model of a fixed displacement motor for controlling the swing circuit of a Caterpillar 320D excavator.

Xiuye and Hiayan [31] studied the kinematics of an axial piston pump using Matlab simulation. The simulation results were compared to the theoretical analysis. They stated that the displacement, velocity, and acceleration relative to the swash-plate is simple harmonic while the 
piston moves in an elliptic trajectory relative to the swash-plate. They also reported that the instantaneous pump flow rate is depending on the piston motion which is affected by the swashplate angle.

Manring [32] developed a complete model for the overall efficiency of hydrostatic transmission for variable displacement pump and motor. More recently, Manring et. al. [33] discussed the speed limitations of an axial piston machines. The first perspective that was studied was the Cylinder block tipping which occurs as a result of operating under the conditions of low pressure, high displacement, or high speed. These conditions occur when the cylinder-block spring fails to counteract imbalance of centrifugal inertial effects as a result of the piston reciprocation and try to separate the cylinder block from the valve plate resulting in a fluid seal between them. The second perspective that was investigated was the cylinder block filling. It occurs at high-speed operation when the cylinder is filled partially with fluid vapor. The last perspective studied in this study was the slipper tipping which means separating the piston from the slipper as a result of the tensile force that is generated as the piston starts the transition from the discharge to the inlet port caused by the same conditions that cause the cylinder block tipping. All the speed limitations were scaled by the inverse cube root of the volumetric displacement of the original machines. New machines were produced by using the scale laws which were shown to be identical for the three speed limitations.

In order to reduce the cost of the displacement-controlled actuation systems, Busquets and Ivantysynova [34] developed a design that uses a single pump for multiple actuators to reduce the number of pumps needed and eventually the cost is reduced. In this system, a set of on/off switching valves are used to direct the flow to/from the actuator. A feedforward controller has been designed to improve the system performance. 
Manring [35] has developed a model to generate an efficiency maps for hydrostatic transmission. His model was similar to his previous model [32] with some modifications concerning the input torque where the friction torque was divided into two parts, the side load within the machine and the normal load. The results that were presented in a nondimensional form showed that the efficiency is nearly independent of neither the output torque nor the speed under certain operating conditions.

\subsection{Fixed displacement pumps}

Generating a variable flow source using a fixed displacement pump and unloading valve was studied by several researchers [36,37]. They presented a way in which a variable flow source is achieved using a fixed displacement pump and unloading valve downstream from the pump. In addition to the low cost and the complexity of this system, it has a longer life compared to the variable displacement pump because the pump in this system is unloaded under zero flow condition which reduces the force exerted on the pump under zero or low flow conditions. They studied the losses resulted from switching power, compressing and decompressing the oil, and the metering when switch pumping between the system and the tank. Their results showed that the main losses were due to transition during the valve opening and closing. It is also shown that switching the unloading valve on and off does not cause the pump to be shock loaded.

A velocity control system for a linear actuator using a feedforward plus PID (FPID) controller was designed by Zhang [38]. In this design, the flow is controlled using directional throttling valve. The system nonlinearity was compensated by the feedforward loop while the velocity tracking error was compensated by the PID controller. The results show that the R-squared resulted from the FPID controller is $15 \%$ lower than that resulted from the feedforward loop and 45\% lower than that from the PID controller. The results also show that using the FPID controller 
improves the stability and the performance of the system. Variable flow can also be generated using a variable speed fixed displacement pump.

Gibson [39] introduced a method of determining the flow of a variable speed centrifugal pump using the flow/head characteristics of the pump. The results showed that for high static head conditions, the head is very sensitive to the speed and requires less than five percent speed variation to cover the whole flow rate range.

Çalişkan, H., et al. [1] studied a position control of a hydraulic system using a variable speed drive to control the flow according to the system requirements. Kalman filter was applied for noise reduction in the feedback signal. The model outputs were compared to open loop and closed loop frequency and step response to depict the dynamic performance of the system. The losses of this system were compared to the losses of the valve controlled hydraulic system. They stated that only $38.5 \%$ of the power produced by the pump could be transmitted to the system in a valve controlled hydraulic system.

Hu et al. [40] conducted simulation and experimental study to control the load velocity for a hydraulic system using variable speed drive. They used a compound algorithm to meet the system requirements. The compound algorithm consists of PD-controller and feedforward-feedback control. The experiments were performed on a hydraulic elevator test rig. They studied the transfer function and frequency-domain of the system. The results showed that the frequency and damping of the large inertia hydraulic speed-control system are low. They also stated there is a steady-state error of velocity when using unity-feedback control without compensation.

An approach for controlling pressure using an inlet metering pump, which uses a fixed displacement pump to provide a variable flow for a water hydraulic system, was introduced by 
Wisch [41]. A nondimensional analytical model was developed that relates the inlet metering valve opening to the discharge flow of the pump. The pressure was shown to exhibit a first order response.

\subsection{Switched systems}

Brown [42] introduced a new technique of controlling system flow rate or the pressure using a switched inertance device. In this technique, the flow is controlled using an extremely fast valve to switch the flow between the tank and the load. For simplicity, it was assumed that the valve switches instantaneously in this study. An experimental study on the design of a rotary fluid switch that is needed to accomplish the required pulse-width modulation at a high frequency is developed by Brown et al. [43]. The efficiency of the rotary valve was shown to be higher than that of the standard servo valve for moderate flow conditions. The study stated that a design of the tank-side chamber with air pockets reduces the cavitation associated with these systems.

Johnston et al. [44] presented an experimental and simulation study on a switched inertance hydraulic system for flow and pressure control in a way that is similar to an electrical switched inductance. They studied two modes of switched inertance hydraulic system which are flow and pressure boosters by changing the connections at the inlet and outlet of the system. The results showed that using a switched inertance system could provide flow and pressure less or more than the inlet flow and pressure respectively as required. The results also showed that the four-port design of the of the switched inertance system better control characteristics and higher efficiency than a four-port closed-center valve.

In order to meet the requirement of the high switching frequency of the switched inertance system, a high-speed rotary valve has been introduced by Pan [45]. They experimentally studied the characteristics of the rotary valve for the steady state and dynamic conditions. The effect of the 
frequency and switching ratio on the pressure, flow, and the efficiency has been studied. The results showed that under the optimal frequency conditions, the efficiency increases as the switching ratio increases. They stated that the inertance switching system has a promising performance.

The problem of noise associated with these systems was discussed in a study developed by Pan et al. [46]. In this study, a controller, that uses a flow booster with a bypass was designed for the purpose of canceling the pressure pulsation that causes the noise. The results showed that using this design can reduce the pressure pulsation. It was also shown that increasing the booster size reduces the noise. However, of the frequency, flow and pressure are limited due to the limitations of the hardware.

Scheidl et al. [47] developed a model for a hydraulic buck converter using time-frequency domain simulation. The time domain has been applied to switching and check valves while the frequency domain has been applied to the pulsating waves in the pipe. The complexity of the check valve behavior was reduced by replacing the valve pressure and flow rate with a single variable which generated a system of nonlinear equations. The system of the nonlinear equations was solved using Newton-Raphson algorithm.

Pan et al. [48] developed an analytical model for three-port switched inertance system using lump and distributed parameter models. The efficiency and performance of the system were studied. The system efficiency was modeled as a function of delivery flow rate, flow loss, resistance, and the pressure difference. The results showed that the pressure loss increases as the delivery flow increases. 
To improve the estimation of the system efficiency and the accuracy of the system dynamics modeling, Pan et al. [49] developed an enhanced model the includes the valve dynamics, leakage, and nonlinearity. The model was also validated against experiments. The results of the improved model showed that the flow loss increases as the delivery flow increases. It was also shown that the flow loss associated with the enhanced model is greater than those associated with the original basic model.

\subsection{Fuel injection systems}

Since the inlet metering pump uses similar principles of the fuel injection systems, a review of some of the available literature on the fuel injection systems and the cavitation associated with it is found in this section. The problem of vibration and noise resulted from the fuel pressure pulsation in the fuel injection system was treated by the experimental research that was done by Ito, and Miyoshi [50]. In this steady, a damper was used to avoid what is called "water hammer phenomenon" in the pipes leading the fuel to the engine that is caused by the excessive fuel pressure variation.

Miyaki, M. et al. [51] developed a design for electronically controlled common rail injection system called ECD-U2 system that is capable of controlling the fuel quantity and pressure independently. The system operates at $120 \mathrm{MPa}$. The flow out of the high-pressure pump is controlled a pressure control valve which, accordingly, controls the rail pressure. A three-way valve was designed to adjust the nozzle back pressure to control the nozzle lift. A simpler design was conducted by Rinolfi, R. et al. [52] using a two-way solenoid valve instead of the three-way valve in the previous design to control the fuel injection. Detailed design of the two-way solenoid two-way valve was developed by Stumpp, and Ricco [53]. In this design, the flow of the radial piston high-pressure pump is controlled by the two-way solenoid valve. 
A new design of a common rail fuel injection system for a high pressure that is up to 160Mpa and a wide range of engine speed was developed by Guerrassi, et al. [54] which is called Locus Diesel Common Rail system. The system consists of a high-pressure pump, rail, injectors, in addition to an electronic control unit. The pump pressure is controlled by a pressure control valve while the fuel quantity is controlled by an inlet metering valve. This design provides engine stability improvement in addition to the ability to use multiple injections each stroke.

A comprehensive model of the vaporization process of the fuel at high pressure was introduced by Zhu and Reitz [55]. The continuous thermodynamic concepts were used to consider the effect of the high pressure on the vaporization process of the fuel droplet in the gas and diesel engines. The effect of fuel type was also studied. Furthermore, the study investigated the influence of using two components fuel and compared the results to the single component fuel case. The results showed that there is a significant effect of using multicomponent fuel on the system performance, especially for high volatility fuels.

Balluchi et al. [56,57] developed a hybrid model to control the rail pressure for the common rail injection systems. The model was compared to the one based on the mean value, and it was shown to have better performance. The model also can handle the delay and the interaction between the system components. In addition, the high-pressure pump efficiency was studied and was shown to be proportional to the discharge pressure.

Ryu et. al. [58] investigated the cavitation phenomena in a fuel injection pump during the process of fuel delivery using optical visualization method. They used twelve pumps with different parts geometries in the study. Two types of cavitation were observed. The first type is a fountainlike cavitation that occurs before the end of the fuel delivery, and it causes a plunger damage. The second type is a jet cavitation which occurs after the spill end, and it causes a barrel damage. Their 
results showed that cavitation could be reduced by decreasing the area of the perpendicular impact with the jet. This can be achieved by using a conical spill port.

The problem of fuel evaporation in the injection systems for the small engines, in which the injector acts as a pump, was dealt with by the study conducted by Allen, et al. [59]. This design provides escaping path for the fuel vapor from the injector to the fuel tank. The injector in this design is immersed in the fuel so that the flow restrictions are reduced by getting rid of the injector casing which improves the efficiency of the system.

While the traditional fuel metering systems consist of pumping device and metering valve, a study conducted by Schwamm, [60] aimed to reduce the complexity of the fuel metering system in aero engines by either controlling the pump speed electronically and getting rid of the metering device or reducing the complexity of the valve itself. The study results showed that this modified design has higher performance, faster response, and $20-40 \%$ lower cost than the traditional systems.

The effect of the nozzle geometry, injection pressure and back pressure on the cavitation in a diesel injection system was studied experimentally and numerically by He, et al. [61]. QuasiNewton and Universal Global Optimization methods were used to predict a correlation between the cavitation number and the critical conditions at which the cavitation starts. It was found that the discharge coefficient is proportional to the cavitation number.

Duan et al. [62] developed a new design of a fuel injection system by adding control orifices that are adjusted by a control piston in order to develop a system with a fast response. The new system performance was compared to that of the conventional one. The nonlinear cavitation model was used with a dynamic grid to study the cavitation associated with both systems 
numerically using CFD technique. Then, the numerical results were compared with the experimental results for the validation purpose.

\subsection{Cavitation}

Cavitation is a Phenomenon that has a strong impact on hydraulic characteristics in hydraulic machines [63]. It happens when the liquid pressure drops below the vapor pressure [64]. Cavitation damage is caused by bubbles collapsing near the surface [65]. Wang [66] studied the cavitation phenomena the axial piston pumps. The study included optimization of the valve plate design in order to reduce the cavitation. The optimization was accomplished by modifying the geometry of the valve plate so that enough fluid flows into the piston internal volume to keep the pressure higher than the vapor pressure. Analytical relationship has been developed that relates the cavitation to the valve plate geometry. The results showed that the cavitation increases as the pumping speed increases.

Many researchers have studied the cavitation resistance of materials and recommended different cavitation resistant materials. Ceramic has been shown to have good cavitation resistance [67 and 68]. CrB2 was also found to have excellent corrosion resistance properties [69].

Poliarus, et al. [70] experimentally studied the corrosion and cavitation wear resistance of new composites based on NiAl and NiTi. The new composites may be used in hydropower equipment that are exposed to aggressive environments and cavitation conditions. The results showed that the new composite (NiTi-30wt.\% CrB2) has better cavitation resistance than NiTi.

The dynamics of the cavitation bubbles interaction in an acoustic field was studied by Liang et al. [71] using a sonication recording system. In addition, the cavitation bubbles interaction dynamics was studied theoretically using Keller-Miksis model. Both the experimental and 
theoretical results showed that the cavitation bubbles interaction plays a major role in the cavitation bubbles dynamics. The results also showed that the bubble sizes have a strong effect on interacting bubbles oscillation.

Wang et al. [72] investigated the effect of filling the defects in carbon steel coated by 8 wt.\% yttria stabilized zirconia with epoxy on the cavitation resistance. The results showed that filling the cavities of the coating with epoxy greatly improves the cavitation resistance. A comparison study of cavitation resistance was performed by Bordeasu et al. [73]. Cavitation resistance of steel with different content of carbon $(0.03 \%-0.1 \%)$, chromium (2\%-24\%) and nickel $(0.5 \%-10 \%)$ was tested. The results showed that steel with the content of $0.1 \%$ carbon, $12 \%$ chromium and $6 \%$ nickel has the best cavitation resistant properties in the studied range.

\subsection{Literature Review Summary}

Numerous studies have been done on providing a variable flow source that has high efficiency, good performance, and low cost. Different techniques have been studied to meet those requirements. Although variable displacement pumps are efficient and have good performance, they are expensive and complicated. On the other hand, traditional valve controlled systems are less expensive because they use fixed displacement pumps. However, the energy dissipated, as heat, that is associated with these systems is high due to the high pressure drop across the valve. Variable speed drive is another option that is used to achieve variable flow. For large systems, the inertia effect is high which limits the speed of the response of these systems. Recently, inertance tube switch systems have been studied as an alternative flow control technique. Noise and flow ripple are problems that are associated with these systems. Switched systems also require extremely fast valves to switch the flow between the tank and the load. 
In this work, a new flow control technique was studied and analyzed. The new technique uses an inlet-metering valve to manipulate the flow of a piston pump in a way similar to the inlet metering system in the fuel injection systems. This work builds on previous analytical work [41] aimed at modeling and analysis of an inlet metering pump used in a pressure control system. The pump used in this system is fixed displacement pump which reduces the cost and complexity of the system. Since the inlet metering valve is placed upstream from the pump, the energy dissipated across the valve is minimized due to the arbitrarily small pressure drop. In addition, the inletmetering system has good performance and does not require an extremely fast valve. Models for the flow, torque, and efficiency of this system have been developed in this study and validated against experimental data collected from an experimental setup. A design of a velocity control system that utilizes the inlet metering system was also a part of this work. Due to the fluid vaporization associated with this system, a cavitation problem may exist. Cavitation resistant material may be used to build the parts that might be exposed to cavitation conditions as suggested by the literature. However, studying the cavitation phenomenon is beyond the scope of this work. 


\section{CHAPTER 3}

\section{INLET-METERED PUMP EFFICIENCY}

\subsection{Introduction}

A general definition of the machine efficiency is the ratio of output power to the input power. The overall efficiency of the system is a combination of the volumetric efficiency and the mechanical efficiency. The volumetric efficiency is a measure of the flow losses while the mechanical efficiency is a measure of the torque losses. The flow loss is a combination of compressibility loss, low Reynolds number loss, and high Reynolds number loss. The torque losses consist of frictional loss, starting torque loss and the torque associated with the vaporization and condensation of the fluid. In this chapter, the models of the flow, torque, and efficiency of the inlet-metered pump shown in Fig. 3.1 are presented.

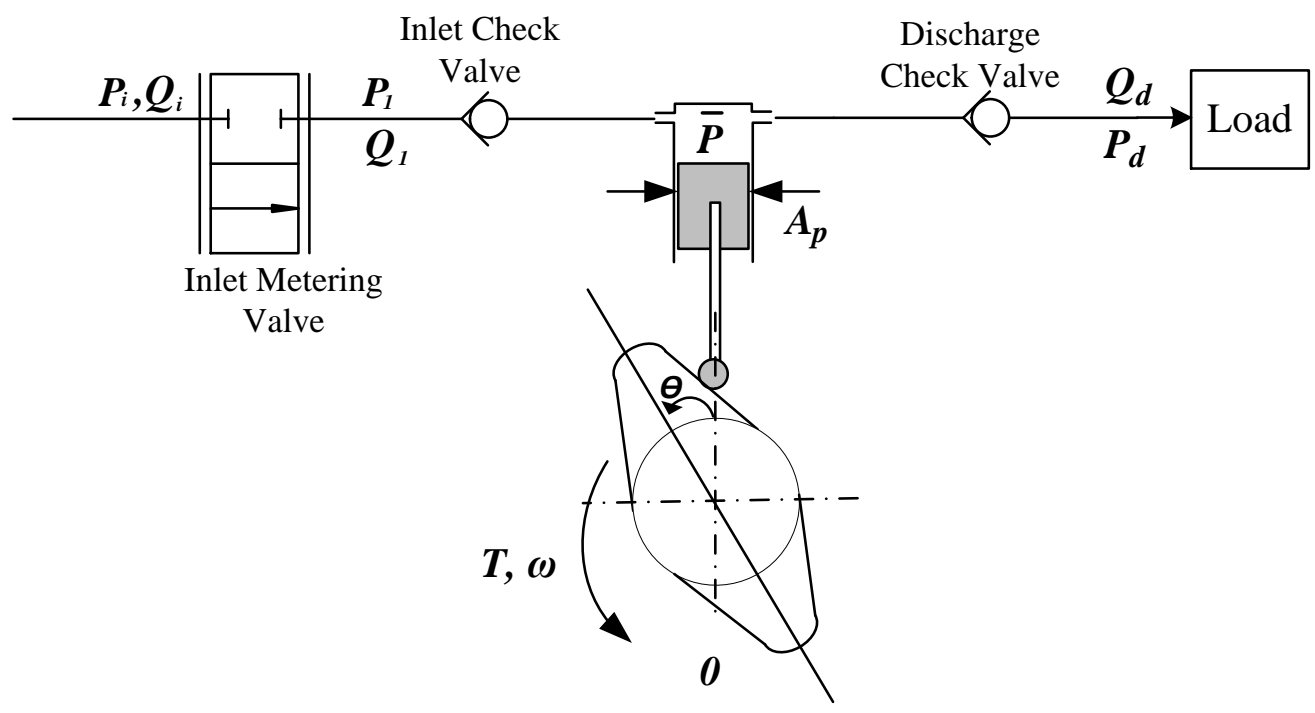

Figure 3.1: Inlet Metering Valve and Fixed Displacement Single Piston Pump System 


\subsection{Modeling and Analysis}

According to the efficiency definition mentioned above, the pump efficiency may be written as:

$\eta=\frac{\Pi_{\mathrm{out}}}{\Pi_{\mathrm{in}}}=\frac{P_{d} Q_{d}}{T \omega}$

Here we are assuming that the power supplied to the system is shaft power and the output is the fluid power. The power supplied due to fluid entering the pump at the inlet $\left(P_{1} Q_{1}\right)$ is neglected when the inlet volume pressure, $P_{1}$, is extremely low as it is when inlet flow is less than the rate of change of the inlet volume of the pump. The energy generated by the charge pump is entirely wasted and not considered in the efficiency analysis. Note that the wasted energy due to charge pump can be made very small by selecting a low charge pressure, $P_{i}$, at the inlet at the expense of having a correspondingly large inlet valve orifice area capability to maintain a desired inlet flow. Models for the flow, torque, and efficiency are presented in the next sections. A nondimensional version of the model is presented in the last section of this chapter for the purpose of generalization and simplification.

\section{3..2.1 Flow Model}

The mass discharge flow from the machine is the difference between the flow enters the pump and the leakage losses calculated using the continuity equation,

$\dot{m}_{d}=\dot{m}_{i}-\dot{m}_{l}$

where $\dot{m}_{d}$ is the mass discharge flow of the pump, $\dot{m}_{i}$ is the ideal mass flow rate which is equal to the pump input flow, and $\dot{m}_{l}$ is the leakage flow at the pump discharge. Since $\dot{m}=\rho Q$, Eq. (3.2) can be rewritten as, 
$Q_{d}=\frac{\rho_{i}}{\rho_{d}}\left(Q_{i}\right)-Q_{l}$.

The density ratio may be determined from the following equation [33],

$\rho=\rho_{\mathrm{o}} \operatorname{Exp}\left(\frac{P}{\beta}\right)$,

where $\rho_{\mathrm{o}}$ is the density at zero pressure and $\beta$ is the fluid bulk modulus which was assumed to be constant. Note that in Eq. (3.4), the symbol, $P$, is used for pressure in general -- this equation would not apply to the pressure, $P$, inside the cylinder due to the prevalence of undissolved gases (air). Then, the ratio of the fluid density at the pump inlet, $\rho_{i}$, and the fluid desity at the pump discharge, $\rho_{d}$, is defined as follows for the inlet and discharge pressure volumes:

$\frac{\rho_{i}}{\rho_{d}}=\operatorname{Exp}\left(\frac{P_{d}}{\beta}\right) \approx 1-\frac{P_{d}}{\beta}=1-k_{0} P_{d}$,

where $\rho_{\mathrm{i}}$ and $\rho_{\mathrm{d}}$ are the fluid densities at the inlet and the discharge respectively and $k_{0}$ accounts for the effect of fluid compressibility. The ideal volumetric flow rate, $Q_{i}$, associated with the fixed displacement pump with an inlet metering valve will be modeled using the orifice equation,

$Q_{i}=A_{v} C_{d} \sqrt{\frac{2\left(P_{i}-P_{1}\right)}{\rho}}$

where $P_{i}$ is pressure of the charge pump, $P_{1}$ is the pressure at the exit of the inlet metering valve which has been assumed to be approximately zero, $A_{v}$ is the valve metering area, and $C_{d}$ is the discharge coefficient. Equation (3.6) is valid as long as the ideal discharge flow does not exceed the maximum flow for a given pump speed i.e. the flow is not restricted by the product pump speed and displacement volume and it is a function of only the valve opening. This means that the valve area has a maximum value such that, 


$$
A_{v} \leq \frac{V_{d} \omega}{C_{d} \sqrt{\frac{2 P_{i}}{\rho}}}
$$

Once the valve opening area exceeds the condition in Eq. (3.7), the ideal flow is simply the product of the volumetric displacement and the pump speed. The internal leakage flow loss is modeled as a combination of high and low Reynolds number flows and is given by

$Q_{l}=k_{1} \frac{1}{\mu} P_{d}+k_{2} \sqrt{P_{d}}$.

where $k_{1}$ and $k_{2}$ are the low Reynolds and the high Reynolds number leakage coefficients, respectively. Substitution of Eq. (3.5) into Eq. (3.4), substituting that result along with Eq. (3.6) into Eq. (3.8) gives the discharge flow,

$Q_{d}=\left(1-k_{0} P_{d}\right) A_{v} C_{d} \sqrt{\frac{2 P_{i}}{\rho}}-k_{1} \frac{1}{\mu} P_{d}-k_{2} \sqrt{P_{d}}$

Three key coefficients are used in the description of volumetric flow rate: fluid compression, $K_{0}$, the low Reynolds number leakage, $K_{l}$, and the high Reynolds number leakage, $K_{l}$. Notice that the flow is only a function of valve opening area if losses are neglected. Note that there is a limitation on the inlet flow and therefore discharge flow cannot exceed the product of the volumetric displacement and pump shaft speed.

The valve opening area, $A_{v}$, is given in (3.10) and was obtained from flow versus voltage data due to an experiment where the discharge pressure was very low with the inlet pressure held constant. The computed valve area is plotted versus voltage and compared to a curve fit in Fig. 4. The quadratic polynomial that relates the valve opening area $\left(\mathrm{m}^{2}\right)$ to the voltage, $V$, is shown in Eq. (3.10): 
$A v=0.97 \times 10^{-7} V^{2}+2.29 \times 10^{-6} V-0.54 \times 10^{-6}$

\subsubsection{Torque Model}

The torque required by the inlet metering pump is a combination of four components; ideal torque, $T_{\text {ideal }}$, torque required to force the trapped air out and to condense the fluid vapor, $T_{c}$, friction torque, $T_{f}$, and the starting torque, $T_{S}$, which includes the constant torque resulting from the spring that holds the piston down. Then, the total torque can be written as:

$T=T_{\text {ideal }}+T_{c}+T_{f}+T_{S}$

The ideal torque may be written as the output power divided by the pump speed,

$T_{\text {ideal }}=\frac{P_{d} Q_{d}}{\omega}=\frac{P_{d} A_{v} C_{d} \sqrt{\frac{2 P_{i}}{\rho}}}{\omega}$

The torque required to compress the partially vaporized fluid and to force air out of or into the fluid solution was found to have a linear relationship with the difference between the pump maximum and actual flows [74] and can be written as $T_{c}=\psi\left(Q_{\max }-Q_{d}\right)$ where $\psi$ is a constant and its value depends on the working fluid. If Eq. (3.6) is used as an approximation for the discharge flow, the compression torque becomes,

$T_{c}=\psi\left(V_{d} \omega-A_{v} C_{d} \sqrt{\frac{2 P_{i}}{\rho}}\right)$

The friction torque is [33]

$T_{\mathrm{f}}=T_{\text {ideal }} \cdot \mu_{\mathrm{s}}$

where $\mu_{\mathrm{s}}$ is the coefficient of friction existing within the machine. The coefficient of friction is modeled by Stribeck curve (Fig.2) as follows: 
$\mu_{\mathrm{s}}=A^{\prime} \operatorname{Exp}\left(-B^{\prime} \frac{\mu U}{W}\right)+C^{\prime} \sqrt{\frac{\mu U}{W}}$

Where $A^{\prime}, B^{\prime}$, and $C^{\prime}$ are constants, $\mu$ is the fluid viscosity, $U$ is the sliding velocity, and $W$ is the load per unit length. The left hand side of (3.15) is represented by the solid line of the Stribeck curve while the terms on the right hand side are represented by the two dashed lines of the curve.

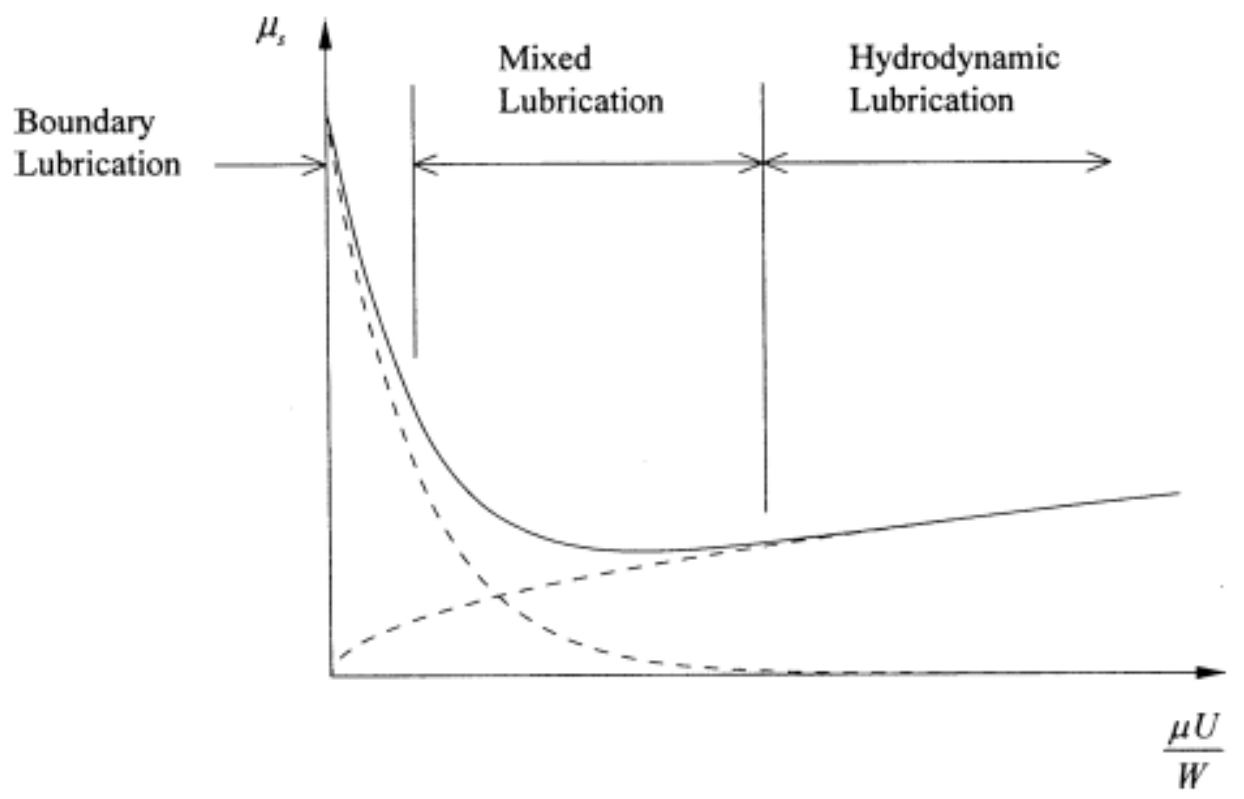

Figure 3.2: Stribeck curve [35]

The sliding velocity $U$ is replaced by the pump angular velocity, $\omega$, multiplied by the cam shaft radius, $r$ as shown in Eq. (3.16) below:

$U=\omega r$

Furthermore, the weight per unit length $W$ is replaced by the force caused by the average pressure on the piston divided by the journal bearing width. The instantaneous volume of the fluid in the piston internal volume can be determined by first assuming the camshaft profile (Fig. 3.3) as follows: 


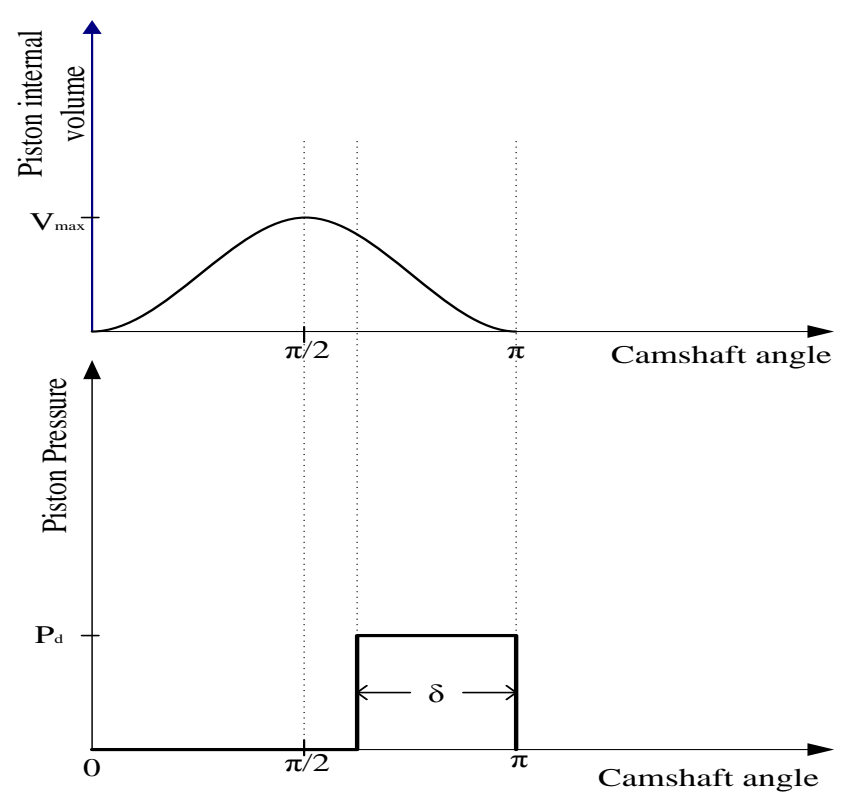

Figure 3.3: Piston volume and pressure

$V(\delta)=\left[\frac{1}{2}(1-\cos 2 \delta)\right] V_{\max }$

where $\delta$ is the range of angles in which the fluid is pressurized and $V_{\text {max }}$ is the maximum fluid volume. The volume of the oil entering the piston internal volume during the inlet stroke is determined using Eq. (3.18):

$V_{i}=\int_{0}^{\frac{\pi}{2 \omega}} Q_{i n} d t=\frac{\pi}{2 \omega} A_{v} C_{d} \sqrt{\frac{2}{\rho} P_{i}}$

The maximum piston internal volume can be calculated by integrating the maximum flow over the time of the inlet stroke as follows:

$V_{\max }=\int_{0}^{\frac{\pi}{2 \omega}} Q_{\max } d t=\frac{\pi}{2 \omega} V_{d} \omega$

Plugging in $V_{\max }$ into Eq. (3.20) and setting $V(\boldsymbol{\delta})=V_{i}$ 
$\delta=\frac{1}{2} \cos ^{-1}\left(1-\frac{2 A_{v} C_{d} \sqrt{\frac{2}{\rho} P_{i}}}{\omega V_{d}}\right)$

The average pressure on the piston, $\bar{P}$, is needed to determine the force exerted on the piston and it is the calculated using Equation (3.21):

$\bar{P}=\frac{\delta}{\pi} P_{d}$

Substitution of Eq. (3.20) into Eq. (3.21) gives the average pressure,

$\bar{P}=\frac{P_{d}}{2 \pi} \cos ^{-1}\left(1-\frac{2 A_{v} C_{d} \sqrt{\frac{2}{\rho} P_{i}}}{\omega V_{d}}\right)$.

Multiplying the average pressure by area of the piston, $A_{p}$, allows for computation of the average force,

$F=\bar{P} A_{p}=\frac{P_{d}}{2 \pi} \cos ^{-1}\left(1-\frac{2 A_{v} C_{d} \sqrt{\frac{2}{\rho} P_{i}}}{\omega V_{d}}\right) A_{p}$.

Dividing the force from (3.23) by the cam shaft journal bearing width, $l$, gives the load per unit width,

$W=\frac{F}{l}=\frac{A_{p} \frac{P_{d}}{2 \pi} \cos ^{-1}\left(1-\frac{2 A_{v} C_{d} \sqrt{\frac{2}{\rho} P_{i}}}{\omega V_{d}}\right)}{l}$. 
Equations (3.16) and (3.24) are substituted into (3.15) to give an expression for the coefficient of friction,

$$
\begin{array}{r}
\mu_{\mathrm{s}}=A \operatorname{Exp}\left(-B^{\prime} \frac{\mu \omega r l}{A_{p} \frac{P_{d}}{2 \pi} \cos ^{-1}\left(1-\frac{2 A_{v} C_{d} \sqrt{\frac{2}{\rho} P_{i}}}{\omega V_{d}}\right)}\right) \\
+\mathrm{C}^{\prime} \sqrt{\frac{\mu \omega \mathrm{rl}}{A_{p} \frac{P_{d}}{2 \pi} \cos ^{-1}\left(1-\frac{2 A_{v} C_{d} \sqrt{\frac{2}{\rho} P_{i}}}{\omega V_{d}}\right)}}
\end{array}
$$

Equation (3.25) can be rewritten as

$$
\mu_{\mathrm{s}}=\mathrm{AExp}\left(-\mathrm{B} \frac{\omega}{P_{d} \cos ^{-1}\left(1-\frac{2 A_{v} C_{d} \sqrt{\frac{2}{\rho} P_{i}}}{\omega V_{d}}\right)}\right)+\mathrm{C} \frac{\omega}{\sqrt{P_{d} \cos ^{-1}\left(1-\frac{2 A_{v} C_{d} \sqrt{\frac{2}{\rho} P_{i}}}{\omega V_{d}}\right)}}
$$

where $\mathrm{B}=\mathrm{B}^{\prime} \frac{2 \pi \mu \mathrm{rl}}{A_{p}}$ and $\mathrm{C}=\mathrm{C}^{\prime} \sqrt{\frac{2 \pi \mu \mathrm{rl}}{A_{p}}}$, Substituting Eq. (3.26) into Eq. (3.14) allows gives the torque resulting from the internal friction, 


$$
\begin{gathered}
T_{f}=T_{\text {ideal }}\left[A \operatorname{Exp}\left(-B \frac{P_{d} \cos ^{-1}\left(1-\frac{2 A_{v} C_{d} \sqrt{\frac{2}{\rho} P_{i}}}{\omega V_{d}}\right)}{\left(1-\frac{2 A_{v} C_{d} \sqrt{\frac{2}{\rho} P_{i}}}{\omega V_{d}}\right)}\right)\right. \\
+C
\end{gathered}
$$

Substitution of Equations (3.12), (3.13), and (3.27) into Eq. (3.11) gives the total torque,

$$
\begin{aligned}
& T=\frac{P_{d} A_{v} C_{d} \sqrt{\frac{2 P_{i}}{\rho}}}{\omega}+\psi\left(V_{d} \omega-A_{v} C_{d} \sqrt{\frac{2 P_{i}}{\rho}}\right) \\
& +\frac{P_{d} A_{v} C_{d} \sqrt{\frac{2 P_{i}}{\rho}}}{\omega}\left[A \operatorname{Exp}\left(-B \frac{\omega}{P_{d} \cos ^{-1}\left(1-\frac{2 A_{v} C_{d} \sqrt{\frac{2}{\rho} P_{i}}}{\omega V_{d}}\right)}\right)\right. \\
& \left.+C \sqrt{\frac{\omega}{P_{d} \cos ^{-1}\left(1-\frac{2 A_{v} C_{d} \sqrt{\frac{2}{\rho} P_{i}}}{\omega V_{d}}\right)}}\right]+\mathrm{T}_{\mathrm{s}} \text {. }
\end{aligned}
$$




\subsubsection{Model Nondimensionalization}

To generalize the model, the equation parameters are normalized about selected reference conditions. Nondimensionalizing the equation also gives a simpler form of the equations with reduced number of parameters. The following definitions were used to nondimensionalize the equations:

$$
\begin{aligned}
& \omega=\widehat{\omega} \omega_{r} \\
& Q_{d}=\hat{Q}_{d} V_{d} \omega_{r}, \\
& P_{d}=\hat{P}_{d} P_{d r} \\
& P_{i}=\hat{P}_{i} P_{i r} \\
& A_{v}=\hat{A}_{v} \frac{V_{d} \omega_{r}}{C_{d} \sqrt{\frac{2 P_{i r}}{\rho}}}
\end{aligned}
$$

and

$T=\widehat{T} P_{d r} V_{d}$

The subscript $(r)$ refers to the reference condition that was chosen such that, $P_{d r}=25 \mathrm{MPa}, \omega_{r}=2500$ RPM, and, $P_{i r}=2 \mathrm{MPa}$. The volumetric displacement is $V_{d}=1.3375 \times 10^{-6} \mathrm{~m}^{3}$ per radian of the pump shaft rotation Applying the above definitions, the flow in Eq. (3.9) can be written in a nondimensional form as:

$\hat{Q}_{d}=\hat{A}_{v} \sqrt{\hat{P}_{i}}-\hat{k}_{0} \hat{A}_{v} \hat{P}_{d} \sqrt{\hat{P}_{i}}-\hat{k}_{1} \hat{P}_{d}-\hat{k}_{2} \sqrt{\hat{P}_{d}}$

where

$\hat{k}_{0}=k_{0} P_{d r} A_{r} \sqrt{P_{i r}}$ 
$\hat{k}_{1}=k_{1} \frac{P_{d r}}{\mu V_{d} \omega_{r}}$, and

$\hat{k}_{2}=k_{2} \frac{\sqrt{P_{d r}}}{V_{d} \omega_{r}}$.

Similarly, the torque equation (3.28) is written in nondimensional form as

$\widehat{T}=\frac{\hat{P}_{d} \hat{A}_{v} \sqrt{\hat{P}_{i}}}{\widehat{\omega}}+\hat{\psi}\left(\widehat{\omega}-\hat{A}_{v} \sqrt{\hat{P}_{i}}\right)$

$$
\begin{aligned}
& +\frac{\hat{P}_{d} \hat{A}_{v} \sqrt{\hat{P}_{i}}}{\widehat{\omega}}\left[\hat{A} \operatorname{Exp}\left(-\hat{B} \frac{\widehat{\omega}}{\hat{P}_{d} \cos ^{-1}\left(1-\frac{2 \hat{A}_{v} \sqrt{\hat{P}_{i}}}{\widehat{\omega}}\right)}\right)\right. \\
& \left.+\hat{C} \sqrt{\frac{\widehat{\omega}}{\hat{P}_{d} \cos ^{-1}\left(1-\frac{2 \hat{A}_{v} \sqrt{\hat{P}_{i}}}{\widehat{\omega}}\right)}}\right]+\hat{T}_{s},
\end{aligned}
$$

where $\hat{\psi}=\psi \frac{\omega_{r}}{P_{d r}}, \hat{A}=A, \hat{B}=B \frac{\omega_{r}}{P_{d r}}, \hat{C}=C \sqrt{\frac{\omega_{r}}{P_{d r}}}$, and, $\widehat{T}_{s}=\frac{T_{s}}{P_{d r} V_{d}}$.

The coefficients $\hat{\psi}, \hat{A}, \hat{B}, \hat{C}$, and $\widehat{T}_{s}$ are determined from experiments. Equation (3.30) may be rewritten as:

$\widehat{T}=\frac{\hat{P}_{d} \hat{A}_{v} \sqrt{\hat{P}_{i}}}{\widehat{\omega}}+\hat{\psi}\left(\widehat{\omega}-\hat{A}_{v} \sqrt{\hat{P}_{i}}\right)+\frac{\hat{P}_{d} \hat{A}_{v} \sqrt{\hat{P}_{i}}}{\widehat{\omega}}[\hat{A} X+\hat{C} Y]+\widehat{T}_{s}$

where

$X=\operatorname{Exp}\left(-\hat{B} \frac{\widehat{\omega}}{\hat{P}_{d} \cos ^{-1}\left(1-\frac{2 \hat{A}_{v} \sqrt{\hat{P}_{i}}}{\widehat{\omega}}\right)}\right)$ 
and

$Y=\sqrt{\frac{\widehat{\omega}}{\hat{P}_{d} \cos ^{-1}\left(1-\frac{2 \hat{A}_{v} \sqrt{\hat{P}_{i}}}{\widehat{\omega}}\right)}}$

Equation (3.1) can then be nondimensionalized to give a nondimensional expression for the pump overall efficiency,

$\eta=\frac{P_{d} Q_{d}}{T \omega}=\frac{\widehat{P}_{d} \hat{Q}_{d}}{\widehat{T} \widehat{\omega}}$. 


\section{CHAPTER 4}

\section{EXPERIMENTAL SETUP}

\subsection{Introduction}

This chapter aimed at presenting the details of the experimental setup. The description of the inlet-metering system prototype used in this work is presented in this chapter. Details of the study-state and transient tests that are performed in this study are also presented. In addition, photos of the inlet-metering system prototype components with their details are also found in this chapter.

\subsection{Test Setup}

The IMP was tested using the hydraulic circuit given in Fig. 4.1 with Caterpillar Hydo Advanced 10 oil. In the circuit, there are several flow, pressure, and temperature sensors. A pressure-controlled pump generates the inlet flow. The discharge flow of the inlet-metered pump, IMP, travels through parallel paths with a flow control valve or a relief valve. After the valves, the flow is returned to the reservoir. More details are given in Fig. 4.1 such as sensor locations. The descriptions of the sensors are given in Table 4.1. The IMP is driven by a variable speed drive (a synchronous AC motor controlled by a variable frequency voltage source). Test speeds ranged from $\sim 3 \mathrm{rpm}$ up to $2500 \mathrm{rpm}$. Most tests were conducted with the relief valve and supply pressures set at constant values with the flow control valve closed. The inlet-metering valve, IMV, (flow control inside the dashed box in Fig. 4.1) was controlled by a modified Caterpillar engine controller. The controller was modified by Caterpillar engineers so that the IMV position command could be manipulated by an external voltage signal. This voltage signal was generated by a PC based data acquisition system. 
The data acquisition was accomplished using a PC with data acquisition expansion card. The expansion card has a 32 channel 16-bit analog input and 4 channel counter timer capabilities. The analog inputs were used to obtain valve feedback, pressure, and temperature signals while the counter timers were used to interpret the digital flow meter signals. The system also has analog output capabilities which were used to generate voltage signals sent to the Caterpillar engine controller to manipulate the IMV opening. Serial (RS-232) communication was used to obtain torque measurements. Speed signals were not acquired using the computer but instead read from a digital readout. Speed signals were found to not vary significantly due to the speed regulation capabilities of the motor drive system. The drive has very high inertia and extremely steep torque rise with decreasing speed.

There were additional measurements utilized in some tests. The acceleration of the pump housing was measured using a Caterpillar knock sensor (P/N 195-2431). The pump head temperature was also measured using a temperature sensor built into the fuel pump head manifold. 


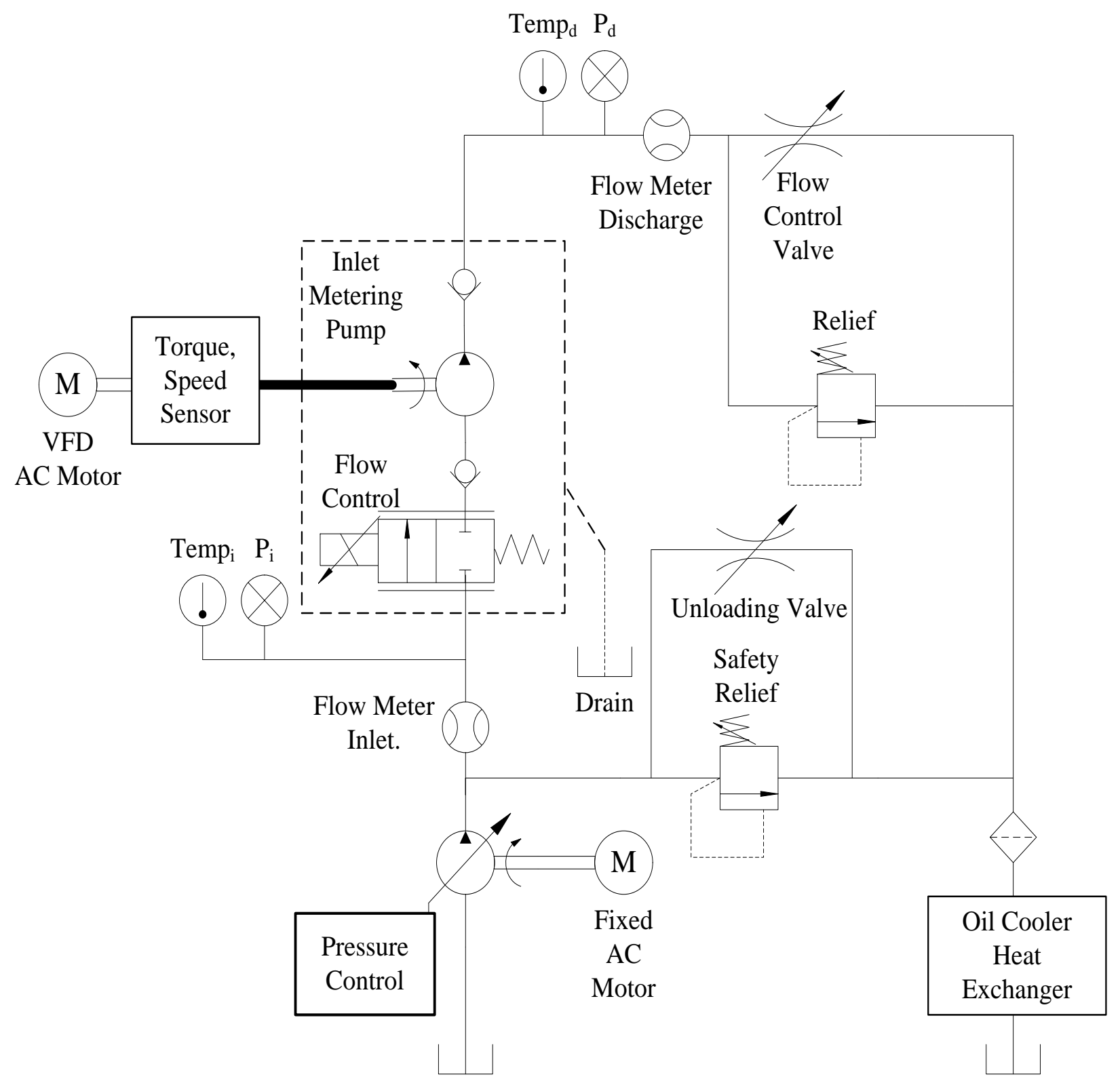

Figure 4.1. Inlet metering pump testing circuit diagram 
Table 4.1 Measurements

\begin{tabular}{|l|l|l|}
\hline Symbol & Description & Identifying Information \\
\hline$P_{d}$ & Discharge Pressure & BT91760CC-102-15-002 (Setra) \\
\hline$P_{i}$ & Inlet Pressure & UB020867 40 (Setra) \\
\hline$Q_{i}$ & Inlet Flow & KY18435224 (Gear type) \\
\hline$Q_{d}$ & Discharge Flow & KY18438224 (Gear type) \\
\hline$T$ & Applied Torque & 48202 V(1-3) (Himmelstein $+/-1000$ in-lb) \\
\hline$\omega$ & Motor Speed & Same as torque \\
\hline$V$ & Inlet Valve Voltage & NI DAQ card \\
\hline$T_{h}$ & Head Temperature & Sensor integrated into pump \\
\hline$T_{i}$ & Inlet Temperature & Same as inlet pressure \\
\hline$T_{d}$ & Discharge Temperature & Same as discharge pressure \\
\hline
\end{tabular}

The experimental setup is shown in Fig. 4.2. The installed pump is shown in Fig.4.3. Various hoses and manifolds were used to complete the hydraulic circuit setup. In Fig. 4.3, the pump is seen attached to a tube with an adapter that contains the torque sensor. This tube is bolted to the $200 \mathrm{hp}$ electric motor. The lubrication line can be seen connecting to the pump housing near the point where the housing meets the adapter. This lubrication line is connected to the charge pump through a pressure reducing valve set at $50 \mathrm{psi}(344 \mathrm{kPa})$. The lubrication system primarily supplies fluid flow to the journal bearings that supports the motor driven cam that drives the piston displacement. The flow from these journal bearings leaks into the pump case and then directly into the adapter tube containing the torque sensor. This flow is carried away by a small impeller pump and returned to the reservoir. This is a nonconventional setup that allows for testing of the pump 
which was originally designed to receive lubrication pressure from an engine lubrication system. The engine lubricant was designed to flow back into the engine crankcase where the pump would normally be attached.

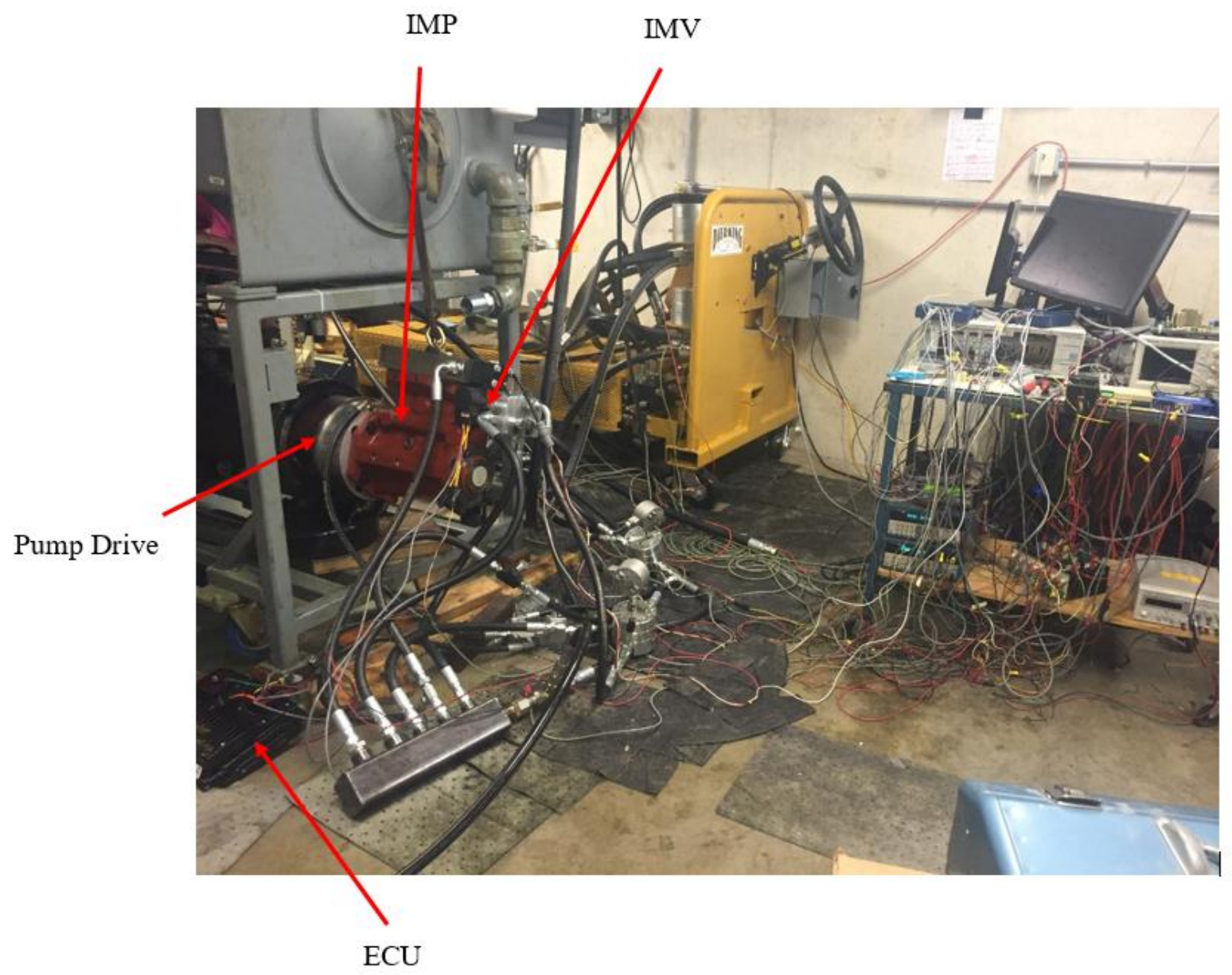

Figure 4.2. Inlet metering system experimental setup 


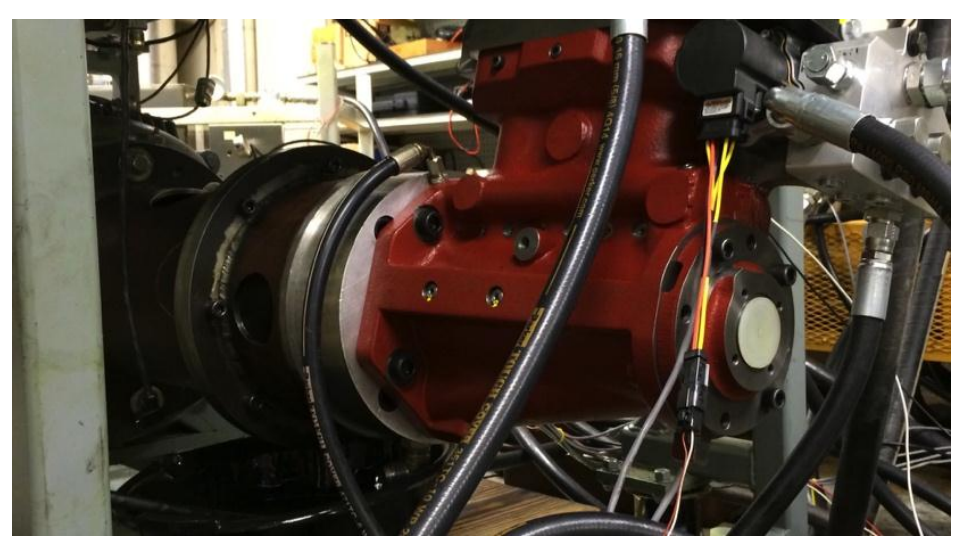

Figure 4.3. Installed pump connected to the torque sensor housing and hydraulic hoses.

\subsection{Steady State Testing}

For steady state tests, inlet pressure, discharge pressure, IMV voltage, and pump speeds were set in combinations for 10 -second periods. Pump speeds were set to $200,500,1000,1500$, and $2500 \mathrm{rpm}$. The inlet pressure was set to 2, 2.5, 3, and 3.5 MPa. The discharge pressure was set to $2,5,10,20$, and $25 \mathrm{MPa}$. Note that the pressure settings were made while the pump was operating with the maximum IMV valve command and varied when the pump flow varied with the valve command. The valve voltage command was set to $0,0.5,1,2,3,4$, and 5 volts.

For each test, pressure and speed settings were made - and a MATLAB SIMULINK ${ }^{\circledR}$ program was used to vary the voltage in steps from zero to 5 volts holding at each level for 10 seconds. Note that the steady state testing data also includes some transient information due to the step changes in IMV voltage. After the tests were completed, the average values for each 10 second period were computed and stored for later analysis. In total, there were over 600 different test conditions obtained. Table 4.2 summarizes the steady-state test conditions. 
Table 4.2. Data collection points associated with experiments.

\begin{tabular}{|l|l|l|}
\hline Pump inlet pressure [MPa] & Pump discharge pressure [MPa] & Pump shaft speed [RPM] \\
\hline 2.0 & $2.0,5.0,10.0,20.0,25.0$ & $200,500,1000,1500,2500$ \\
\hline 2.5 & $2.0,5.0,10.0,20.0,25.0$ & $200,500,1000,1500$ \\
\hline 3.0 & $2.0,5.0,10.0,20.0,25.0$ & $200,500,1000,1500$ \\
\hline 3.5 & $2.0,5.0,10.0,20.0,25.0$ & $200,500,1000,1500$ \\
\hline
\end{tabular}

\subsection{Transient Testing}

Transient testing was completed using dynamic signals for the IMV voltage command. These signals include modulation, step, and chirp signals. Pressure and speed settings were held constant. Quasi-steady tests in the form of voltage modulations were also completed. The IMV voltage was modulated from zero to 5 volts while holding speed and pressures constant. Chirp signals were supplied to the IMV valve command to validate the model for different dynamic conditions. The frequency range included 0.1 to $30 \mathrm{~Hz}$. Additional step responses were measured while the flow control valve was opened. This allowed for a dynamic response in the pressure signal when flow varied due to a step change in the IMV valve command.

\subsection{Inlet-metering valve and Pump Components}

The photos of the pump components are given in the following figures with their description. Both inlet and discharge poppet valves have springs that hold them closed in addition to pressure forces. The spring on the inlet poppet is captured within a screw in housing. The inlet poppet spring was found to be especially stiff and was held open for the photograph (the stiffness was not measured). The IMV is a rotary actuated valve driven by a servomotor (motor is not 
shown). In the photos, it can be seen that there is no damage visible on any components. There is damage on the journal bearing inserts, possibly due to initial startup or poor lubrication. Poor lubrication could be due to using hydraulic oil for lubrication rather than engine oil that is present when the pump is used in engine fuel pumping applications. In addition, it was noted that there was an extremely large amount of air in the lubrication oil flow exiting the pump crank case. The air in the fluid would have degraded the lubrication in the journal bearing.

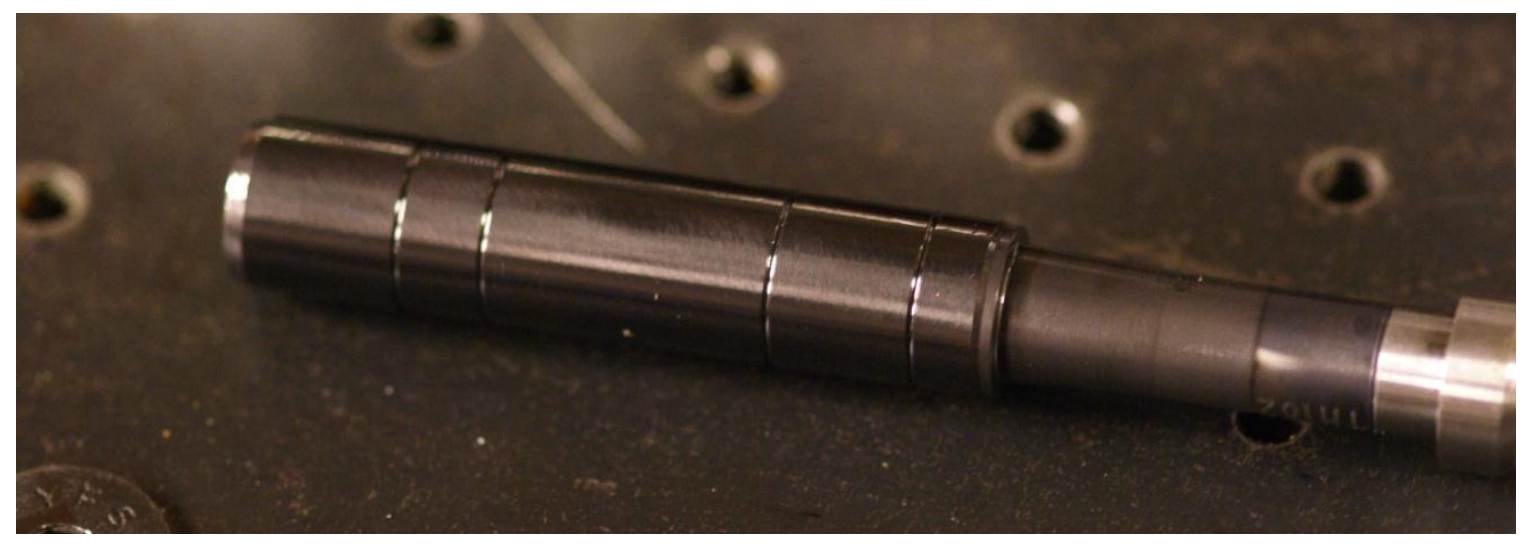

Figure 4.4. Piston side view (length of largest diameter is $59 \mathrm{~mm}$, overall length is $103 \mathrm{~mm}$ ) 


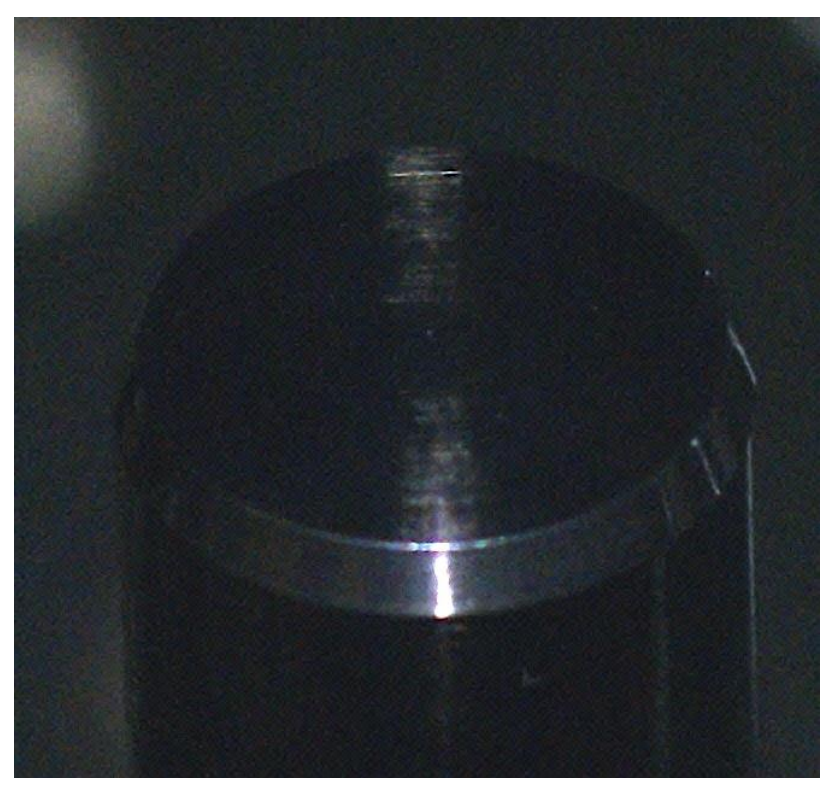

Figure 4.5. Piston crown

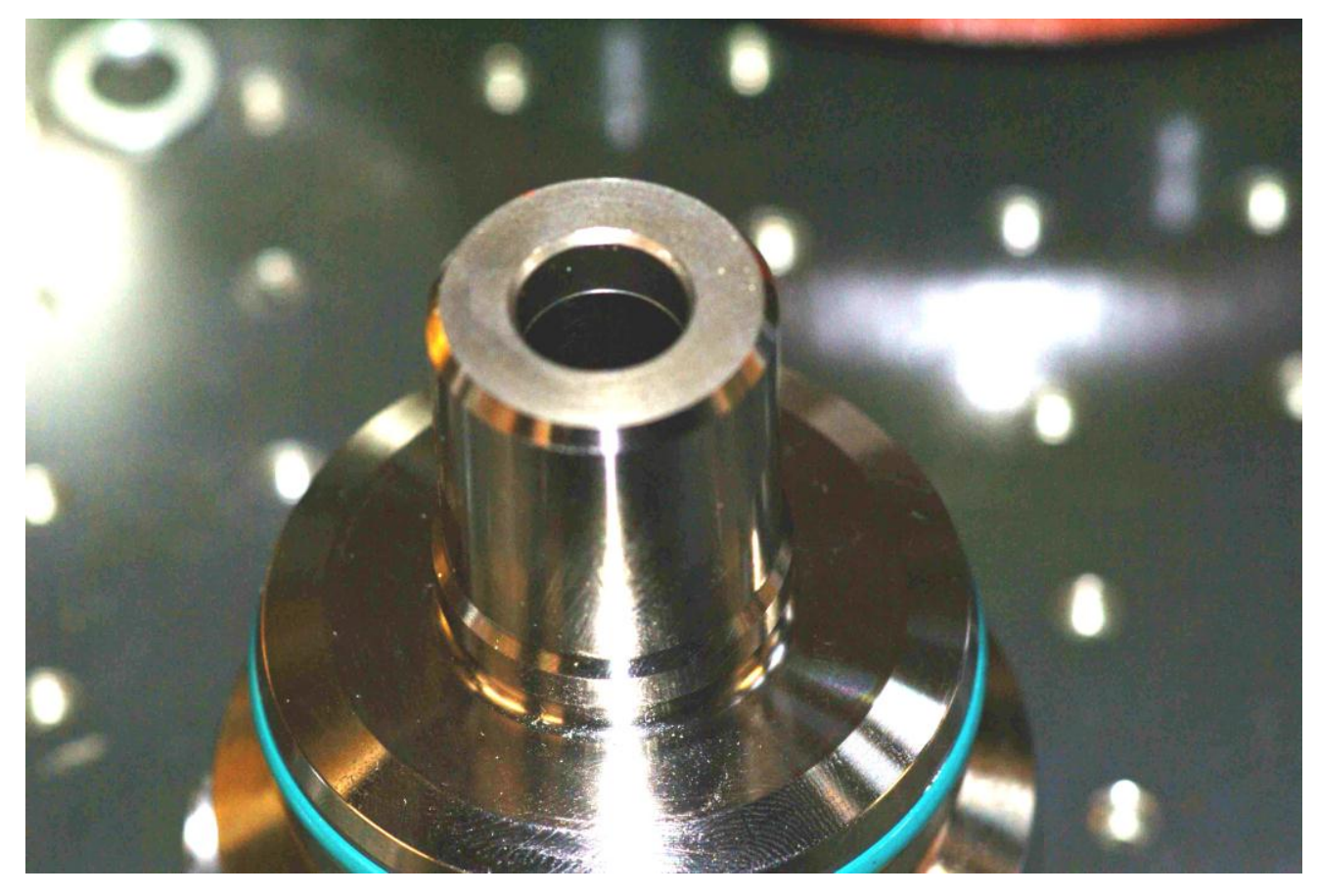

Figure 4.6. Pump cylinder 


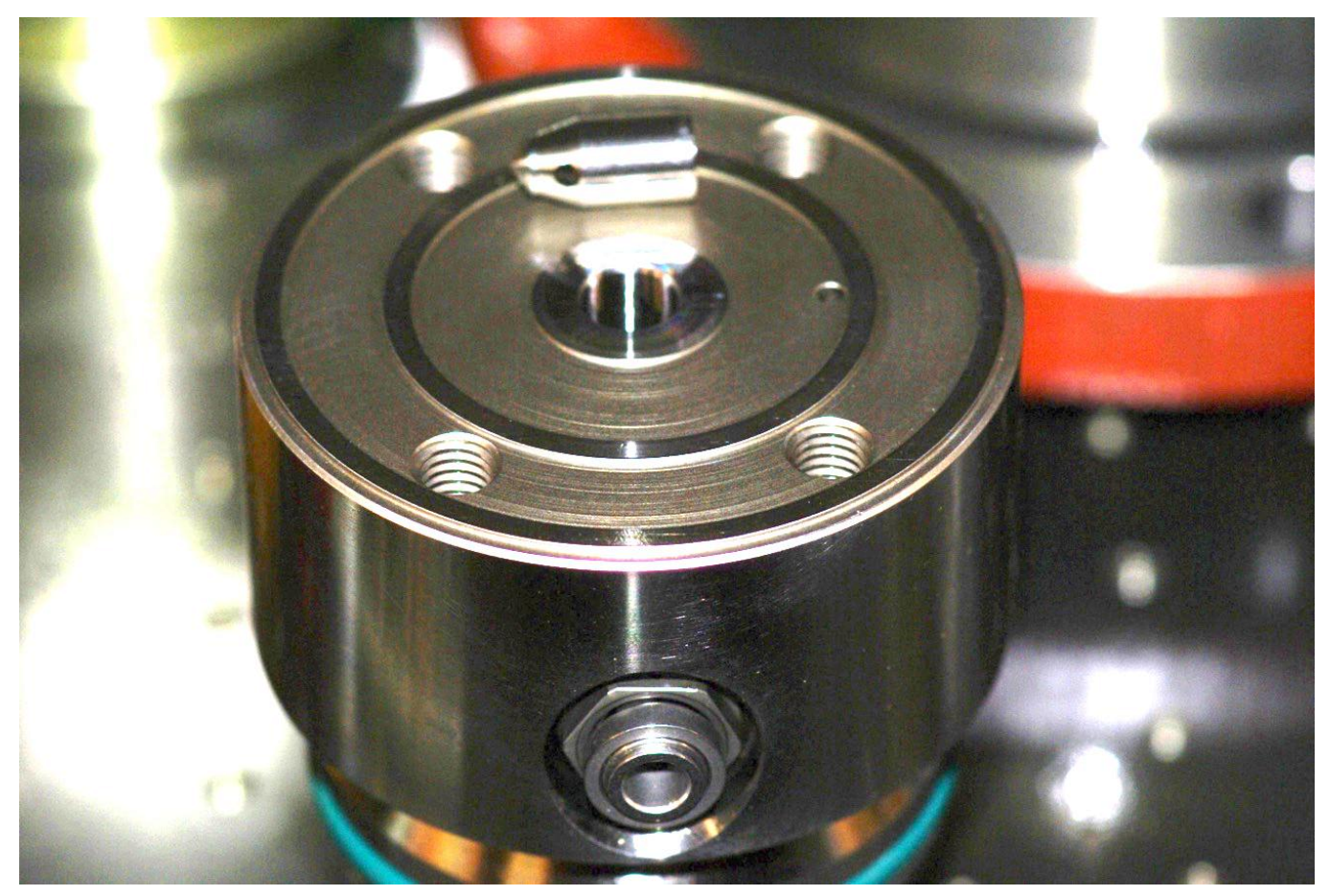

Figure 4.7. Cylinder head with inlet check on the side and discharge check valve placed on top.

The discharge poppet (Fig. 4.7) is designed to have damped motion to help slow closing speeds in the fuel pump application. It is believed that this damped design contributes to flow moving back into the pump cylinder during the intake phase of the pump operation. This is believed to reduce the volumetric efficiency significantly. Redesigning the discharge check valve would likely improve the volumetric efficiency of the pump. Much less damping is needed in the discharge check valve for a hydraulic system due to the dramatically lower pressures at the pump discharge. For example, in a hydraulic system pressures of around $30 \mathrm{MPa}$ are needed compared to $300 \mathrm{MPa}$ in the fuel pump application. Due to the lower pressures in a hydraulic system, much less damping could be utilized to reduce volumetric losses while still protecting the valve from damage due to rapid closing. 


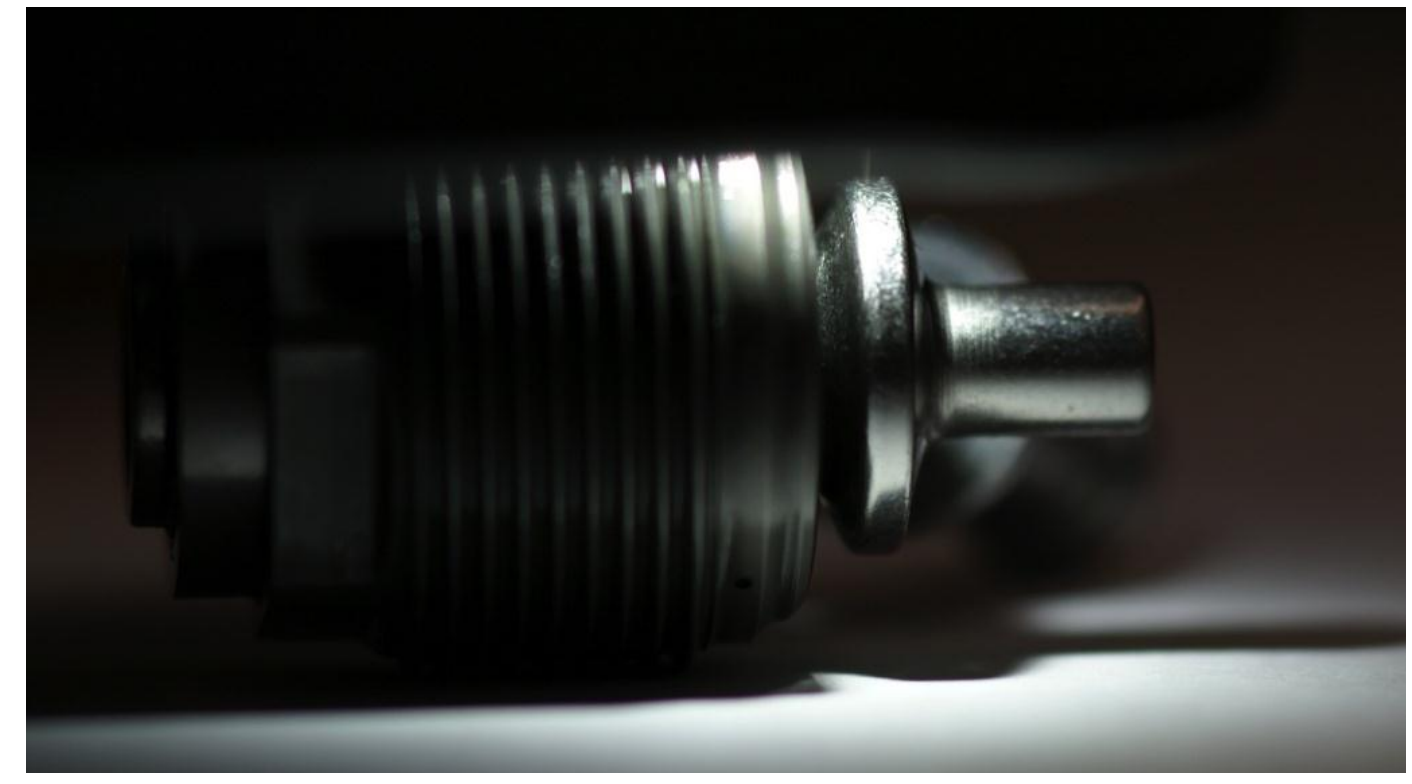

Figure 4.8. Inlet poppet (held open).

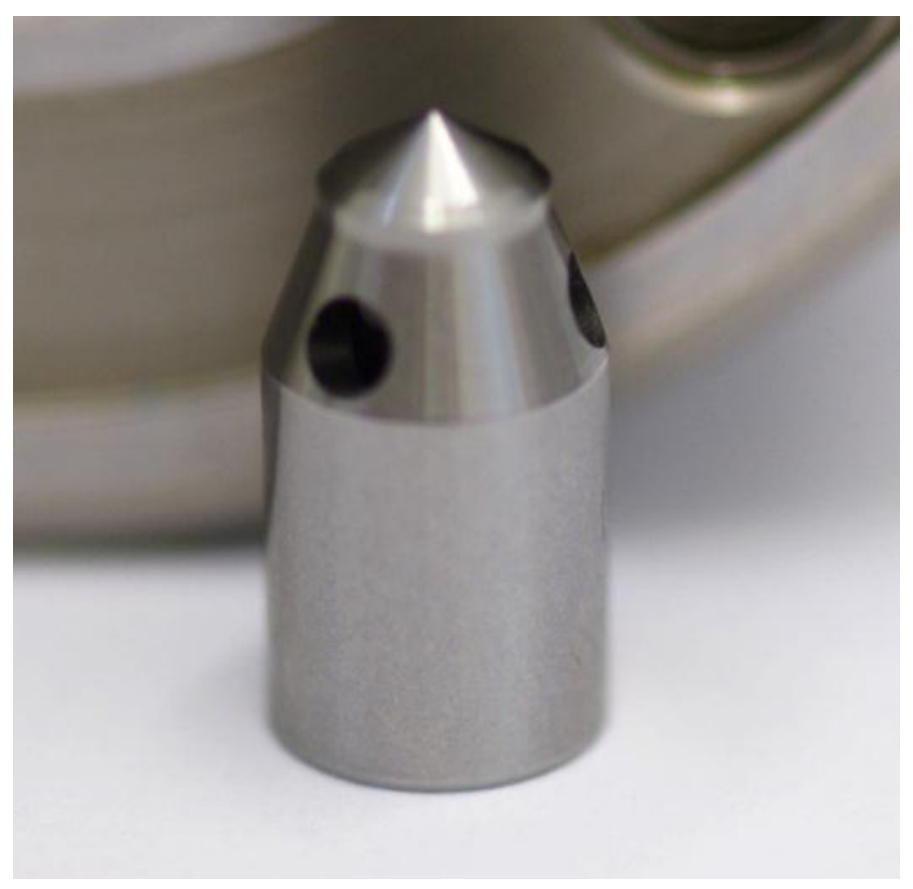

Figure 4.9. Discharge poppet. 


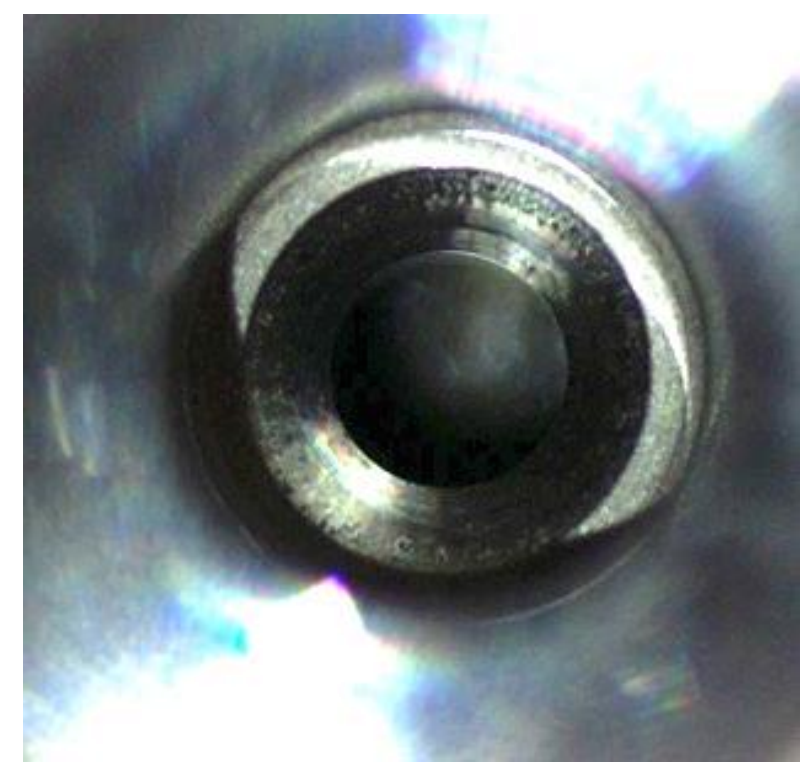

Figure 4.10. Discharge poppet seat.

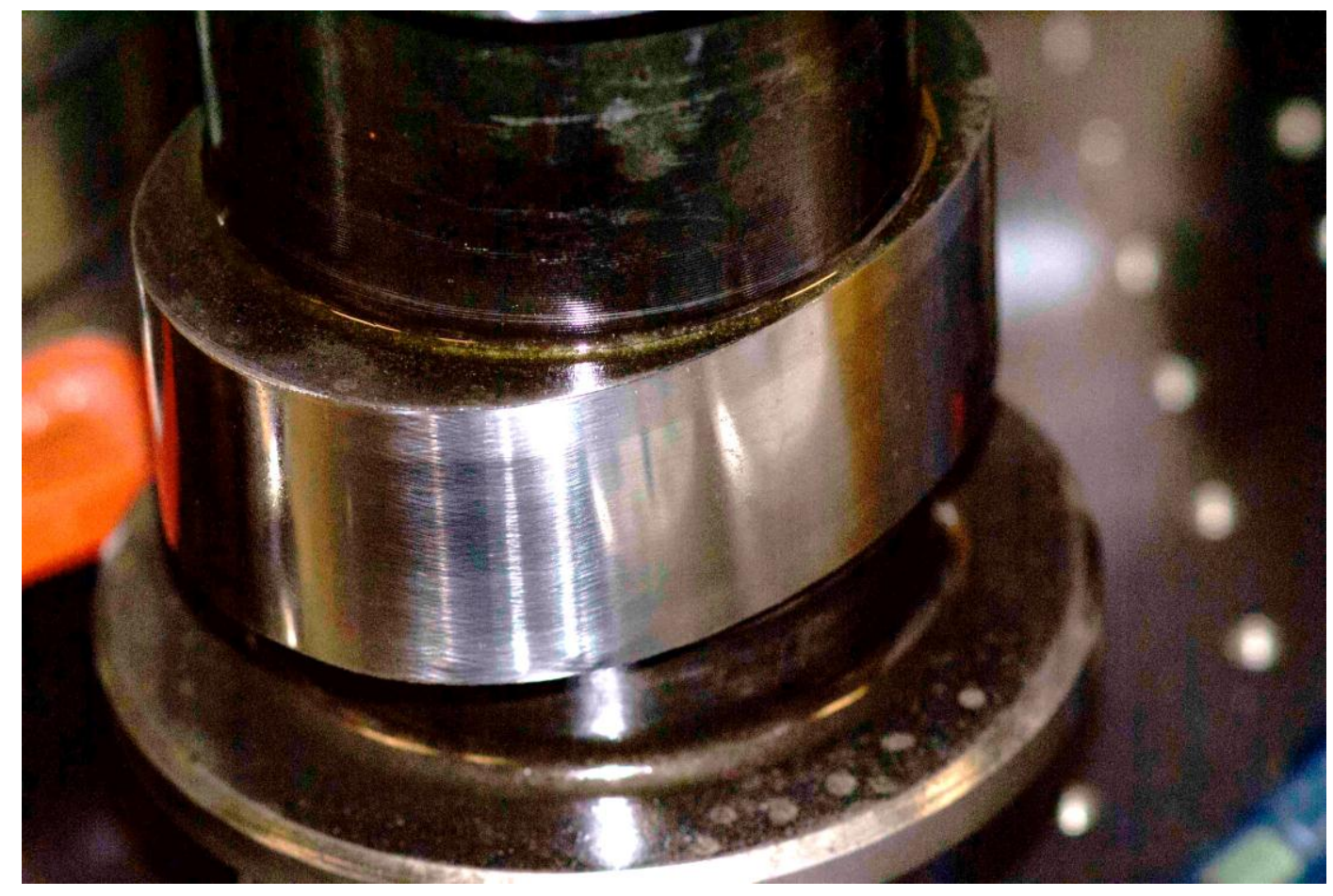

Figure 4.11. Cam lobe. 


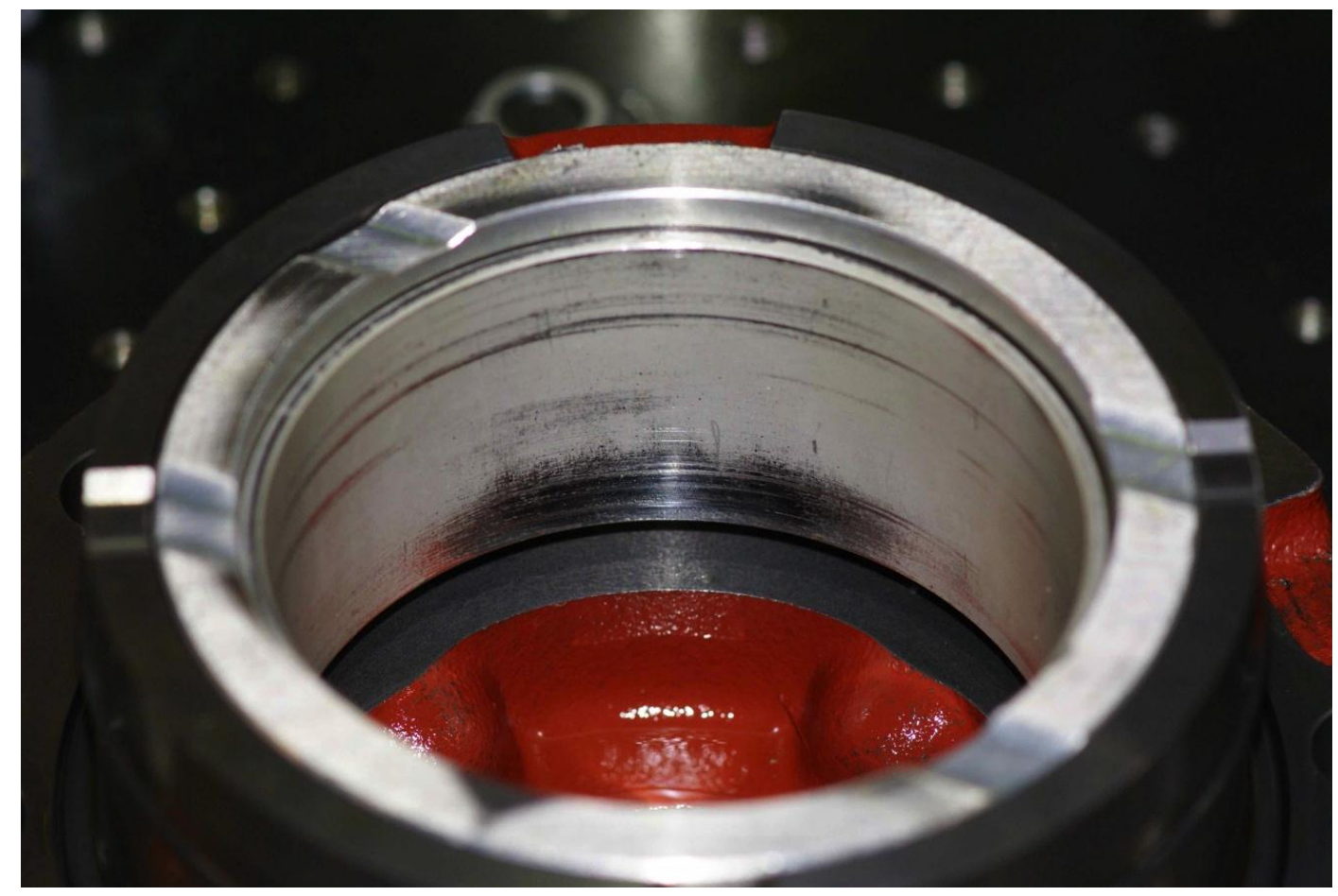

Figure 4.12. Journal bearing insert in the pump housing end cap. 


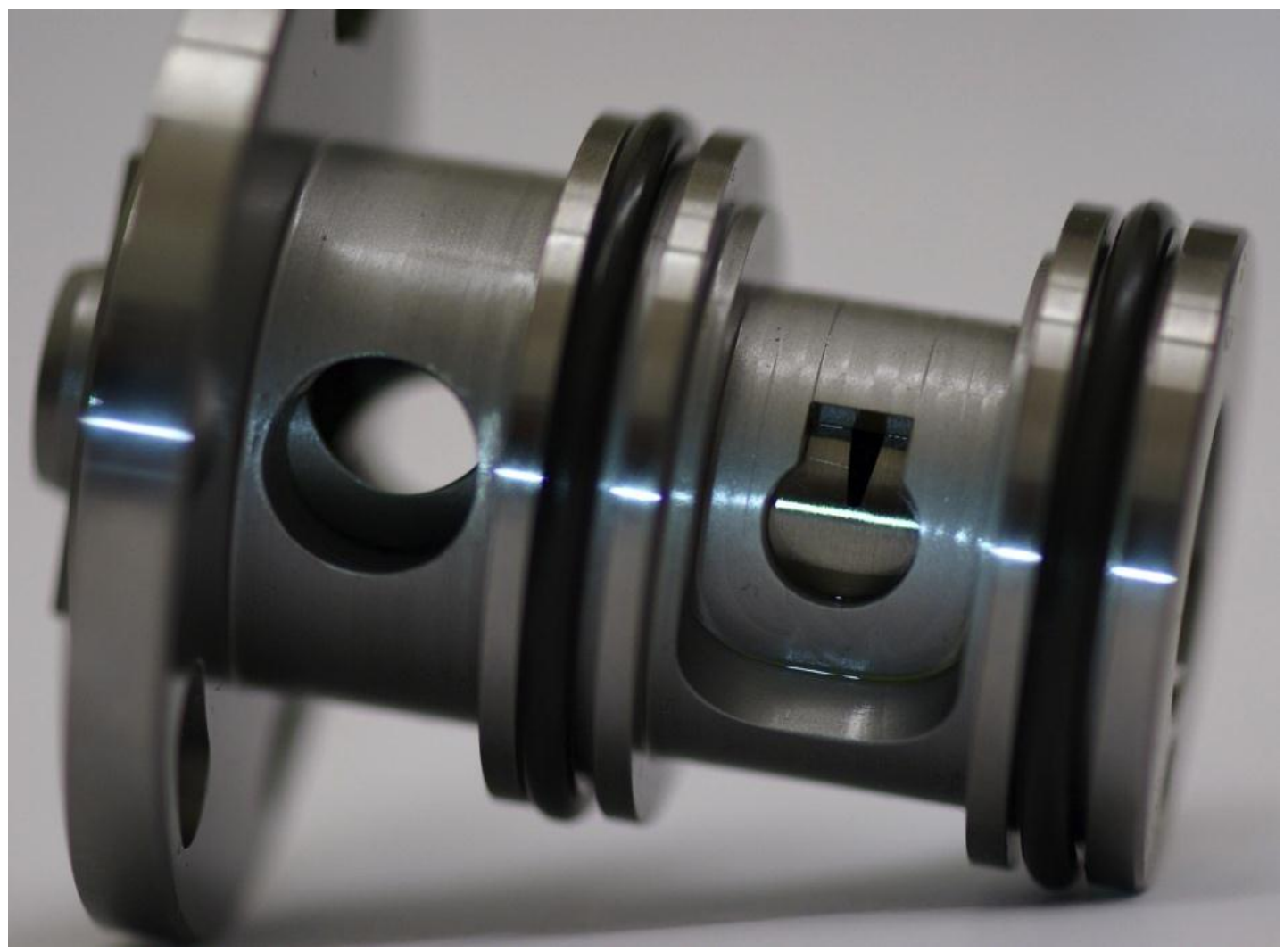

Figure 4.13. IMV sub assembly. The round part of the keyhole shape has a diameter of $7.5 \mathrm{~mm}$. The flat part of the keyhole shape has a diameter of $5 \mathrm{~mm}$. The inner part of the valve rotates changing the size of the triangular flow area. 


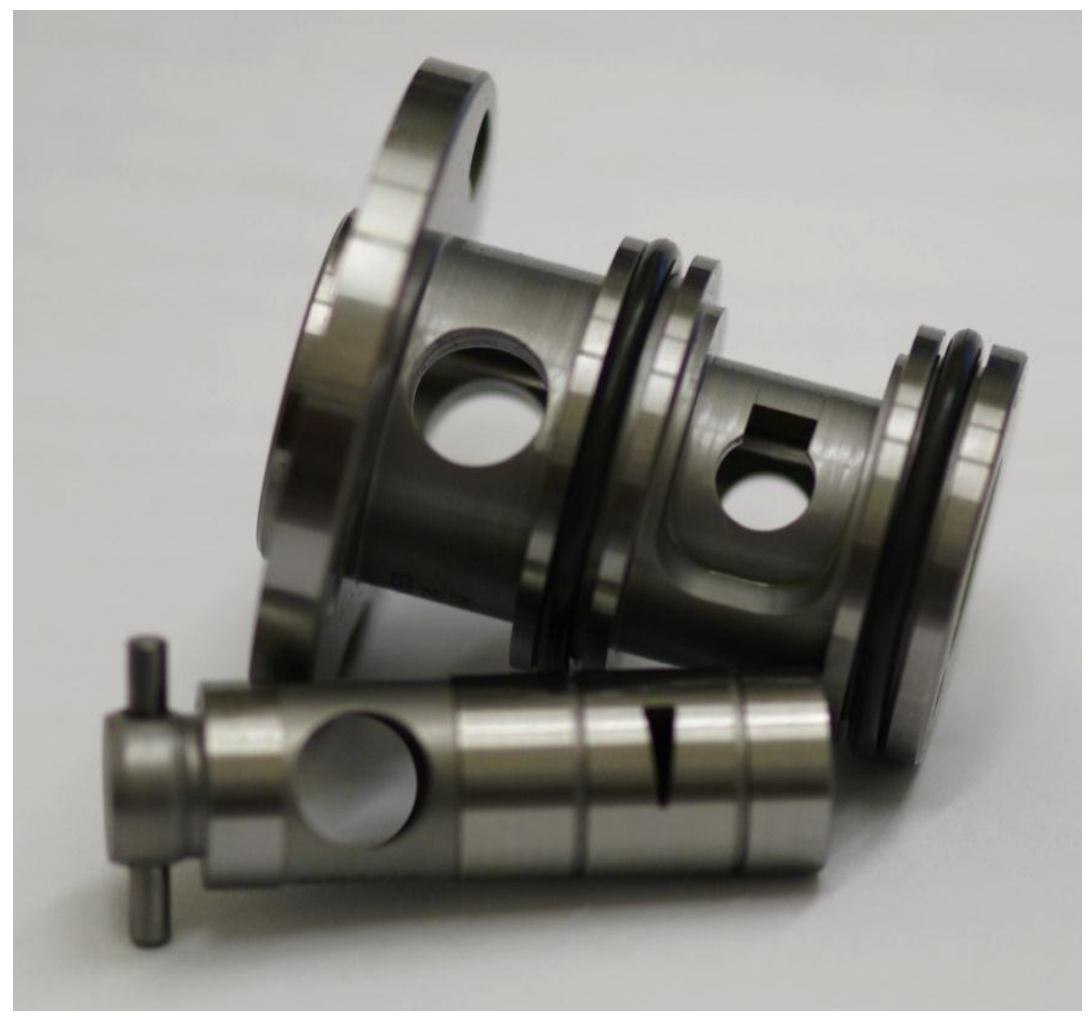

Figure 4.14. IMV disassembled. The dimensions of the triangle portion in the valve are approximately $2.7 \mathrm{~mm}$ x $8 \mathrm{~mm}$.

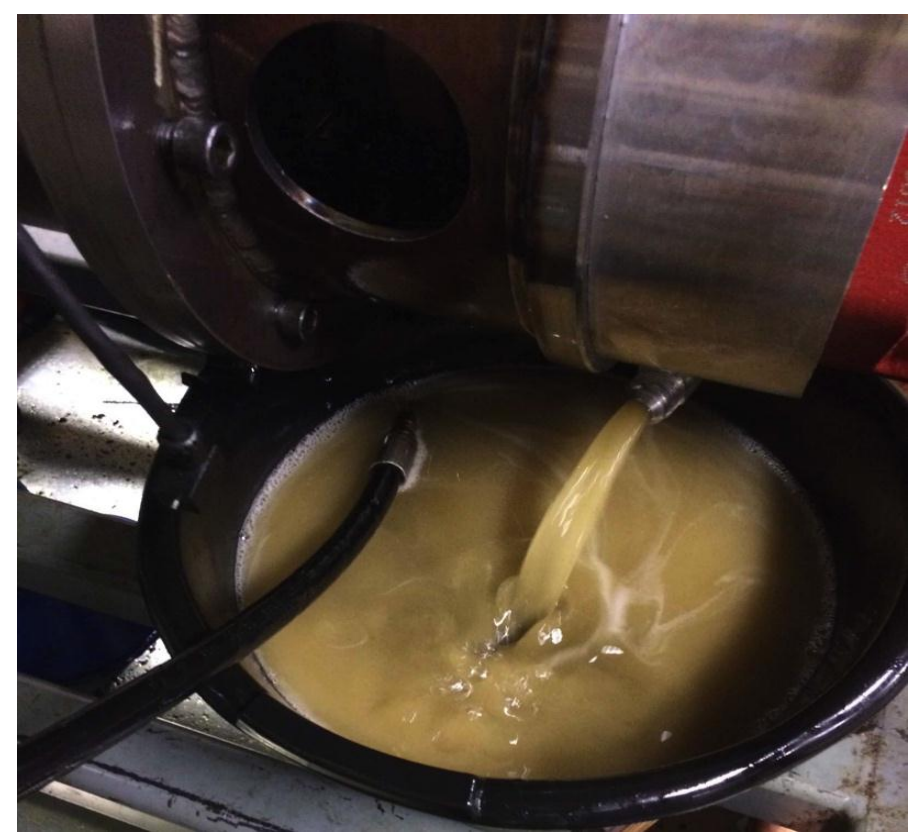

Figure 4.15. Case drain for lubrication flow, highly aerated. 


\section{CHAPTER 5}

\section{VELOCITY CONTROL SYSTEM DESIGN}

\subsection{Introduction}

Hydraulic linear actuators are used to convert the pressurized fluid energy into mechanical energy that is used to move loads linearly. Hydraulic actuators are used in many motion control applications such as in off-highway machinery, aircraft, automotive, and industrial machinery. The velocity of hydraulic actuators is controlled by manipulating the flow entering the actuator. This chapter presents a theoretical model and methods for designing a velocity control system for a hydraulic actuator using an inlet metering pump system to control the fluid flow to a hydraulic cylinder. The velocity control system for a linear actuator is shown in Figure 1. The system consists of an inlet metering pump system, a four-way directional valve, and a linear actuator. The fourway valve is a wide open switching valve and it is used to switch the flow direction to one of the actuator ports depending on the desired direction of the hydraulic cylinder. The discharge flow is supplied to one of the actuator ports, as required, using a four-way directional valve. The flow from the other port of the actuator is returned to the tank through the four-way directional valve. 


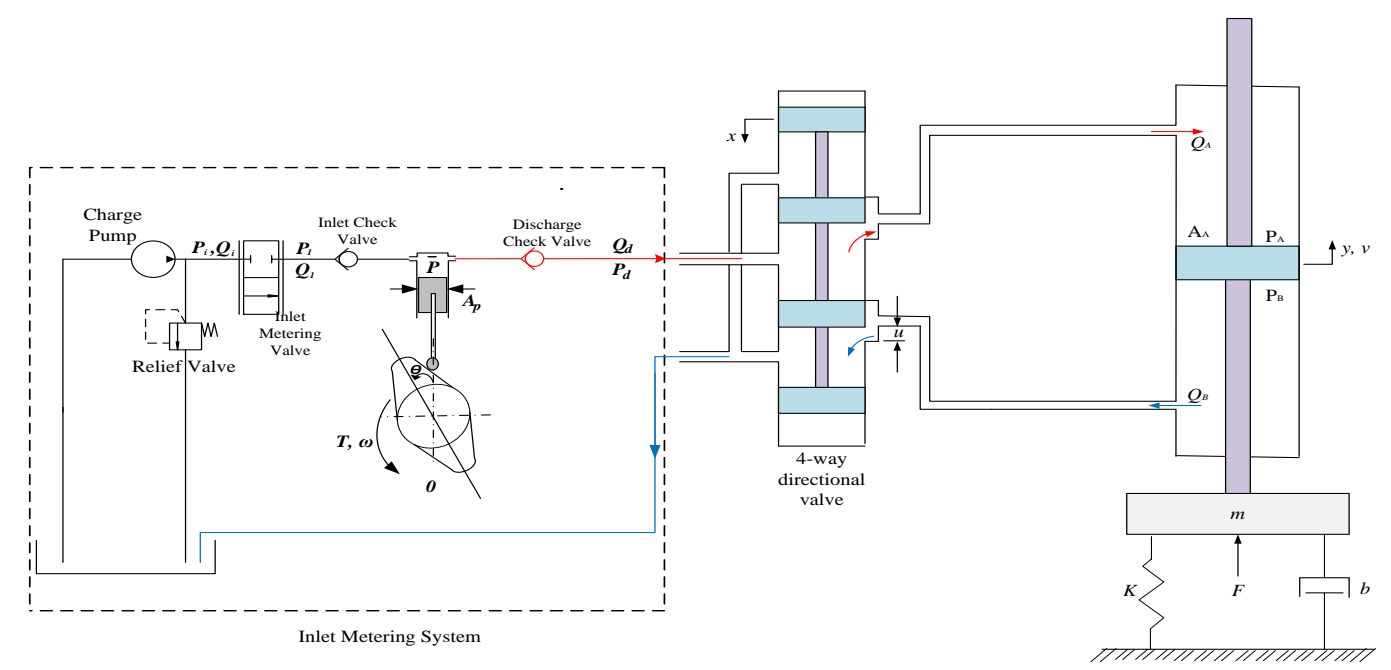

Figure 5.1: Velocity Control System for a Linear Actuator

\subsection{Modeling the system}

The following assumptions are made for creating a model for the system. Let $P_{A}=$ $P_{d}$, assuming that the size of directional valve orifice is large enough so that there is no restriction on the flow through the valve which means that the pressure drop through the passages and directional control valve are small. The system is modeled as if there is one volume extending from the discharge check valve to the piston surface. Since this is a piston pump, flow from a single piston would be discontinuous. However, we assume that multiple pistons would be used and therefore only consider the average flow and do not model any flow ripple or discontinuity (to be considered in future work). The governing equations include the equation of motion of the linear actuator and the pressure rise rate equation. The equation of motion can be written as:

$m \ddot{y}+b \dot{y}+k y-m g=\eta_{a f} P_{d} A_{A}-F_{o}-F$

For steady state conditions, $=\dot{y}=\ddot{y}=0, F=0$ and $P_{d}=0$, then, $F_{o}=m g$. In this analysis, we will consider $F_{o}=m g$ for all cases. Also, the load spring is usually not included 
in analysis where the goal of which is controlling the velocity [75], i.e., $k=0$. So, the equation of motion becomes,

$m \dot{v}+b v=\eta_{a} P_{d} A_{A}-F$

where the cylinder velocity, $v=\dot{y}$. The pressure rise rate equation is written as:

$\dot{P}_{d}=\frac{\beta}{V_{o}+A_{A} y}\left(Q_{i}-k_{1} P_{d}-A_{A} v\right)$

where $Q_{i}$ is the inlet flow which is equal to the ideal discharge flow of the inlet-metered pump and defined in Eq. (5.4).

$Q_{i}=C_{d} A_{v} \sqrt{\frac{2 P_{i}}{\rho}}$

The relationship between valve area and flow through the inlet metering pump given in Eq. (5.4) was derived in Chapter 3. The leakage coefficient, $k_{1}$ was assumed to have a constant value and to account for leakage in the cylinder and other flow losses such as in the pump. A reasonable value for the leakage coefficient is $k_{1}=\frac{Q_{\max }}{10 P_{\max }}$.

Equation (5.3) may be linearized using the following nominal conditions: $y_{o}=v=$ $Q_{d o}=P_{d o}=0$. The linearized equation for the pressure rise rate is,

$\dot{P}_{d}=\frac{\beta}{V_{o}}\left(Q_{i}-k_{1} P_{d}-A_{A} v\right)$

Substituting Eq. (5.4) into Eq. (5.5) gives:

$\dot{P}_{d}=\frac{\beta}{V_{o}}\left(C_{d} A_{v} \sqrt{\frac{2 P_{i}}{\rho}}-k_{1} P_{d}-A_{A} v\right)$ 
In order to generalize the model, all the quantities in Eqs. (5.2) and (5.6) are normalized about reference conditions. Eq. (5.2) can be nondimensionalized using the following reference conditions:

$P_{d}=\hat{P}_{d} P_{d r}, v=\hat{v} v_{r} \quad A_{v}=\hat{A}_{v} A_{r}, P_{i}=\hat{P}_{i} P_{i r}$ and $t=\hat{t} \tau$

Using these reference conditions, Eq. (5.6) can be written as:

$\frac{d\left(\hat{P}_{d} P_{d r}\right)}{d(\hat{t} \tau)}=\frac{\beta}{V_{o}}\left(C_{d} A_{r} \sqrt{\frac{2 P_{i r}}{\rho}} \hat{A}_{v} \sqrt{\hat{P}_{i}}-k_{1} \hat{P}_{d} P_{d r}-A_{A} v_{r} \hat{v}\right)$

Multiplying Eq. (5.7) by $\tau / P_{d r}$ gives:

$\dot{\hat{P}}_{d}=\frac{\tau \beta}{V_{o} P_{d r}} C_{d} A_{r} \sqrt{\frac{2 P_{i r}}{\rho}} \hat{A}_{v} \sqrt{\hat{P}_{i}}-\frac{\tau \beta}{V_{o}} k_{1} \hat{P}_{d}-\frac{\tau \beta v_{r}}{V_{o} P_{d r}} A_{A} \hat{v}$

Let

$\tau=\frac{V_{o}}{\beta k_{1}}$

then, that the nondimensional pressure rise equation can be written as:

$\dot{\hat{P}}_{d}+\hat{P}_{d}=\xi_{1} \hat{A}_{v} \sqrt{\hat{P}_{i}}-\xi_{2} \hat{v}$

where the nondimensional groups $\xi_{1}$ and $\xi_{2}$ in Eq. (5.9) are defined as

$\xi_{1}=\frac{C_{d} A_{r} \sqrt{\frac{2 P_{i r}}{\rho}}}{P_{d r} k_{1}}$, and
$\xi_{2}=\frac{\tau \beta v_{r} A_{A}}{V_{o} P_{d r}}$. 
Similarly, using the reference conditions mentioned above, Eq. (5.2) may be written in nondimensional form as:

$m \frac{d\left(\hat{v} v_{r}\right)}{d(\hat{t} \tau)}+b \hat{v} v_{r}=\eta_{a f} P_{d} A_{A}-F$

Dividing Eq. (5.10) by $P_{d r} A_{A}$ gives:

$\hat{m} \dot{\hat{v}}+\hat{b} \hat{v}=\eta_{a f} \hat{P}_{d}-\hat{F}$

where

$$
\left\{\begin{array}{c}
\widehat{m}=\frac{m v_{r}}{P_{d r} A_{A} \tau} \\
\hat{b}=\frac{b v_{r}}{P_{d r} A_{A}} \\
\hat{A}_{A}=\frac{A_{A}}{A_{A}}=1 \\
\hat{F}=\frac{F}{P_{d r} A_{A}}
\end{array}\right\}
$$

\subsection{Stability Analysis}

From Eqs. (5.9) and (5.11) the dynamic system equations can be written in state-space matrix form, i.e.,

$$
\dot{\boldsymbol{x}}=A \boldsymbol{x}+B \boldsymbol{u} \text { and } y=C \boldsymbol{x}+D \boldsymbol{u} .
$$

Let $\boldsymbol{x}=\left[\hat{P}_{d} \hat{v}\right]^{T}, \boldsymbol{u}=\left[\hat{A}_{v} \hat{F}\right]^{T}$ and $\boldsymbol{y}=\hat{v}$. By examining Eqs. (5.9) and (5.11), the matrices A, B, C, and D can be found to be,

$$
A=\left[\begin{array}{cc}
-1 & -\xi_{2} \\
\frac{\eta_{a}}{\widehat{m}} & -\frac{\widehat{b}}{\widehat{m}}
\end{array}\right],
$$


$B=\left[\begin{array}{cc}\xi_{1} \sqrt{\widehat{P}_{i}} & 0 \\ 0 & -\frac{1}{\widehat{m}}\end{array}\right]$,

$C=\left[\begin{array}{ll}0 & 1\end{array}\right]$, and

$D=0$.

For stability analysis, the characteristic equation can be computed,

$\operatorname{det}(s I-A)=s^{2}+\left(\frac{\hat{b}}{\widehat{m}}+1\right) s+\left(\frac{\hat{b}+\eta_{a} \xi_{2}}{\widehat{m}}\right)=0$

The coefficients in the characteristic equation are:

$$
\left\{\begin{array}{c}
a_{o}=1 \\
a_{1}=\frac{\hat{b}}{\widehat{m}}+1 \\
a_{2}=\frac{\hat{b}+\hat{A}_{A}^{2} \eta \xi_{2}}{\hat{m}}
\end{array}\right\}
$$

Routh stability criterion was used to determine the system stability. According to that criterion, the system is stable if the following condition is satisfied:

$a_{i}>0$ where $\mathrm{i}=0,1$ and 2 .

For real world systems, all the parameters in Eq. (5.13) are positive which means that the system is always stable for any realistic selection of the parameters and no further stability analysis is needed.

\subsection{Performance Analysis}

Two cases were considered in the performance analysis of the system. In the first case, the valve dynamics was neglected assuming an extremely fast valve actuator and the 
controller was designed based on the dynamics of the rest of the system for both open-loop and closed-loop cases. In the second case, the valve dynamics was included in the performance analysis. A valve that has the same characteristics of the valve used in the IM system test setup was considered. PID, $\mathrm{H}_{\infty}$, and two degrees of freedom controllers were designed. Extremely fast valve was assumed next to verify that the assumption of neglecting the valve dynamics in the first case is valid.

\subsubsection{No Valve Dynamics}

The block diagram of the open-loop system with a disturbance force is shown in Fig. 5.2. The system transfer function that relates the output velocity to the input valve opening area neglecting disturbance can be written as follows:

$\frac{\hat{v}_{A}}{\hat{A}_{v}}=\frac{\eta_{a} \xi_{1} / \widehat{m}}{s^{2}+\left(\frac{\hat{b}}{\widehat{m}}+1\right) s+\left(\frac{\hat{b}+\eta_{a} \xi_{2}}{\hat{m}}\right)}$

Also, the transfer function that relates the output velocity to the disturbance force can be written as:

$G_{d}(s)=\frac{\hat{v}_{F}}{\hat{F}}=\frac{-\frac{s+1}{\hat{m}}}{s^{2}+\left(\frac{\hat{b}}{\hat{m}}+1\right) s+\left(\frac{\hat{b}+\eta_{a} \xi_{2}}{\hat{m}}\right)}$ 


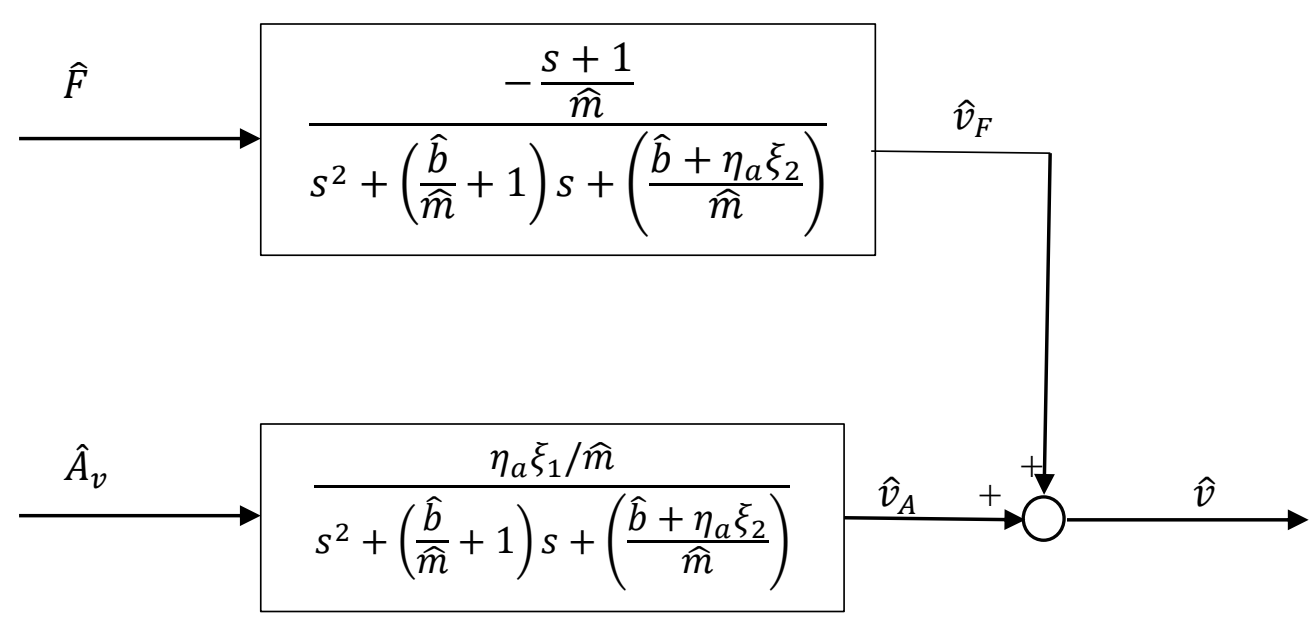

Figure 5.2: Block diagram of the open loop system

The analysis shows that in order for this system to respond to inputs or initial conditions without oscillations, the poles of Eq. (5.14) must be real which means that the following condition must be satisfied:

$\left(\frac{\hat{b}}{\widehat{m}}+1\right)^{2}>4\left(\frac{\hat{b}+\eta_{a} \xi_{2}}{\widehat{m}}\right)$

The condition in Eq. (5.16) cannot be met unless a significant amount of damping is added to the system, which significantly reduces the system efficiency. An alternative way to satisfy the condition in (5.16) is to design a controller. The controller reduces the deviation between the actual plant output and the desired value to zero or a small value by comparing the two values and producing a control signal that reduces the deviation [76]. A feedback controller will be designed to reduce or eliminate the system oscillations (and any overshoot) and to have low velocity reference tracking error.

\subsubsection{Proportional controller design}

The system with P-controller is shown in Fig. 5.3. The transfer function of the system with the disturbance force neglected is shown in Eq. (5.17). 


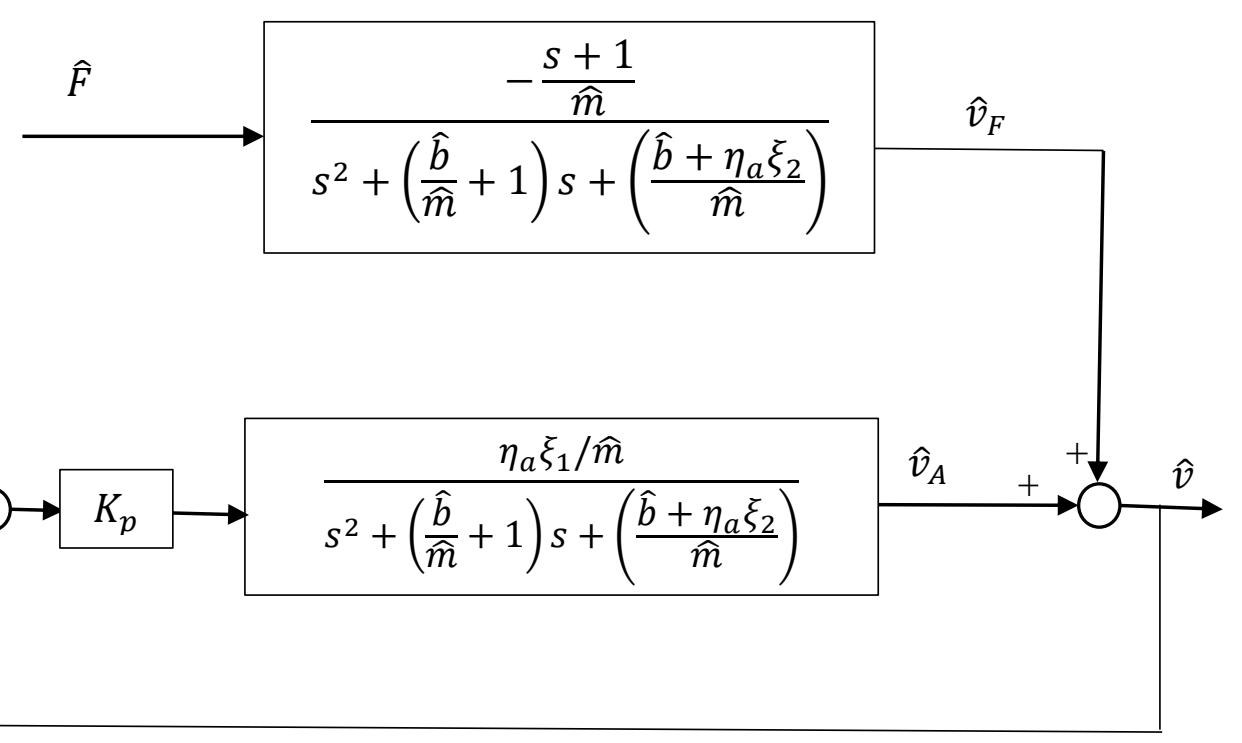

Figure 5.3: Block diagram of the system with $\mathrm{P}$ controller

$$
\frac{\hat{v}_{A}}{\widehat{\mathrm{R}}}=\frac{\eta_{a} \xi_{1} K_{p} / \widehat{m}}{s^{2}+\left(\frac{\hat{b}}{\widehat{m}}+1\right) s+\left(\frac{\hat{b}+\eta_{a} \xi_{2}+\eta_{a} \xi_{1} K_{p}}{\hat{m}}\right)}
$$

In order for the system to have no oscillation, all poles of Eq. (5.17) should be real valued - and the inequality condition in (5.18) must be met.

$$
\left(\frac{\hat{b}}{\widehat{m}}+1\right)^{2}>4\left(\frac{\hat{b}+\eta_{a} \xi_{2}+\eta_{a} \xi_{1} K_{p}}{\widehat{m}}\right)
$$

It is clear that the performance criterion (Inequality (5.18)) cannot be satisfied by changing the value of the proportional controller. Therefore a proportional-derivative controller will be considered next.

5.4.1.2 Proportional-Derivative controller design 
Figure 5.4 shows the block diagram of the closed-loop system with PD-controller. The PD controller will be designed with the goal of eliminating oscillations and overshoot and limiting steady-state tracking error due to a reference input to a specified value. In order to avoid the sharp response of the sudden change in the step input signal, the derivative controller is moved from the closed-loop forward path to the feedback path [77]. The transfer function of this system without disturbance force is shown in Eq. (5.19).
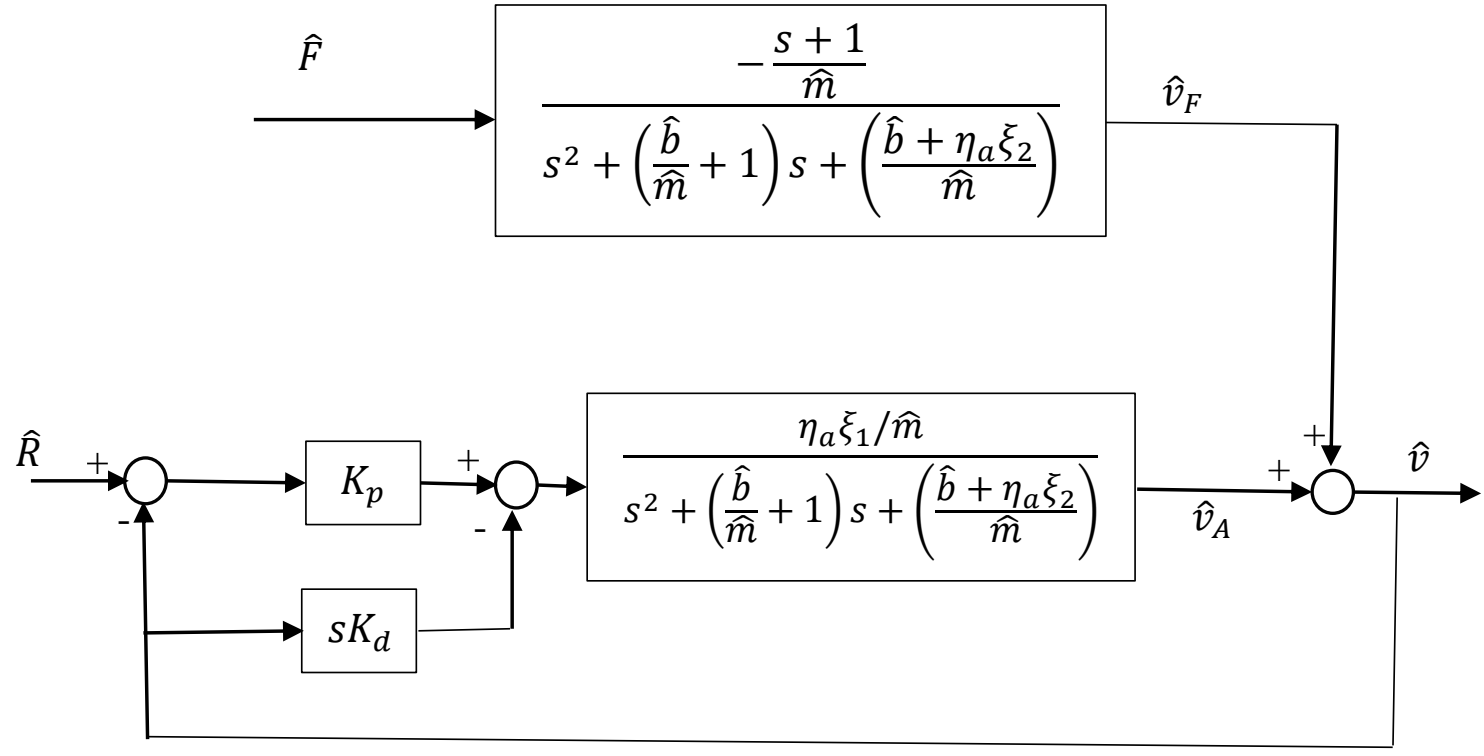

Figure 5.4: Block diagram of the system with PD controller

$\frac{\hat{v}_{A}}{\widehat{R}}=\frac{\frac{\eta_{a} \xi_{1} K_{p}}{\widehat{m}}}{s^{2}+\left(\frac{\hat{b}}{\widehat{m}}+\frac{\eta_{a} \xi_{1} K_{d}}{\widehat{m}}+1\right) s+\left(\frac{\hat{b}+\eta_{a} \xi_{1} K_{p}+\eta_{a} \xi_{2}}{\widehat{m}}\right)}$

Setting the DC gain of this system equal to $(1-e)$ where $e$ is the controller tracking error gives:

$\frac{\eta_{a} \xi_{1} K_{p}}{\widehat{b}+\eta_{a} \xi_{1} K_{p}+\eta_{a} \xi_{2}}=1-e$ 
Solving for $K_{p}$ gives:

$K_{\mathrm{p}}=\frac{(1-e)\left(\hat{b}+\eta_{a} \xi_{2}\right)}{e \eta_{a} \xi_{1}}$

Letting the error be $e=0.01$ and using the values for the other parameters defined in Table 5.1 yields $K_{p}=100.76$

In order for the poles of Eq. (5.19) to be real, the following condition must be satisfied:

$\left(\frac{\hat{b}}{\widehat{m}}+\frac{\eta_{a} \xi_{1} K_{d}}{\widehat{m}}+1\right)^{2}>4\left(\frac{\hat{b}+\eta_{a} \xi_{1} K_{p}+\eta_{a} \xi_{2}}{\widehat{m}}\right)$

Solving for $K_{d}$ and using the variable values from Table 5.1 gives $K_{d}>10.7$. In the simulation, $K_{d}$ was chosen to be 11 .

The block diagram of the overall system with a disturbance force and a PD controller shown in Fig. 5.4 could be rearranged as shown in Fig. 5.5:

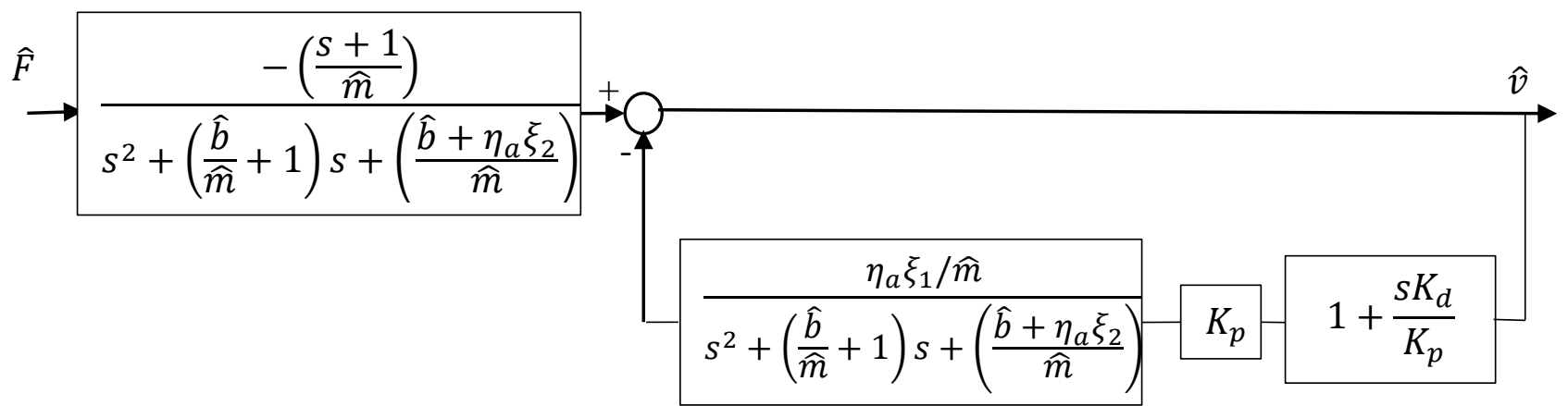

Figure 5.5: The block diagram of the overall system with PD-controller

The overall closed-loop disturbance response transfer function with PD control is, 


$$
\frac{\hat{v}}{\hat{F}}=\frac{-\left(\frac{s+1}{\hat{m}}\right)}{s^{2}+\left(\frac{\hat{b}-\eta_{a} \xi_{1} K_{d}}{\hat{m}}+1\right) s+\left(\frac{\hat{b}+\eta_{a} \xi_{2}-\eta_{a} \xi_{1} K_{p}}{\widehat{m}}\right)}
$$

Now, using the previously defined values for the parameters and the controller gains, $K_{d}$ and $K_{p}$, calculated earlier, gives,

$\lim _{s \rightarrow 0} \hat{\hat{v}}=\frac{-\left(\frac{s+1}{\hat{m}}\right)}{s^{2}+\left(\frac{\hat{b}-\eta_{a} \xi_{1} K_{d}}{\widehat{m}}+1\right) s+\left(\frac{\hat{b}+\eta_{a} \xi_{2}-\eta_{a} \xi_{1} K_{p}}{\widehat{m}}\right)}=0.001$

This is one tenth the size of the error specification, $e$, indicating that the controller can reject steady disturbances well, as track steady reference signals.

\subsubsection{Including the Valve Dynamics}

If the valve dynamics model is included in the simulation, the closed-loop block diagram of the overall system becomes as shown in Fig. 5.6.

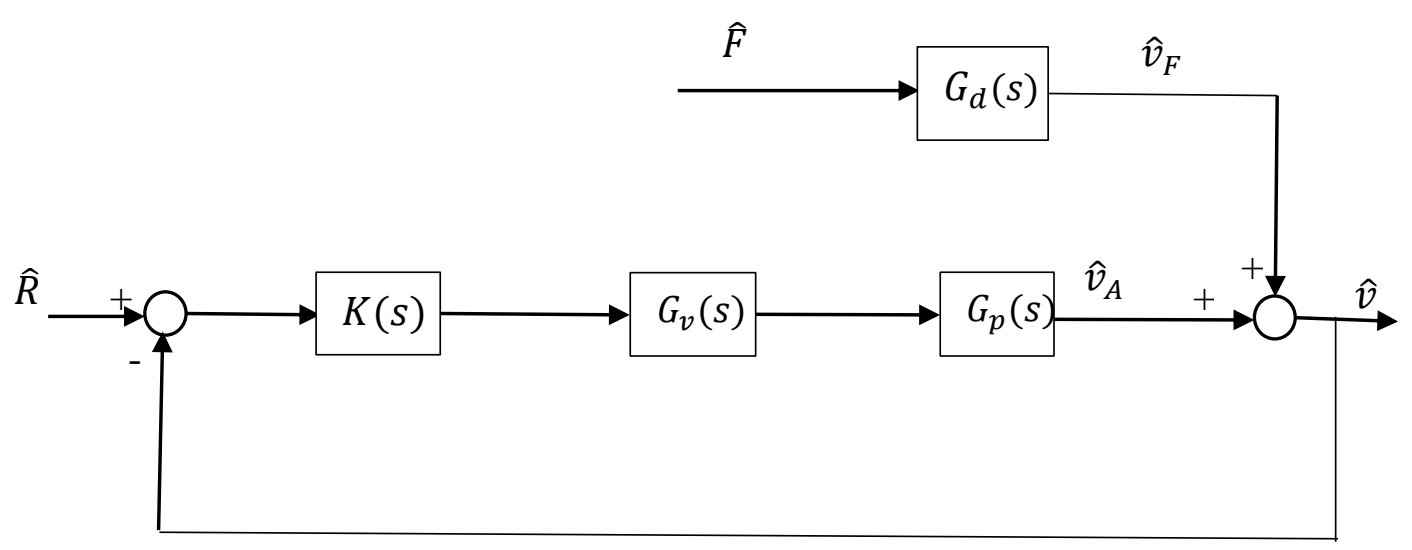

Figure 5.6: Overall system block diagram

where $K(s), G_{v}(s), G_{p}(s)$, and $G_{d}(s)$ are the non-dimensional transfer functions of the controller, the valve, the plant, and the disturbance respectively. 
The transfer function of the valve used in the experimental setup of the inlet metering system has a second order response which can be expressed as shown below,

$\frac{V_{\text {out }}}{V_{\text {in }}}=\frac{k_{s} e^{-s t_{d}} \omega_{n}^{2}}{s^{2}+2 \xi \omega_{n} s+\omega_{n}^{2}}$

where $V_{\text {in }}$ is valve input voltage, $V_{\text {out }}$ is the valve feedback voltage, $k_{S}$ is the static gain of the valve, $\xi$ is the valve damping ratio, $\omega_{n}$ is the valve natural frequency, and the exponential quantity represents the valve time delay. The valve characteristics in Eq. (5.24) are found from the experimental data using curve fitting (Fig. 5.7) and they are listed in Table 5.2. The relationship between the valve feedback voltage, $V_{\text {out }}$, and the valve metering area, $A_{v}$, can be approximated by a linear relationship as shown in Eq. (5.25).

$A_{v}=k_{v} \cdot V_{\text {out }}$

where $k_{v}$ is the constant of proportionality and was found from the experimental data. The value of $k_{v}$ is found in Table 5.1. From Eqs. (5.24) and (5.25), the valve transfer function can be rewritten as:

$\frac{A_{v}}{V_{i n}}=\frac{k_{v} k_{s} e^{-s t_{d}} \omega_{n}^{2}}{s^{2}+2 \xi \omega_{n} s+\omega_{n}^{2}}$

Equation (5.26) can be nondimensionalized to give the non-dimensional valve transfer function, $G_{v}(s)$, shown in Eq. (5.27).

$G_{v}(s)=\frac{\hat{A}_{v}}{\widehat{V}_{i n}}=\frac{k_{v} k_{s} V_{r} e^{-s \hat{t}_{d}} \widehat{\omega}_{n}^{2}}{A_{r}\left(s^{2}+2 \xi \widehat{\omega}_{n} s+\widehat{\omega}_{n}^{2}\right)}$

where $\widehat{\omega}_{n}=\omega_{n} \tau$ is the nondimensional natural frequency of the valve, $\hat{t}_{d}=t_{d} / \tau$ is the nondimensional time delay of the valve, $\tau$ is the time constant defined earlier, and $V_{r}$ is the 
reference input voltage. The values of $k_{v}, V_{r}$ and $\tau$ are found in Table 5.1. The calculations showed that the valve dynamics is slower than the dynamics of the rest of the system. However, the difference in the dynamics speed between the valve and the rest of the system is not enough to neglect the dynamics of the rest of the system and design the controller according to the valve dynamics. That is being said, no order reduction could be performed. The open-loop response has a large overshoot with oscillations and a large steady state error with respect to the expected output in the absence of a disturbance. A controller was considered to reduce the overshoot, the number of oscillations, and the steady state error.

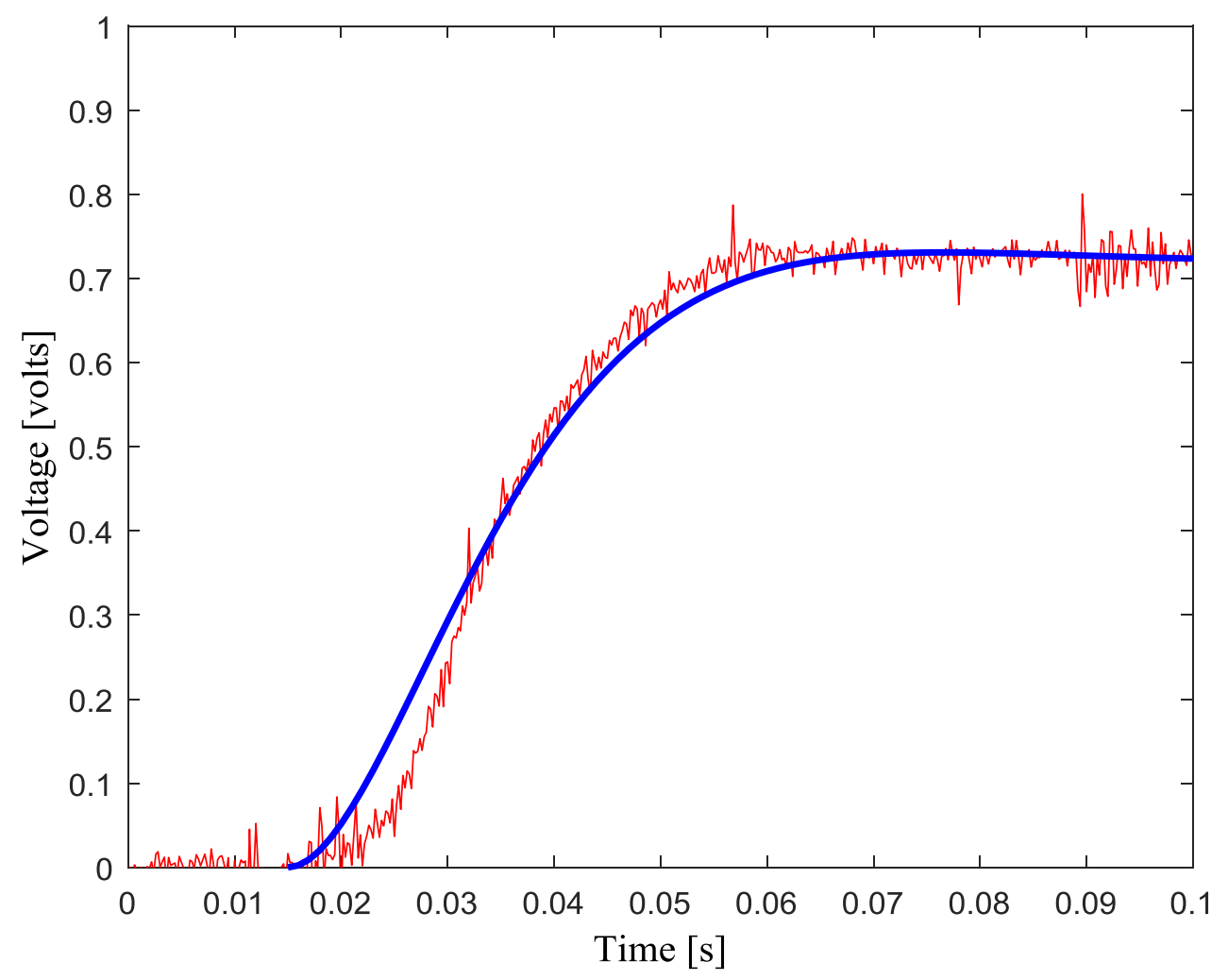

Figure 5.7: The inlet metering valve dynamics curve fit 


\subsubsection{Limitation Imposed by the Time Delay}

The time delay introduces a serious limitation on the controller performance that can be achieved. The reason for that limitation is that the effect of the change of the input on the output will be delayed by the by an amount of time that is equal to the time delay. The time delay limits the closed-loop bandwidth frequency to be less than the reciprocal of the time delay [79]. Mathematically, this can be expressed as shown in Eq. 5.28.

$\widehat{\omega}_{b}<\frac{1}{\hat{t}_{d}}$

where $\widehat{\omega}_{b}$ is the nondimensional bandwidth frequency. From Eq. (5.36) the bandwidth frequency limitation can be found to be:

$\widehat{\omega}_{b}<4.17$

\subsubsection{PID Controller design}

PID controller was considered first. Auto-tuning was used to determine the controller gains. The resulting controller gains are $K_{p}=0.12, K_{d}=0$, and $\mathrm{Ki}=0.8$.

If an extremely fast valve actuator is assumed, the controller can be designed based on the dynamics of the rest of the system. The procedure in Section 5.4.1.2 can be used to design a PD controller for the system with extremely fast valve using PD controller designed based on the dynamics of the rest of the system. The valve characteristics were $\xi=0.8, \omega=8500 \mathrm{rad} / \mathrm{s}$, and a time delay of $\tau / 100 \mathrm{~s}$. That gives the controller gains which are, in this case, $K_{p}=83$ and $K_{d}=3.5$. The simulation showed that the response of the system in this case is similar to the case discussed earlier where valve dynamics is neglected. 


\subsubsection{Hळ Controller Design}

The analysis showed that the system with the valve dynamics would respond to disturbances with overshoot and oscillations with the PID design. In order to improve the system performance, a higher order controller $(\mathrm{H} \infty)$ was considered. The details of the $\mathrm{H} \infty$ controller design are presented in this section. The block diagram of the system with the performance weight, $w_{p}(s)$, and the control effort weight, $w_{u}(s)$, is shown in Fig. (5.8).

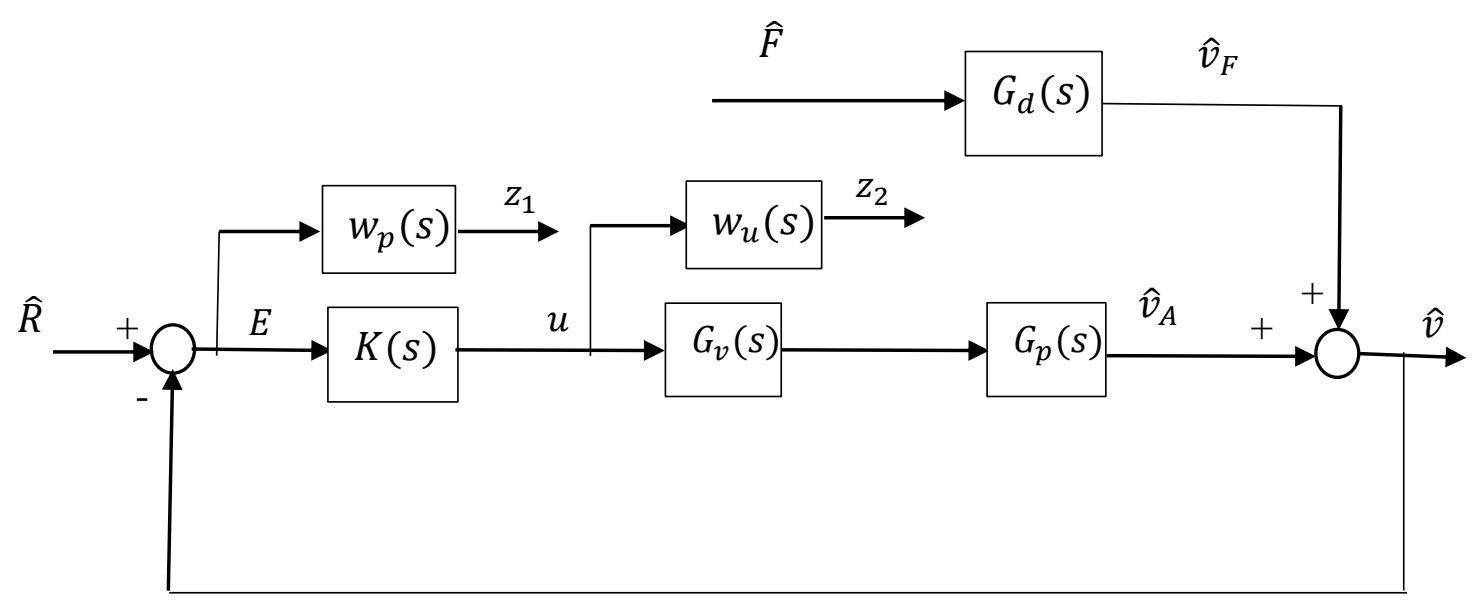

Figure 5.8: The system block diagram with the weights

The performance weight, $w_{p}(s)$, represents the inverse of the upper bound of the magnitude of the sensitivity function, $S$ (s). A typical tracking error performance weight is given as [78],

$w_{p}(s)=\frac{\frac{s}{M}+\widehat{\omega}_{b}}{s+a \widehat{\omega}_{b}}$

where $\widehat{\omega}_{b}$ is the nondimensional bandwidth frequency, $M$ is the high-frequency error and $a$ is the low-frequency error. $\widehat{\omega}_{b}$ was chosen to be less than the frequency limitation introduced by the time delay (Eq. (5.28)). The bandwidth was chosen to be the same as the open loop system. Note that the control design goal is to improve low frequency error to achieve good tracking and disturbance rejection. Different values have been used for $M$ in the literature. For example, Carpenter [78] 
used a value of 1.5 for $M$ while a higher value was used by Fales [80] which is 6. A reasonable value of the low frequency error is 0.01 [78]. The values of $a, M$, and $\widehat{\omega}_{b}$ are given in Table 5.3. In addition, a convenient selection for the controller effort weight, $w_{u}$, for nondimensional systems is 1 . The sensitivity function, $S$, is the transfer function from the reference signal to the error signal and it is written as [79]:

$S(s)=\frac{E(s)}{\hat{R}(s)}=\frac{1}{1+G(s) D_{c}(s)}$.

where $G(s)=G_{v}(s) G_{p}(s)$. Also, the transfer function from the disturbance signal to the error signal is written as:

$\frac{E(s)}{\widehat{F}(s)}=-S(s) \cdot G_{d}(s)$

A common objective for the for the system performance is minimizing the weighted sensitivity function, $S(s) w_{p}(s)$ [81]. In this work, the goal is to find $K(s)$ such that $\left\|S G_{d}\right\|_{\infty}$ is small and $K$ stabilizes the system. For this to be done, the following condition should be met.

$\left|S . G_{d}(j \omega)\right|<\left|\frac{1}{w_{p}(j \omega)}\right|,|S|<\left|\frac{1}{w_{p}(j \omega)}\right|,|S . K|<\left|\frac{1}{w_{u}(j \omega)}\right|$, and $\left|S . K . G_{d}(j \omega)\right|<\left|\frac{1}{w_{u}(j \omega)}\right| \quad \forall \omega$

or

$\left\{\begin{array}{c}\left\|S G_{d} w_{p}(j \omega)\right\|_{\infty}<1 \\ \left\|S w_{p}(j \omega)\right\|_{\infty}<1 \\ \left\|S K w_{u}(j \omega)\right\|_{\infty}<1 \\ \left\|S K G_{d} w_{u}(j \omega)\right\|_{\infty}<1\end{array}\right\}$

From Fig. 5.7, $z_{1}, E$ and $z_{2}$ can be written as:

$z_{1}=w_{p} \hat{R}-G_{d} w_{p} \hat{F}-G w_{p} u$ 
$E=\hat{R}-G_{d} \hat{F}-G u$

$z_{2}=w_{u} \mathrm{u}$

From Eqs. (5.33), (5.34), and (5.35), the generalized plant $(P)$ shown in Fig. 5.8 can be written

as:

$P=\left[\begin{array}{ccc}w_{p} & -G_{d} w_{p} & -G w_{p} \\ 1 & -G_{d} & -G \\ 0 & 0 & w_{u}\end{array}\right]$

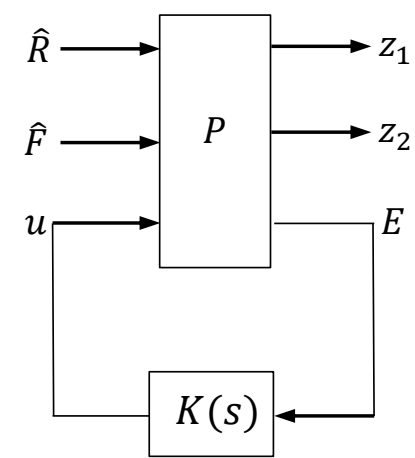

Figure 5.9: The generalized plant

The time delay of the valve was approximated by a first order Padé approximation. Using MATLAB $^{\circledR}$, the sixth order $\mathrm{H}_{\infty}$ controller transfer function, $K(s)$, is found and is shown in Eq. (5.37).

$K(s)=\frac{178.9 s^{5}+3318 s^{4}+4.161 e 04 s^{3}+3.879 \mathrm{e} 05 s^{2}+1.929 \mathrm{e} 06 s+4.41 \times 10^{6}}{s^{6}+200.9 s^{5}+5439 s^{4}+7.593 e 04 s^{3}+6.178 \mathrm{e} 05 s^{2}+3.496 e 06 s+3.49 \times 10^{4}}$

The controller contains fast dynamics that may be difficult to implement in a practical application. The controller in Eq. (5.37) satisfies the conditions described in Eq. (5.32) as shown in Figs. 5.10 and 5.11. 


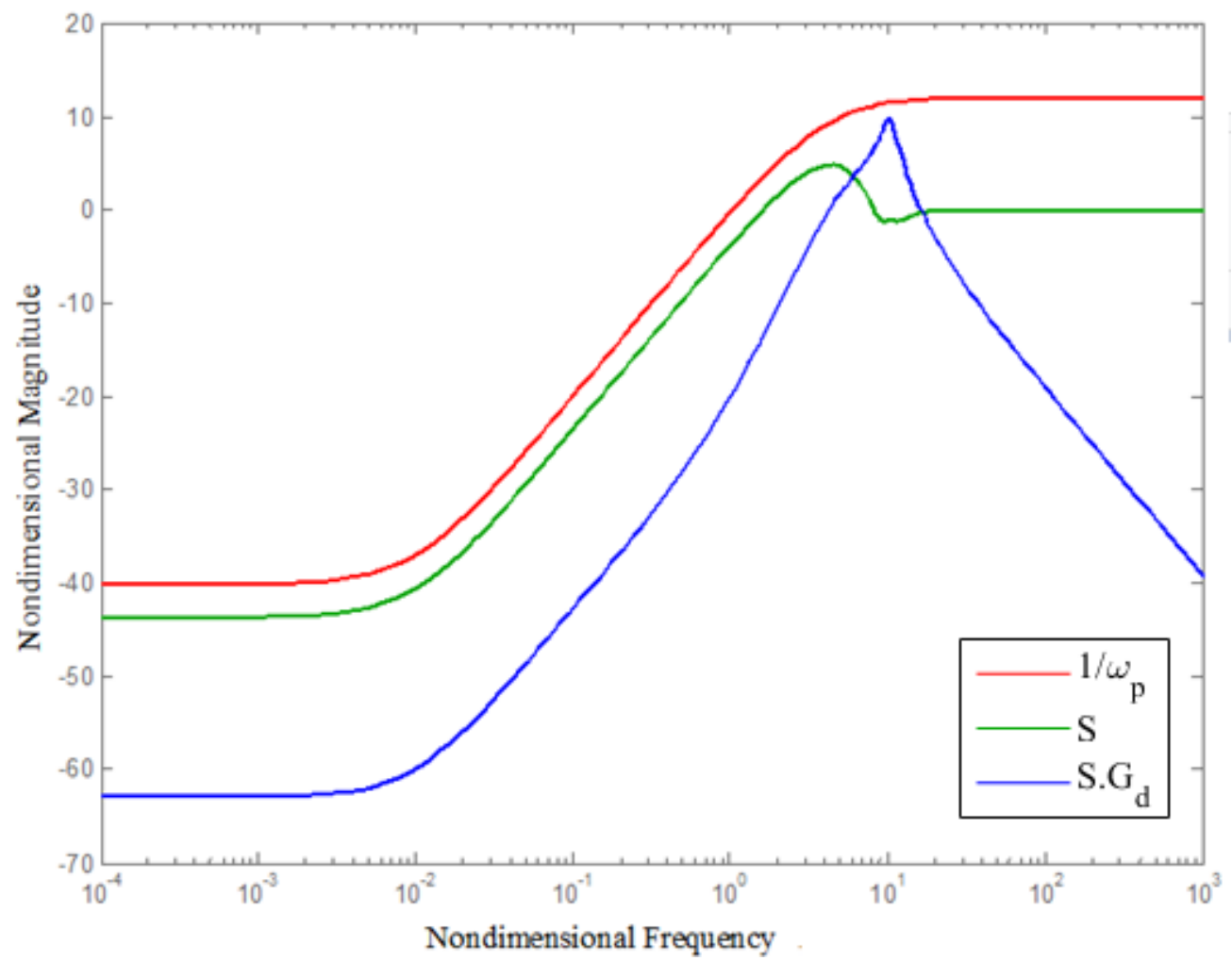

Figure 5.10: The frequency response of the inverse performance weight, $S$, and $S . G_{d}$

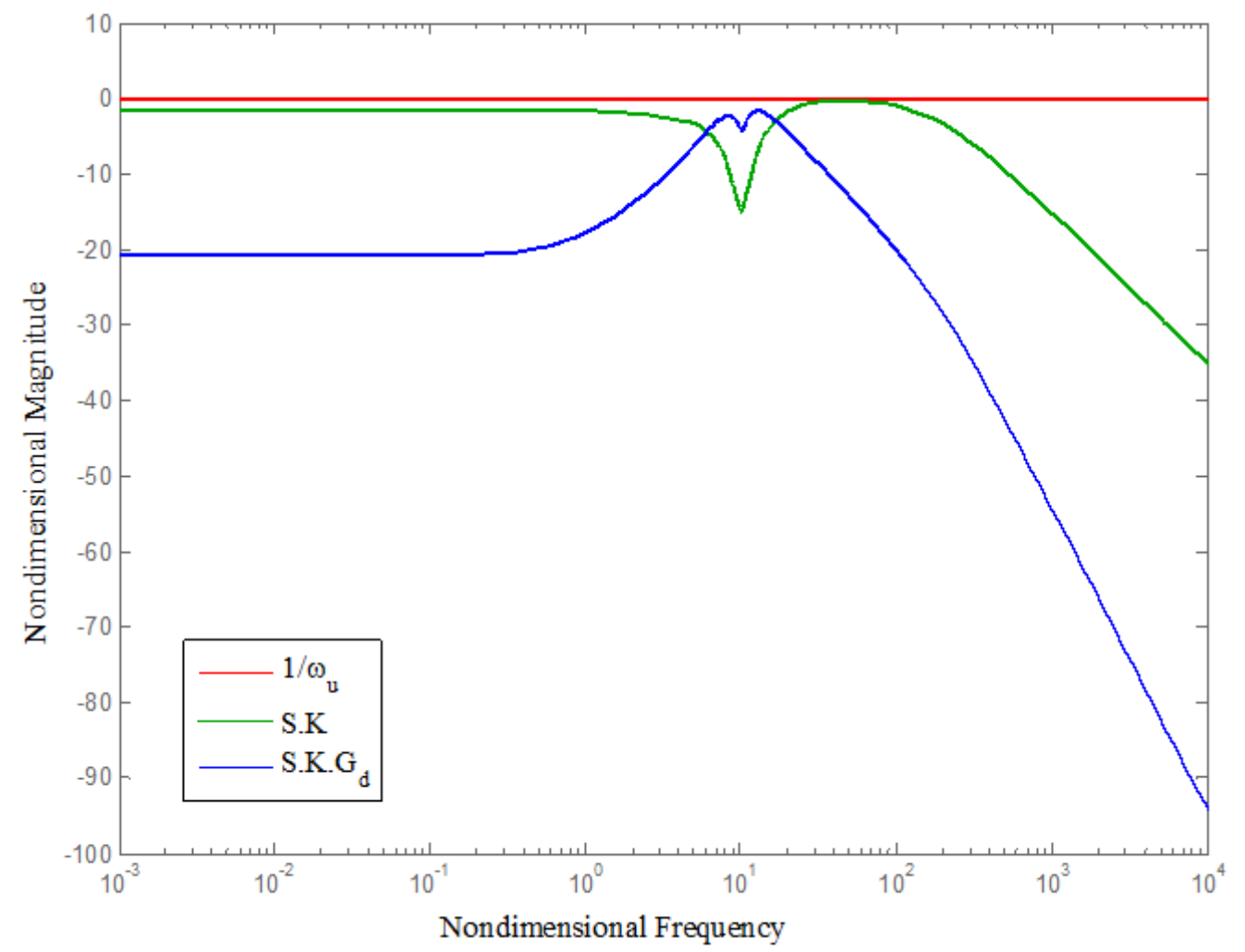

Figure 5.11: The frequency response of the inverse control effort weight, S.K, and S.K.G $G_{d}$ 


\subsubsection{Two Degrees of Freedom Controller Design}

Typically, the desired controller takes the form $\frac{1}{s} G^{-1}$ for reference tracking and $\frac{1}{s} G^{-1} G_{d}$ for disturbance rejection. Since these specifications cannot be achieved simultaneously with traditional controllers, a two degrees of freedom (TDOF) controller is used. The two degrees of freedom controller has two inputs; one for the reference input and the other for the measured output -- and these two inputs are treated independently. One way to set up the two degrees of freedom controller, which is used in this work, is to split it into two blocks as shown in Fig. 5.12.

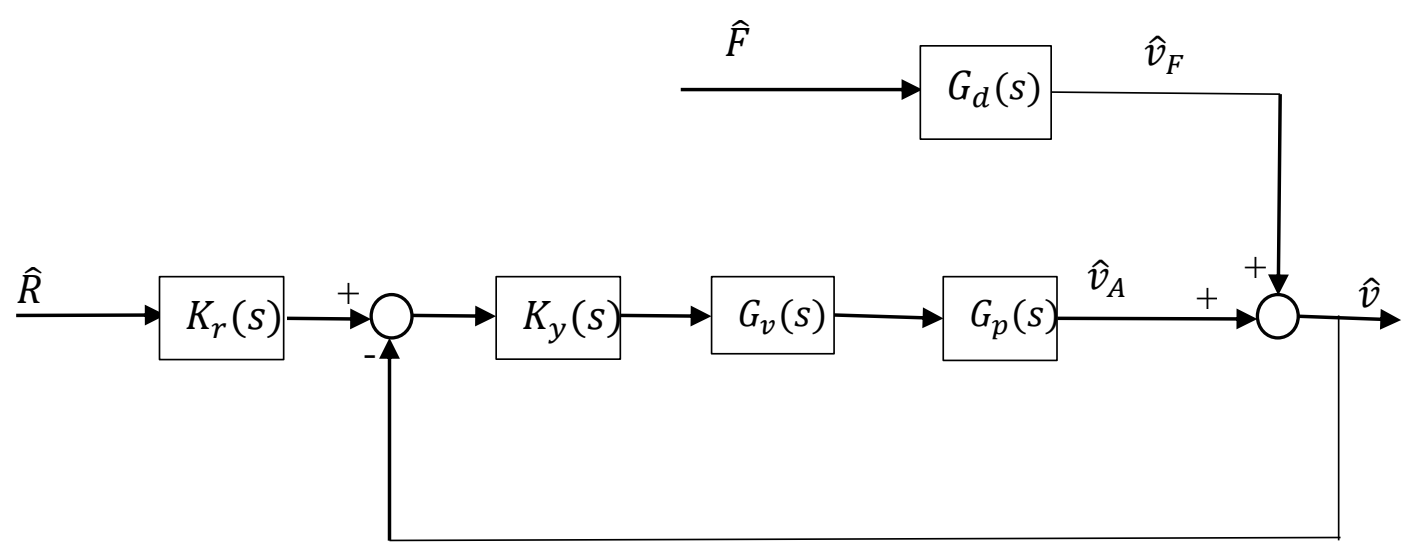

Figure 5.12: Two degrees of freedom controller

The first block, $K_{y}$, represents the feedback part of the controller while the other block, $K_{r}$, works as a pre-filter for the reference signal. The feedback part of the controller takes the form shown in Eq. (5.38) [79].

$K_{y}=\left(\frac{G_{d}}{G}\right)\left(\frac{s+\widehat{\omega}_{I}}{s}\right)\left(\frac{\tau_{\text {lead }} s+1}{\tau_{\text {lag }} s+1}\right)$

Since the denominator degree of $G$ is higher than the denominator degree of $G_{d}$, the degree of the numerator of the first term in Eq. (5.38) will be higher than the degree of the denominator which results in an improper controller transfer function. To avoid that, only the DC gain of the $\frac{G_{d}}{G}$ term was considered. The values of $\omega_{I}, \tau_{\text {lead }}$, and $\tau_{\text {lag }}$ (all found by trial and error) are listed in Table 
5.4. Using those values, the feedback part of the two degrees of freedom controller, $K_{y}$, was determined to be first order and it can be written as shown in Eq. (5.39).

$K_{y}=0.914\left(\frac{s+1}{s}\right)\left(\frac{0.1 s+1}{s+1}\right)=0.0914 \frac{s+10}{s}$

The pre-filter part of the controller, $K_{r}$, is found as shown in Eq. (5.40) [79].

$K_{r}=T_{r e f} T^{-1}$

where $T_{\text {ref }}$ is the desired closed-loop transfer function. Since $T$ has a RH plane zero at $s=8.33$ that arises from the time delay transfer function, $K_{r}$ will need to be multiplied by the term $(s-8.33)$ in order to provide a pole-zero cancellation. In addition, to keep the DC gain unchanged, $K_{r}$ is divided by -8.33 . The desired closed-loop transfer function, $T_{\text {ref }}$, was chosen to have only real poles so that there is no over shoot. The number of poles that $T_{\text {ref }}$ has is equal to the difference between the degrees of the numerator and the denominator of $\mathrm{T}$ in order to get a proper controller. The desired transfer function, $T_{r e f}$ is shown in Eq. (5.40).

$T_{\text {ref }}=\frac{1}{(0.1 s-1)^{5}}$

Then, the pre-filter, $K_{r}$, can be written as shown in Eq. (5.41).

$K_{r}=\frac{38.29 s^{6}+768 s^{5}+9785 s^{4}+8.71 \times 10^{4} s^{3}+4.05 \times 10^{5} s^{2}+9 \times 10^{5} s+1 \times 10^{6}}{s^{6}+60 s^{5}+1500 s^{4}+2 \times 10^{4} s^{3}+1.5 \times 10^{5} s^{2}+6 \times 10^{5} s+1 \times 10^{6}}$ 
Table 5.1: Simulation parameters

\begin{tabular}{|c|c|c|c|}
\hline Parameters & Dimensional Value & Units & Non-dimensional Value \\
\hline$A_{A}$ & $3.5 E-4$ & $m^{2}$ & 1 \\
\hline$A_{v}$ & $6.5 E-6$ & $m^{2}$ & 0.8 \\
\hline$b$ & 1750 & $N-s / m$ & 0.2 \\
\hline$F$ & 6562.5 & $N$ & 0.75 \\
\hline$k_{1}$ & $0.14 E-11$ & $m^{4} \mathrm{~s} / \mathrm{kg}$ & \\
\hline$k_{s}$ & & & 0.72 \\
\hline$k_{v}$ & $3.75 E-6$ & $m^{2} /$ Volt & \\
\hline$k$ & 0 & $N / m$ & 0 \\
\hline$m$ & 50 & $\mathrm{~kg}$ & 0.09 \\
\hline$P_{d r}$ & $25 E+6$ & $P a$ & 1 \\
\hline$P_{\text {ir }}$ & $2 E+6$ & $P a$ & 1 \\
\hline$t_{d}$ & 0.015 & $s$ & 0.24 \\
\hline$V_{r}$ & 3.7 & Volt & 1 \\
\hline$R$ & 0.8 & $m / s$ & 0.8 \\
\hline$v_{r}$ & 1 & $\mathrm{~m} / \mathrm{s}$ & 1 \\
\hline$\beta$ & $2 E 9$ & $P a$ & \\
\hline$\tau$ & 0.0625 & $s$ & \\
\hline$\xi_{1}$ & & & 10 \\
\hline$\xi_{2}$ & & & 10 \\
\hline$\xi_{1}$ & & & 0.8 \\
\hline
\end{tabular}




\begin{tabular}{|l|l|l|c|}
\hline$\omega_{n}$ & 85 for slow valve & $\mathrm{Rad} / \mathrm{s}$ & 5.31 \\
\cline { 2 - 4 } & 8500 for fast valve & $\mathrm{Rad} / \mathrm{s}$ & 531 \\
\hline
\end{tabular}

Table 5.2: Non-dimensional valve characteristics

\begin{tabular}{|c|c|}
\hline The parameter & The value \\
\hline Valve static gain, $k_{s}$ & 0.72 \\
\hline Valve time delay, $\hat{t}_{d}$ & 0.24 \\
\hline Valve natural frequency, $\widehat{\omega}_{n}$ & 5.31 \\
\hline Valve damping ratio, $\xi$ & 0.8 \\
\hline
\end{tabular}

Table 5.3: Performance weight parameters

\begin{tabular}{|c|c|}
\hline The parameter & The value \\
\hline Low-frequency error, $a$ & 0.01 \\
\hline High-frequency error, $M$ & 4 \\
\hline Bandwidth frequency, $\widehat{\omega}_{b}$ & 1 \\
\hline
\end{tabular}

Table 5.4: The parameters of the feedback part of the TDOF controller (Eq. (5.38))

\begin{tabular}{|c|c|}
\hline The parameter & The value \\
\hline$\widehat{\omega}_{I}$ & 1 \\
\hline$\tau_{\text {lead }}$ & 0.1 \\
\hline$\tau_{\text {lag }}$ & 1 \\
\hline
\end{tabular}




\section{CHAPTER 6}

\section{RESULTS AND DISCUSSION}

\subsection{Background Information}

The inlet metering system was studied. Flow, torque, and efficiency were modeled. The models were verified using experimental data collected in the laboratory from an experimental setup. The effect of valve metering area, pump shaft speed, and pressure on the inlet metering pump flow, torque, and efficiency was studied. A velocity control system that uses inlet-metering system was designed. The stability and performance of the system were studied for the open-loop and closed-loop systems with and without the valve dynamics. This chapter presents all the experimental and theoretical results of this work.

6.2 Determination of the Coefficients in Eqs. (3.29) and (3.31).

In order to determine the experimentally derived leakage coefficients, the measurements corresponding to the $2.5 \mathrm{MPa}$ inlet pressure, $1000 \mathrm{rpm}$ and $1500 \mathrm{rpm}$ shaft speed were used. It was found that models formed from these measurements were representative of all test conditions - and therefore the data taken at 1000 and $1500 \mathrm{rpm}$ were used to find model parameters and verify the model (other conditions were used for validation). For these measurements, the torque, discharge flow rate, and outlet pressure were averaged for each 10 seconds interval with fixed outlet pressure and valve position. Equations (3.29) and (3.31) were manipulated to form matrix equations for flow and torque given $n$ sets of data (flow, torque, pressures, valve area, and speed) with unknown parameter vectors separated out. The relevant data averages were taken from the experimental measurements and were then applied to flow and torque modeling equations, (6.1) and (6.2). 


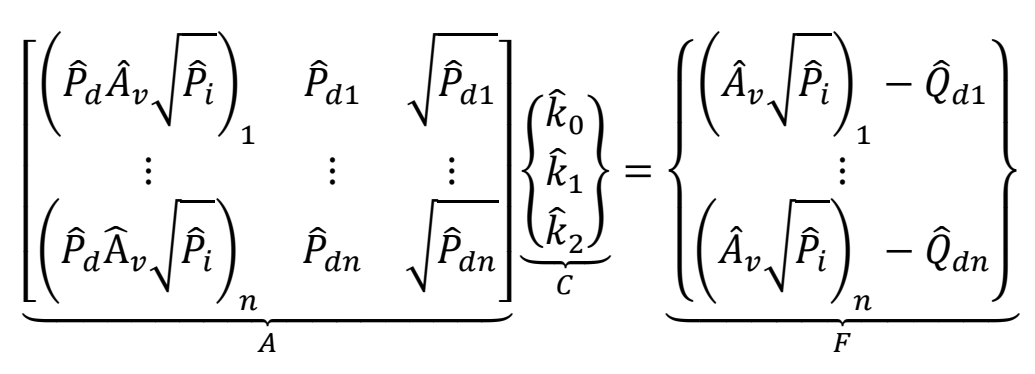

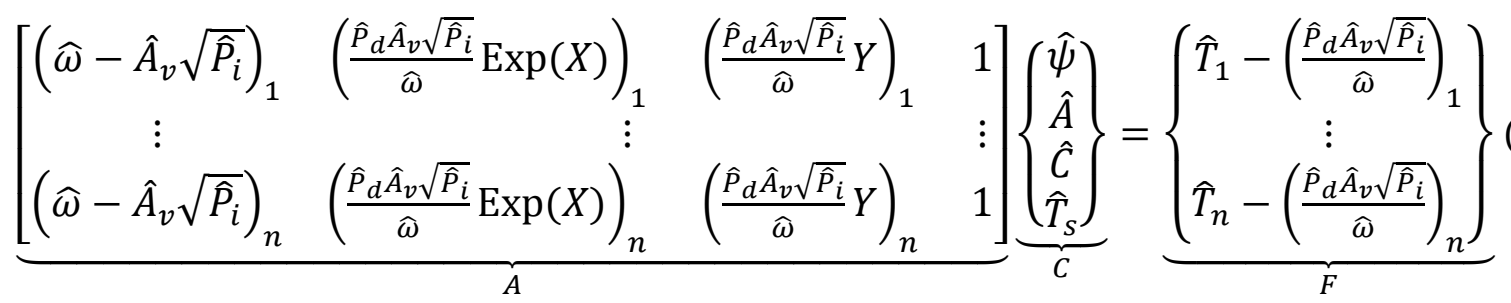

Each row in matrix $A$ and column vector $F$ represents an experiment that has been conducted in the laboratory, where there was a total of $n$ experiments. The quantities in $A$ and $F$ are known from experimental measurements. The only unknowns in (6.1) and (6.2) are the coefficients found in the column vector $C$. The theory of the least squares curve fitting method was then applied using Eq. (6.1) and (6.2) to find the discharge flow coefficients vector, $C$, as given by Eq. (6.3),

$$
C=\left(A^{T} A\right)^{-1} A^{T} F
$$

By applying Eq. (6.3) to the matrices and vectors labeled $A, C$, and F in Eq. (6.1) and (6.2), the unknown coefficients can be found and are provided in Table 1. 
Table 6.1. Inlet metering pump coefficients

\begin{tabular}{|c|c|c|}
\hline Physical Meaning & Symbol & Value \\
\hline Fluid compression & $\hat{k}_{0}$ & 0.0375 \\
\hline Low Reynolds Number leakage & $\hat{k}_{1}$ & 0.0119 \\
\hline High Reynolds Number leakage & $\hat{k}_{2}$ & 0.0029 \\
\hline Static friction & $\hat{A}$ & Effectively 0 \\
\hline Decay rate for boundary lubrication & $\hat{B}$ & N/A \\
\hline Hydrodynamic lubrication & $\hat{C}$ & 0.5631 \\
\hline Starting torque & $\hat{T}_{S}$ & 0.1257 \\
\hline Thermodynamic fluid properties & $\hat{\psi}$ & 0.0943 \\
\hline
\end{tabular}

These fit coefficients produced a coefficient of determination, $R^{2}$, value of 0.99 for the determination of flow rate as a function of pressures and valve area, and 0.97 for the prediction of torque as a function of pressures, speed, and valve area.

\subsection{Instantaneous Results and Discussion}

Results given in Figs. (5-9) compare the predicted and the actual instantaneous discharge flow, torque, and efficiency. It can be seen that the projections of the flow rate, torque, and efficiency based on the coefficients in Table 1 are very close to those of the actual system computed using data taken at all pump speeds (and all pressures and valve areas). Note that the 
coefficients given in Table 1 were generated using data with pump shaft speeds of $1000 \mathrm{rpm}$ and $1500 \mathrm{rpm}$ only. This indicates that the model generated using data for just two speeds is applicable to all other speeds and other conditions considered.

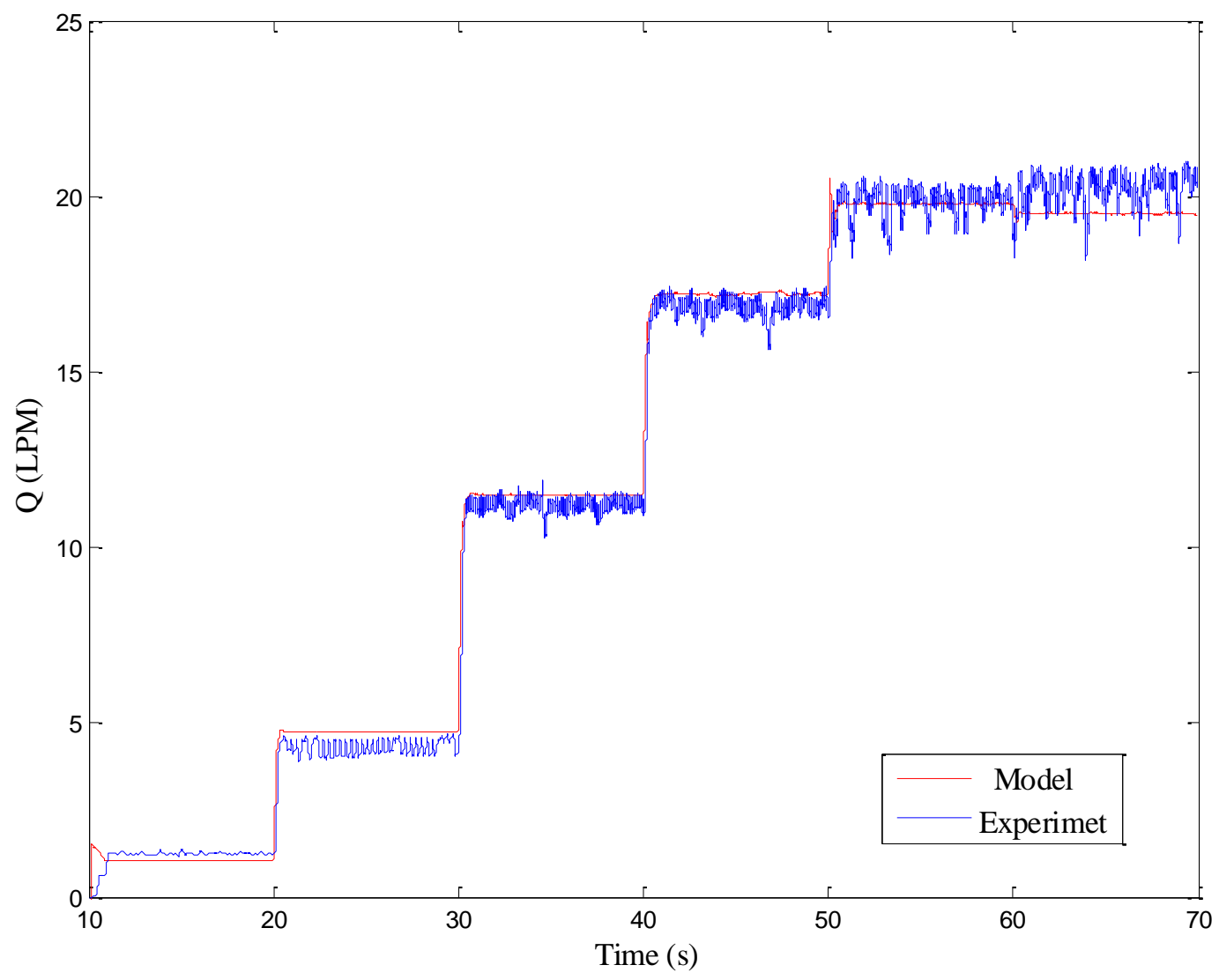

Figure 6.1: Comparison of IMP flow rate projections with actual data for 2500RPM, 2 MPa inlet pressure, $25 \mathrm{MPa}$ discharge Pressure and a step input signal 


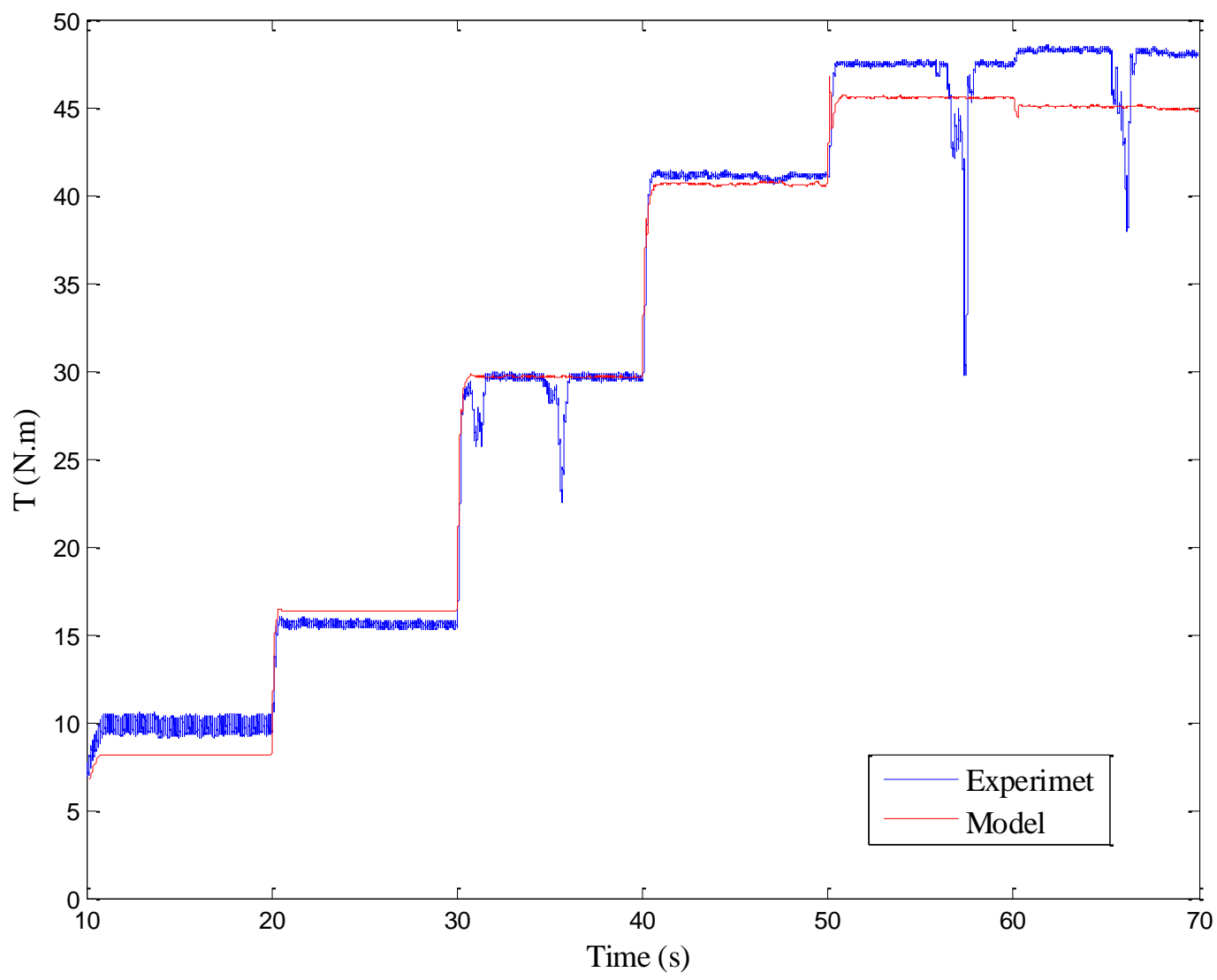

Figure 6.2: Comparison of IMP torque projections with actual data for 2500RPM, 2 MPa inlet pressure, $25 \mathrm{MPa}$ discharge Pressure and a step input signal 


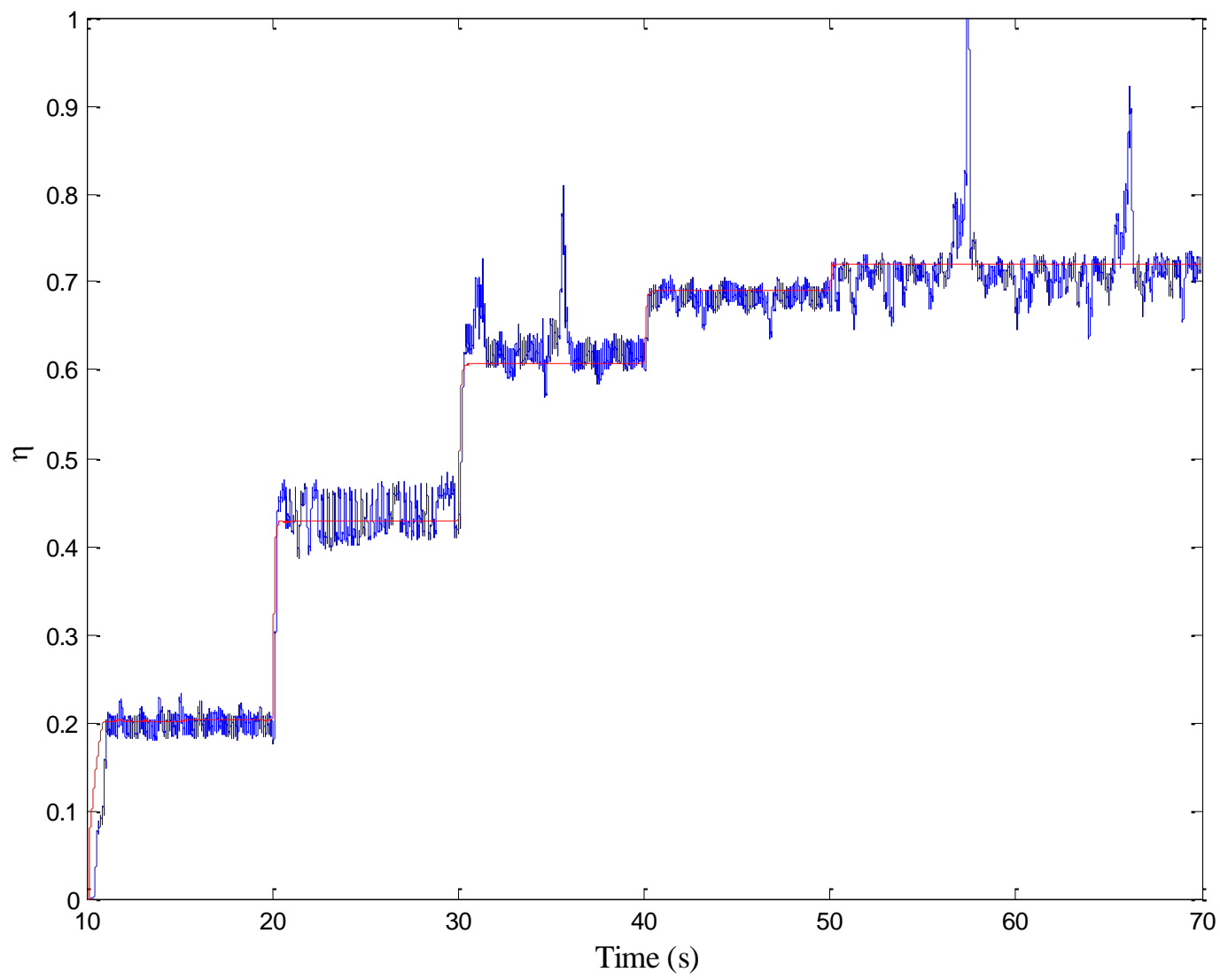

Figure 6.3: Comparison of IMP efficiency projections with actual data for 2500RPM, 2 MPa inlet pressure, $25 \mathrm{MPa}$ discharge Pressure and a step input signal 


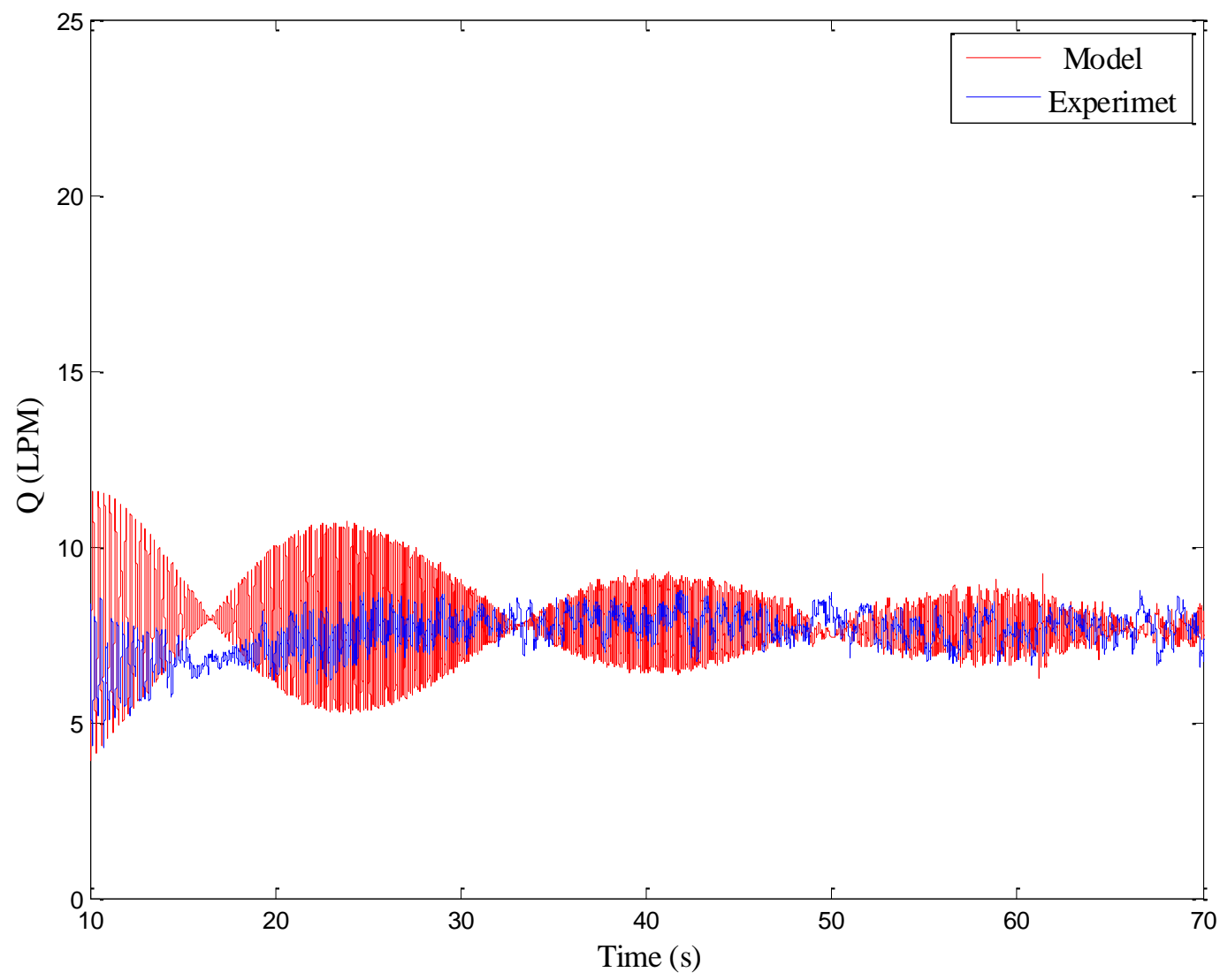

Figure 6.4: Comparison of IMP flow rate projections with actual data for chirp input signal 


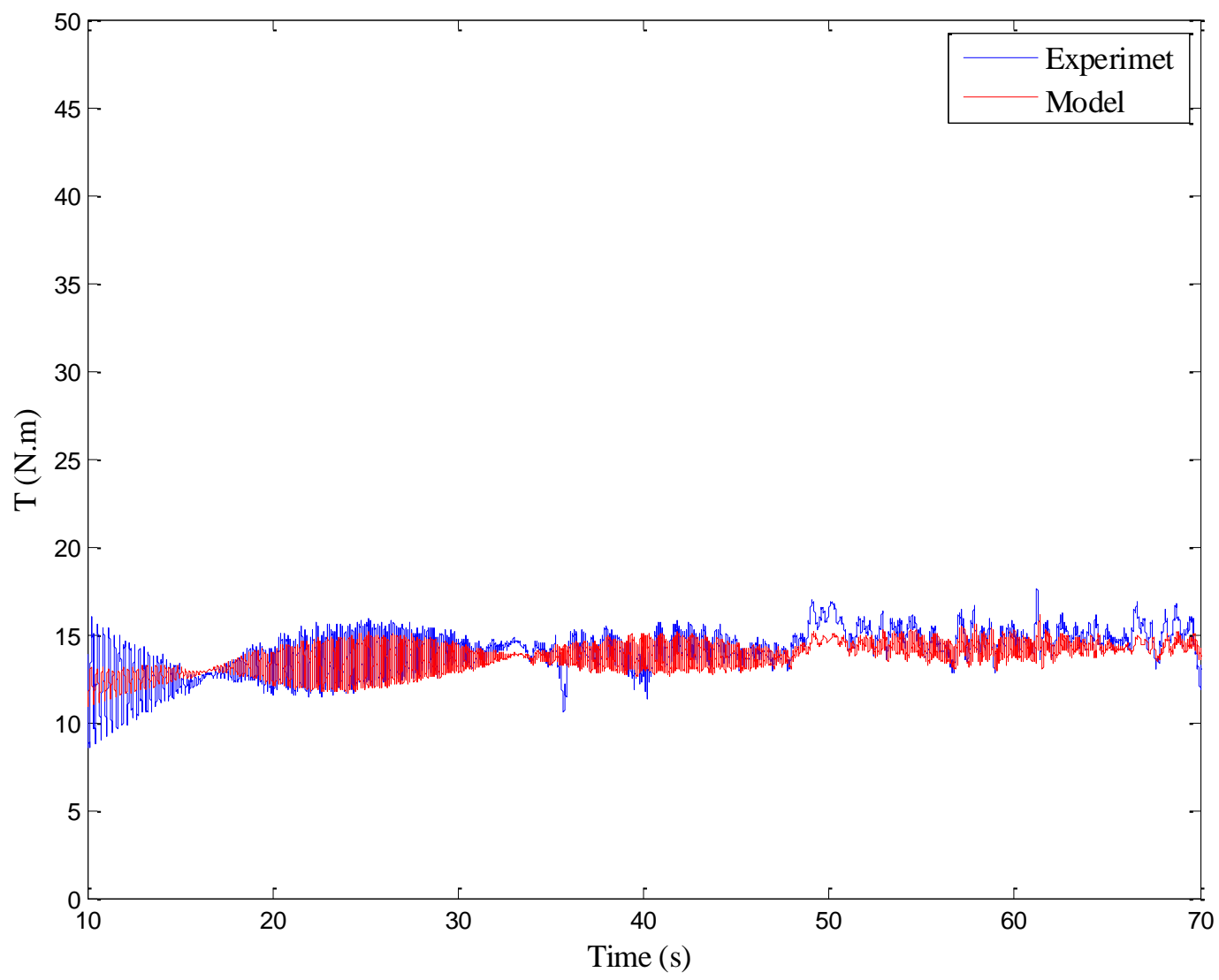

Figure 6.5: Comparison of IMP torque projections with actual data for chirp input signal 


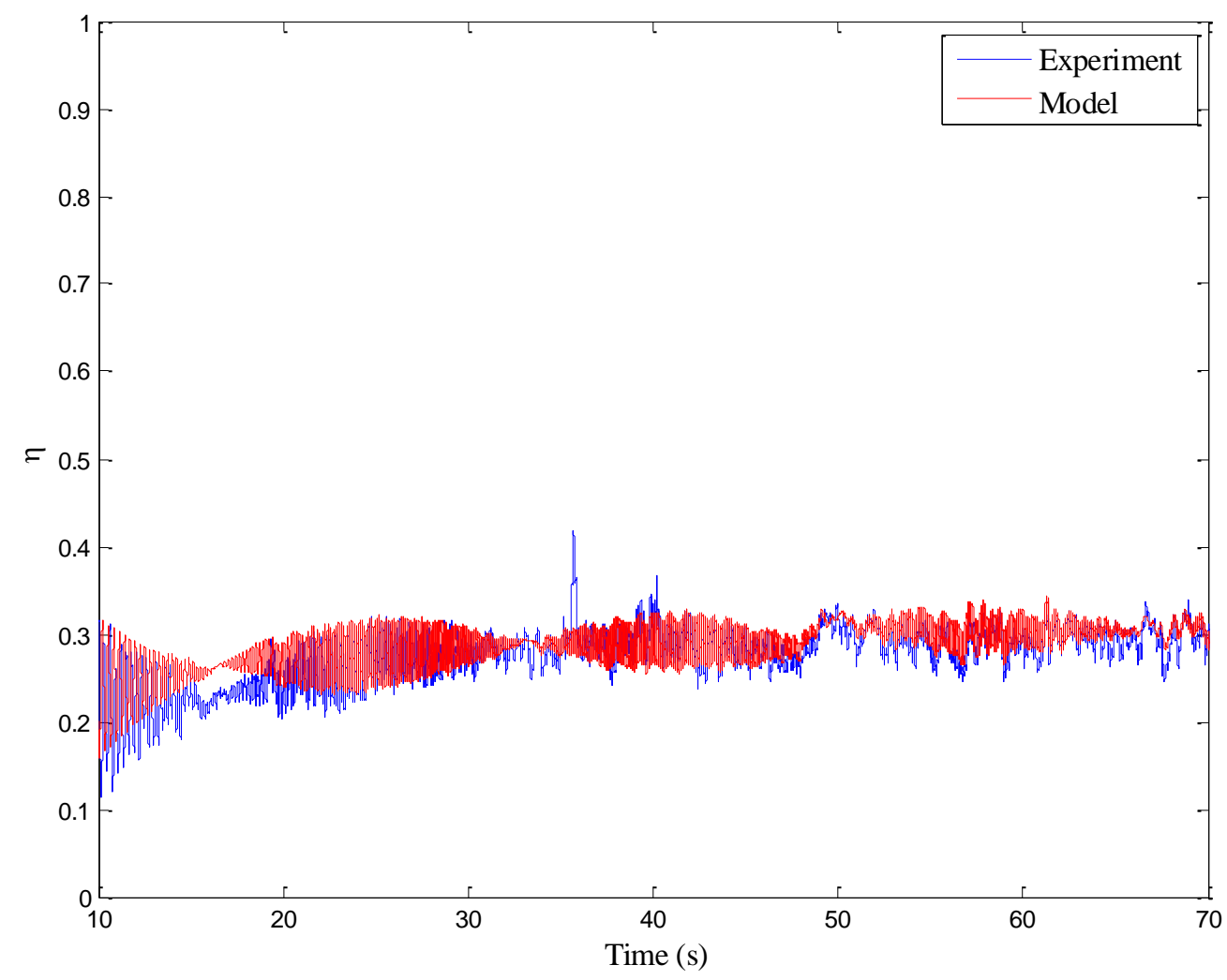

Figure 6.6: Comparison of efficiency projections with actual data for chirp input signal

\subsection{Averaged Results and Discussion}

In this section, the average results of the flow, torque, and efficiency are presented. The flow and torque results presented in this section compare the theoretical results with the experimental results as a validation of the model.

\subsubsection{Flow Rate Results and Discussion}

Figure 6.7 contains flow data and modeled flow over a range of valve openings and for all pump speeds with the inlet pressure at $2 \mathrm{MPa}$ and discharge pressure at $25 \mathrm{MPa}$. It can be noticed from Fig. 6.7 that the pump volumetric flow rate is not a function of the pump speed when the pump operates in the inlet metering mode. When the flow is less than the maximum possible flow for a given speed, the ideal flow is only a function of the valve opening area. Once the discharge 
flow reaches the amount restricted by the pump speed, then the discharge flow will not increase by increasing the valve opening and it becomes a function of the pump rotational speed only. Figure 6.8 shows the variation of the inlet metered pump flow rate as the pump speed changes. Again, it can be seen that the flow is a function of the pump speed only when the pump is running at maximum flow rate. This is represented by the inclined line in Fig. 6.8. The discharge pressure was shown to have no significant impact on the discharge flow as shown in Fig. 6. This is expected because the ideal discharge flow is not a function of the discharge pressure. Note that flow losses, however, are functions of pressure. It can be noticed from Fig. 6.9 that the discharge flow increases as the inlet pressure supplied by the charge pump increases. This is because the ideal flow across the inlet-metering valve is proportional to the inlet pressure.

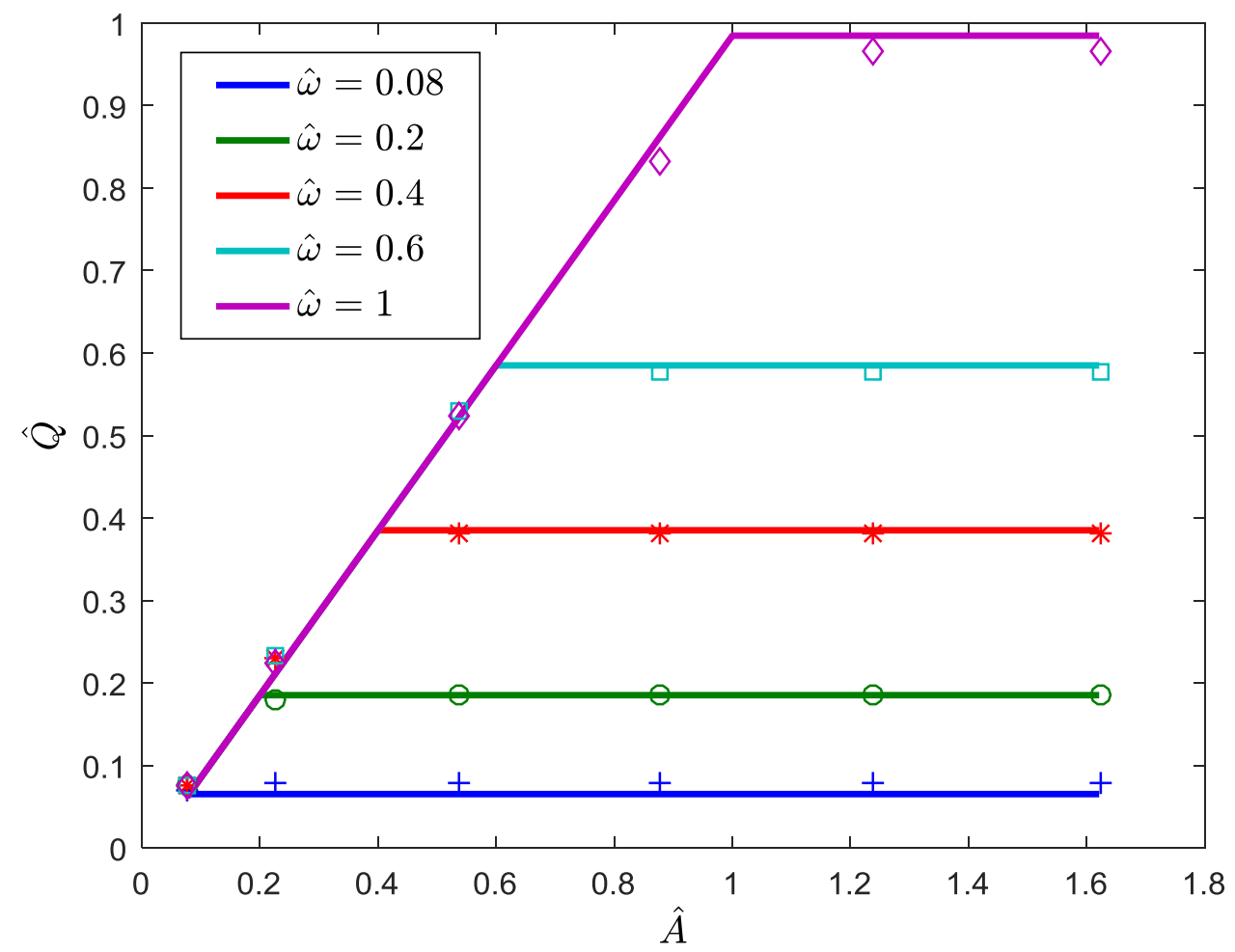

Figure 6.7: Non-dimensional pump discharge flow vs. non-dimensional valve opening for $2 \mathrm{MPa}$ inlet pressure and $25 \mathrm{MPa}$ discharge pressure where the solid lines represent the model and the markers represent the data 


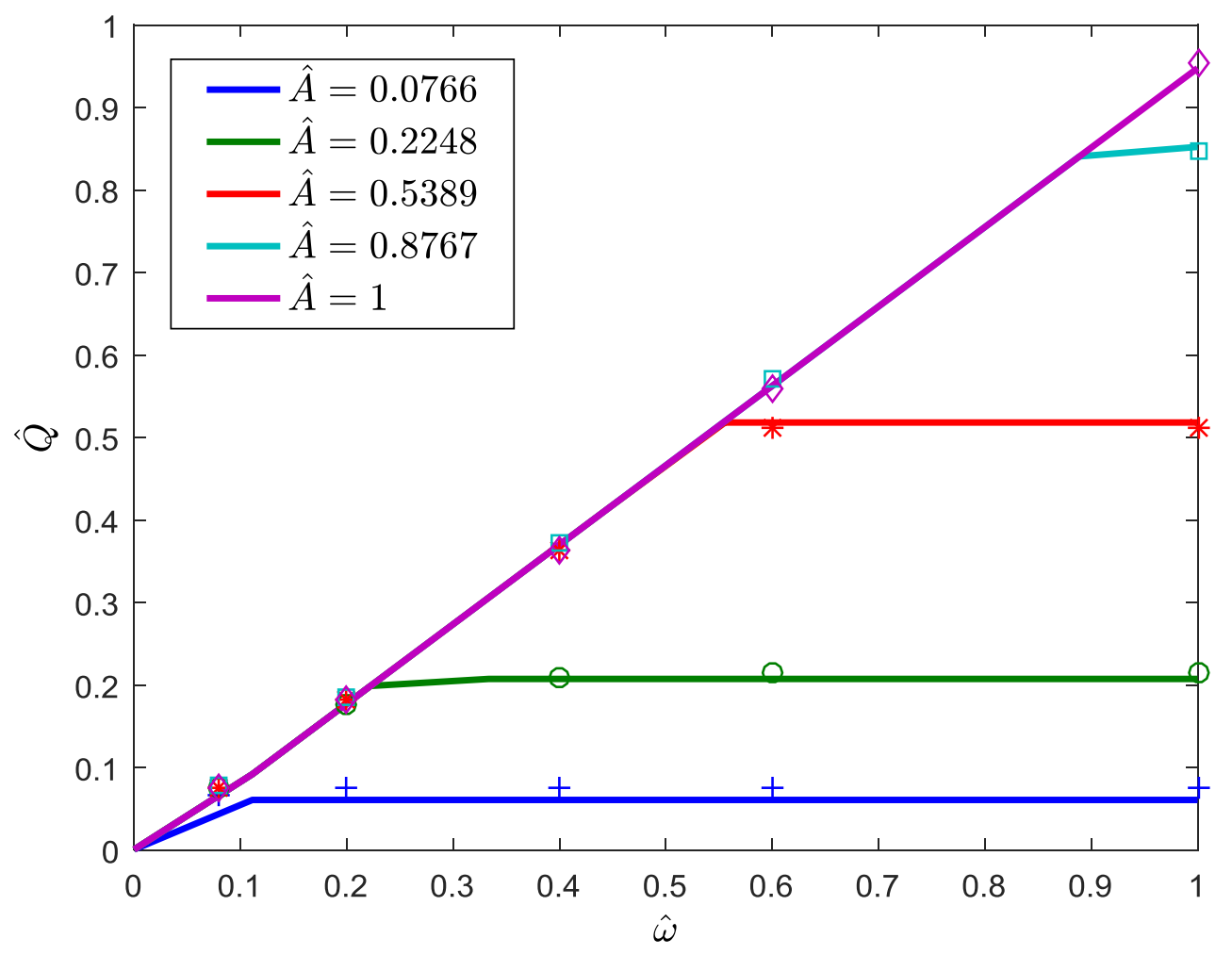

Figure 6.8: Non-dimensional pump discharge flow vs. non-dimensional pump speed for $2 \mathrm{MPa}$ inlet pressure and $25 \mathrm{MPa}$ discharge pressure where the solid lines represent the model and the markers represent the data 


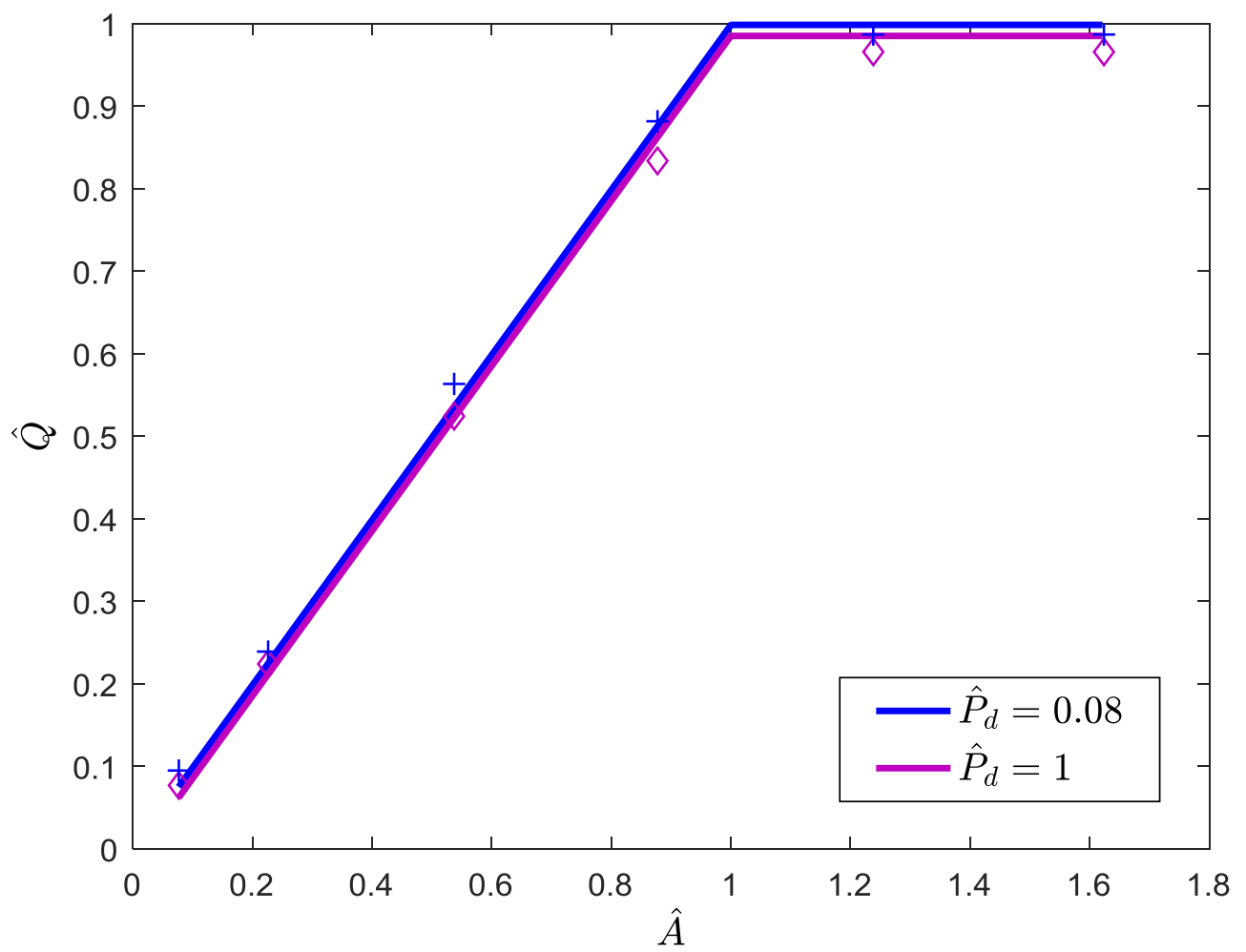

Figure 6.9: Non-dimensional pump discharge flow vs. non-dimensional valve opening for $2 \mathrm{MPa}$ inlet pressure and 2500 RPM speed where the solid lines represent the model and the markers represent the data 


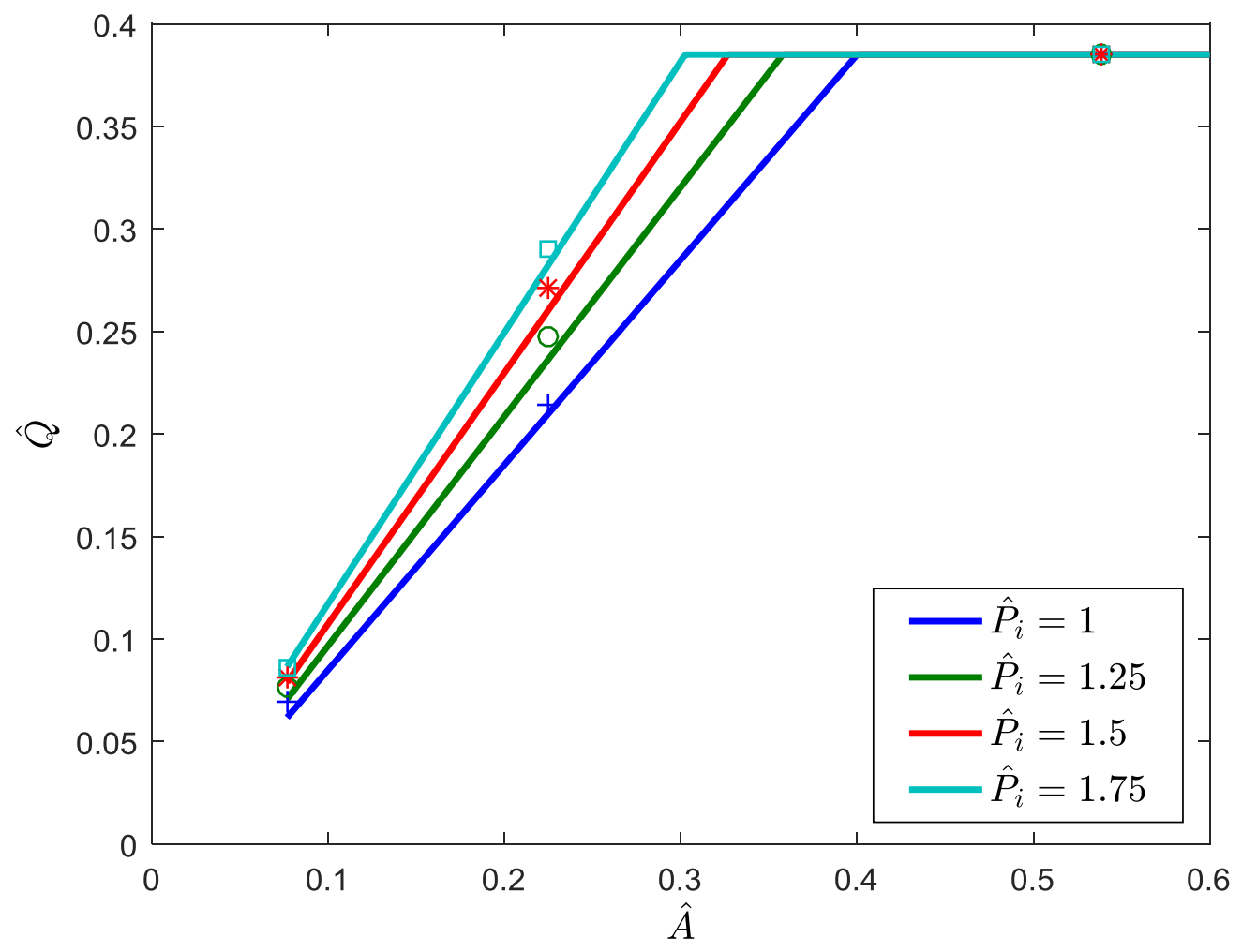

Figure 6.10: Non-dimensional pump discharge flow vs. non-dimensional valve opening for 25 MPa discharge pressure and 1000 RPM speed where the solid lines represent the model and the markers represent the data

\subsubsection{Torque Results and Discussion}

Figure 6.11 shows that for the inlet metering conditions, the torque is a function of both the pump speed and the valve area. Torque increases as the valve opening area increases and decreases as the pump rotational speed increases until flow reaches its maximum value which is proportional to the pump speed and due to the maximum volumetric displacement of the pump. Once the flow is at the maximum possible value, the torque no longer depends on the valve opening area. Under maximum flow condition, Torque increases when the pump speed increases because of an increase in the torque losses after the maximum flow is reached. This is shown in Fig. 6.12. 
The torque from experimental data and model due to Eq. (30) are plotted for various pressures vs. valve area with a pump speed of $2500 \mathrm{rpm}$ in Fig. 6.13. The discharge pressure has the most significant impact on the torque because of its effect on both the ideal and the frictional torque as shown in Fig. 6.13.

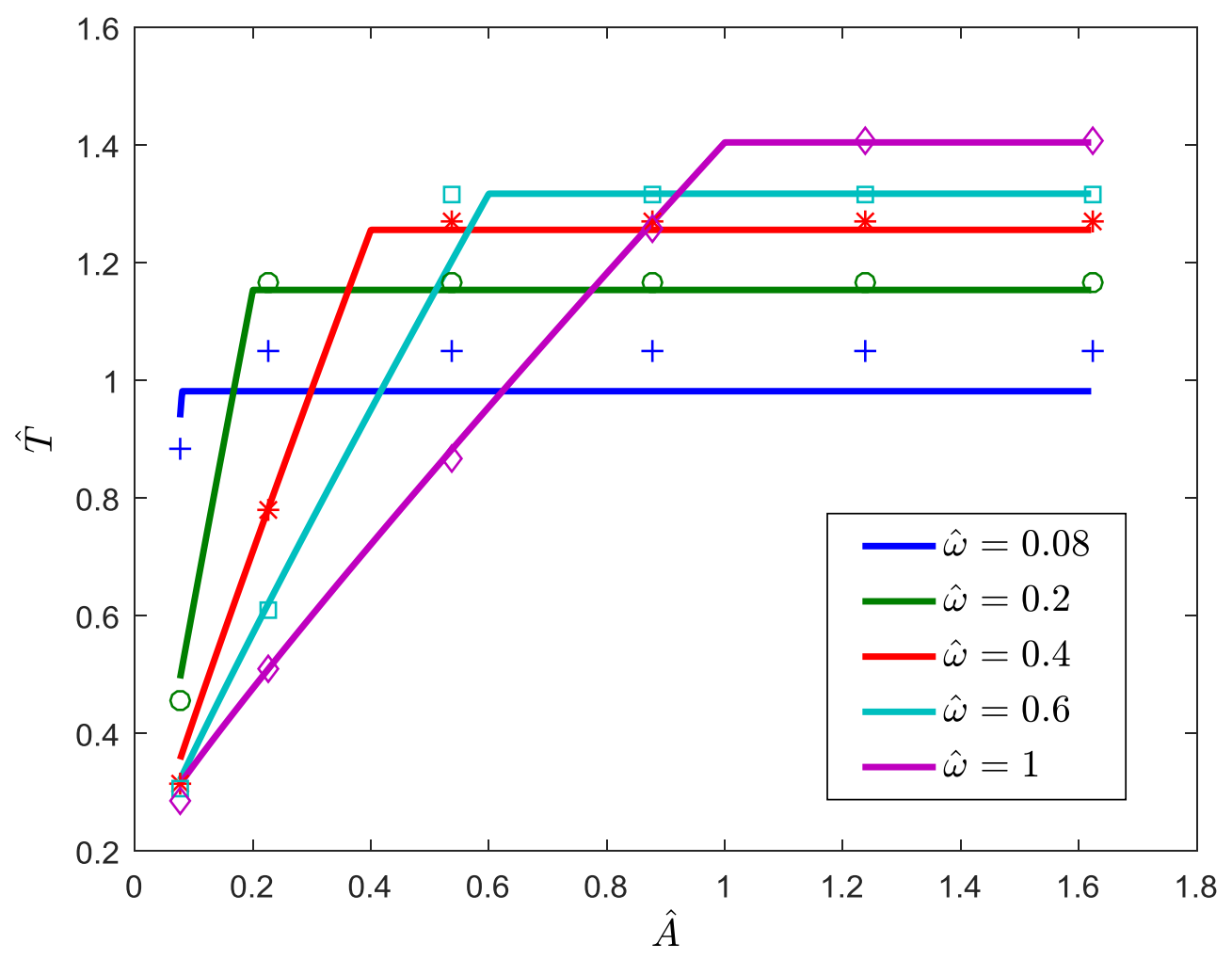

Figure 6.11: Non-dimensional torque vs. non-dimensional valve opening for $25 \mathrm{MPa}$ discharge pressure and $2 \mathrm{MPa}$ inlet pressure where the solid lines represent the model due to Eq. (31) and the markers represent the data 


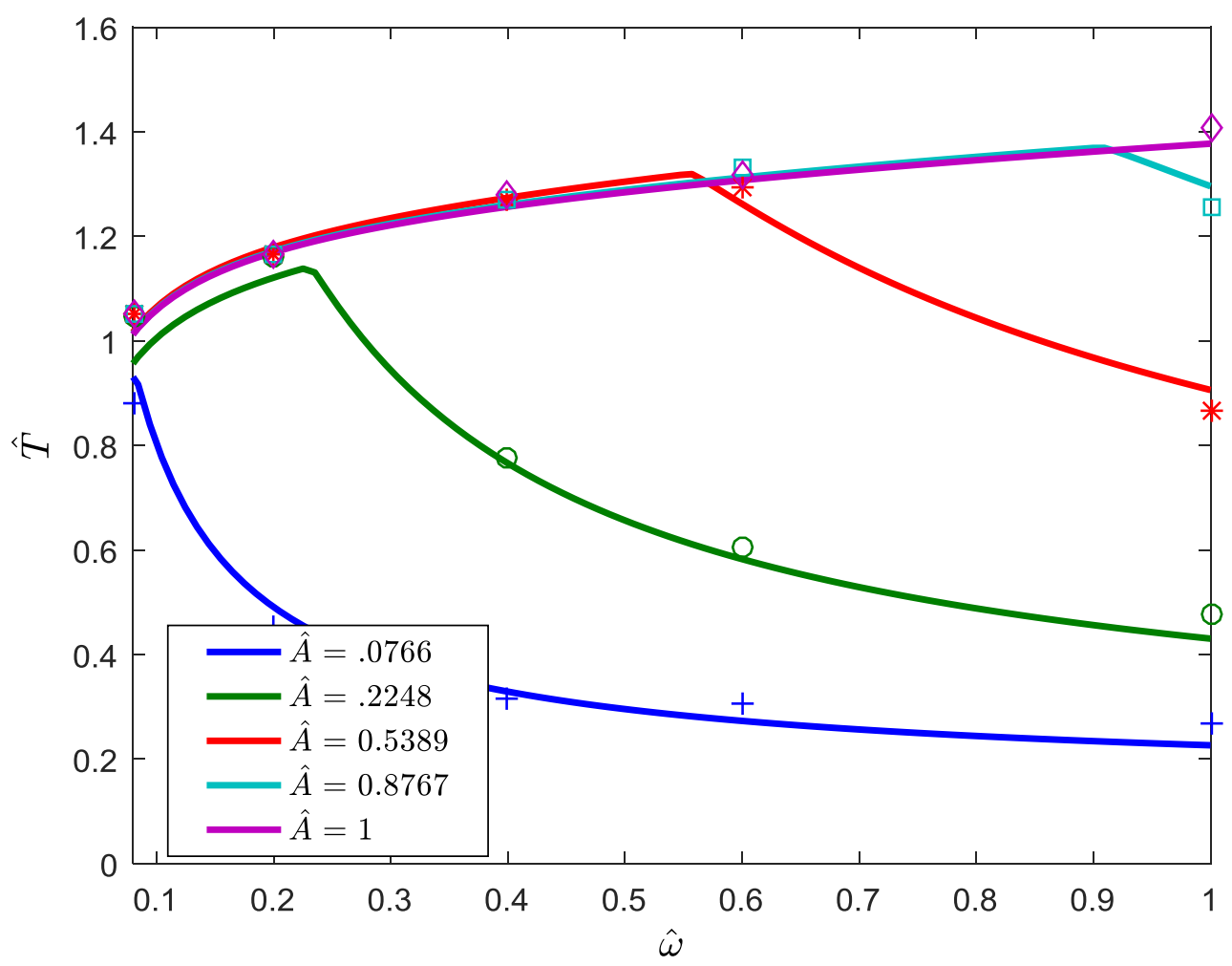

Figure 6.12: Non-dimensional torque vs. non-dimensional valve opening for $25 \mathrm{MPa}$ discharge pressure and $2 \mathrm{MPa}$ inlet pressure solid lines represent the model due to Eq. (31) and the markers represent the data 


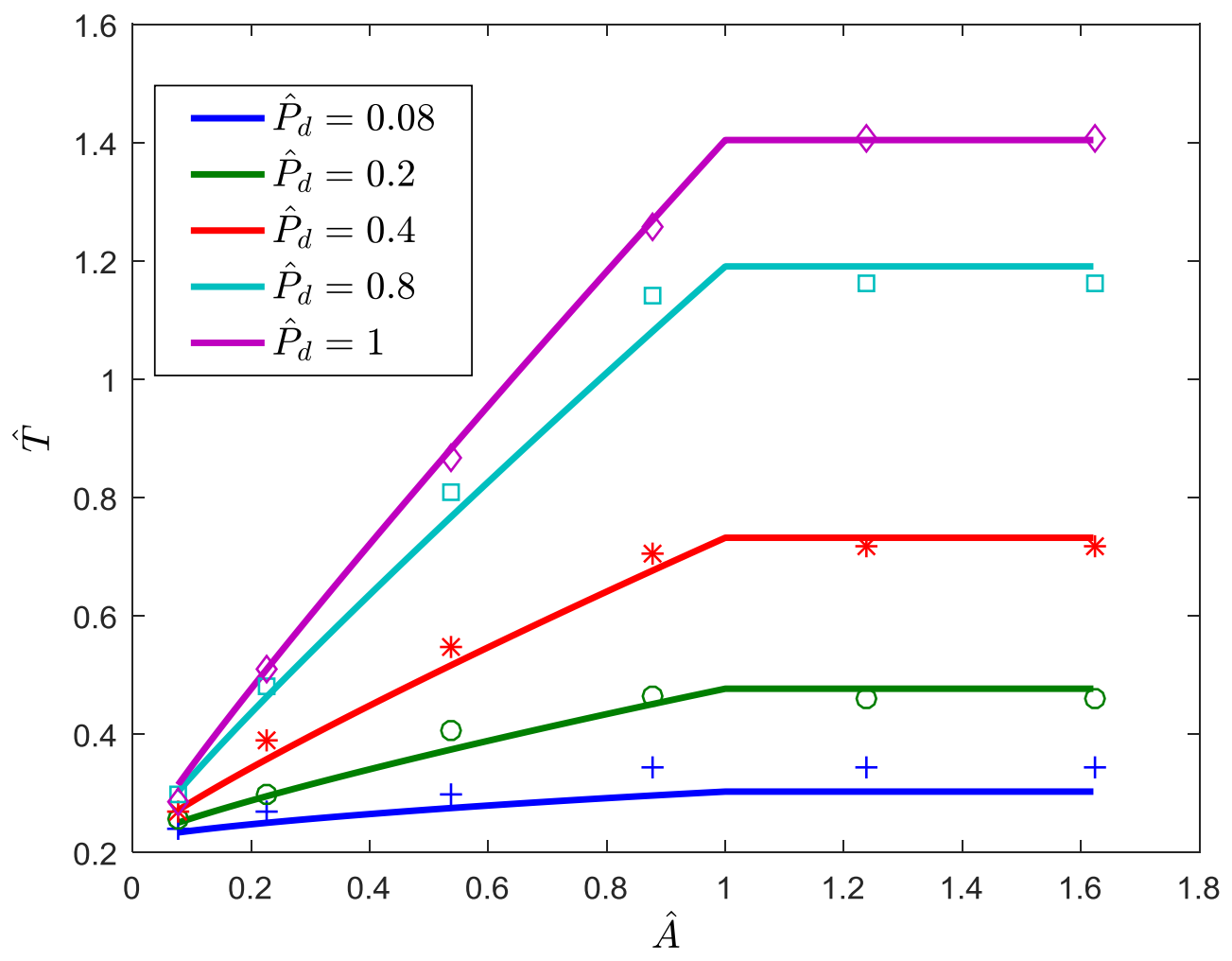

Figure 6.13: Non-dimensional Torque vs. non-dimensional valve opening for 2500 RPM discharge pressure and $2 \mathrm{MPa}$ inlet pressure where the solid lines represent the model and the markers represent the data

\subsubsection{Efficiency Results and Discussion}

Figure 10 shows that the modeled pump efficiency due to Eq. (32) increases as the discharge pressure increases. It can also be seen that the efficiency increases as the valve opening area increases for all operating pressures as illustrated in Fig. 6.14. Figure 6.15 shows that the pump efficiency decreases as pump rotational speed increases. The inlet pressure was shown to have no significant effect on the pump efficiency as shown in Fig. 6.16. It was determined that the coefficients that were derived using the data from the $2.5 \mathrm{MPa}$ inlet pressure data were applicable to all of the collected data. 


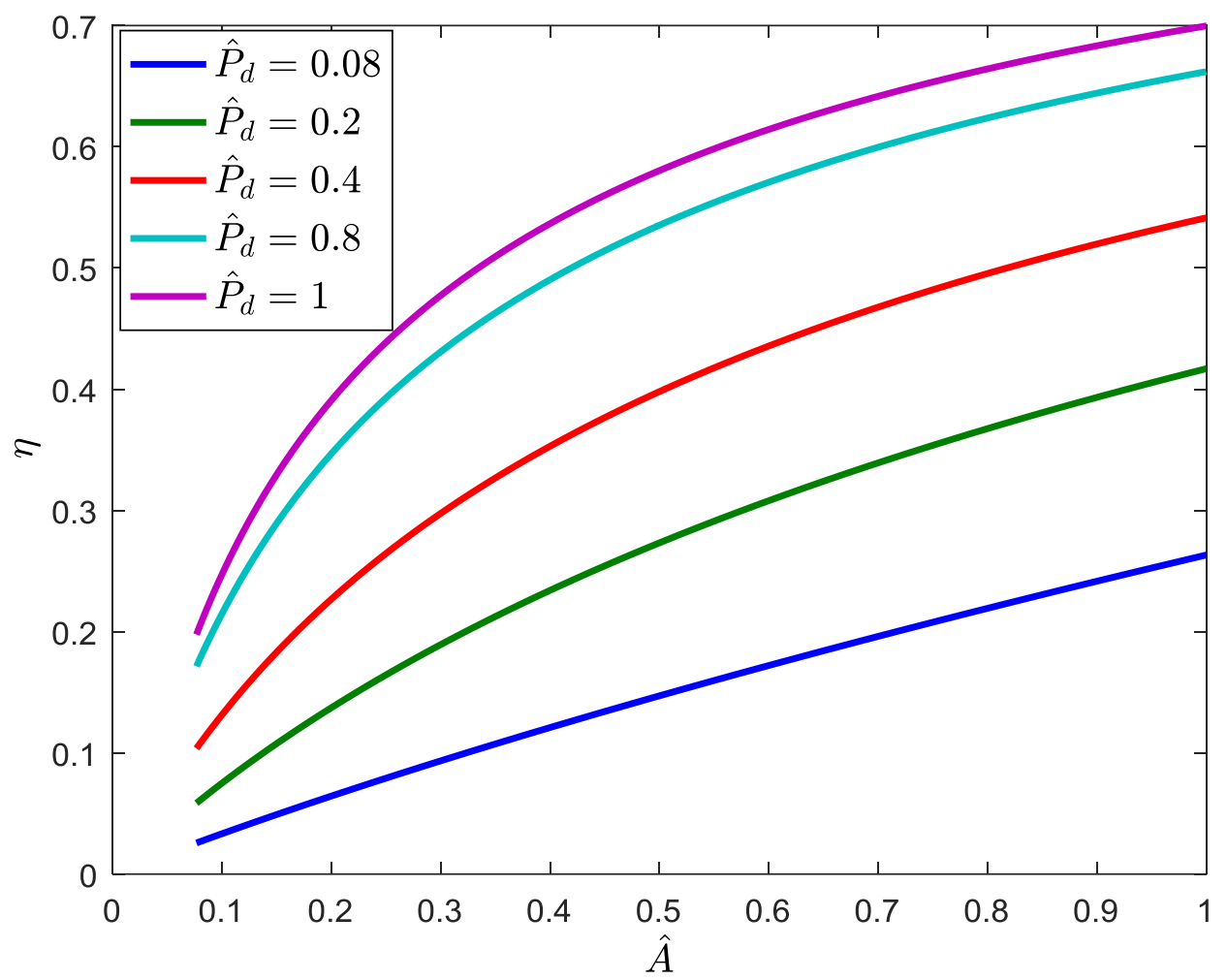

Figure 6.14: Overall pump efficiency vs. valve non-dimensional area for an inlet pressure of 2 MPa, pump shaft speed of 2500 RPM, and listed discharge pressures 


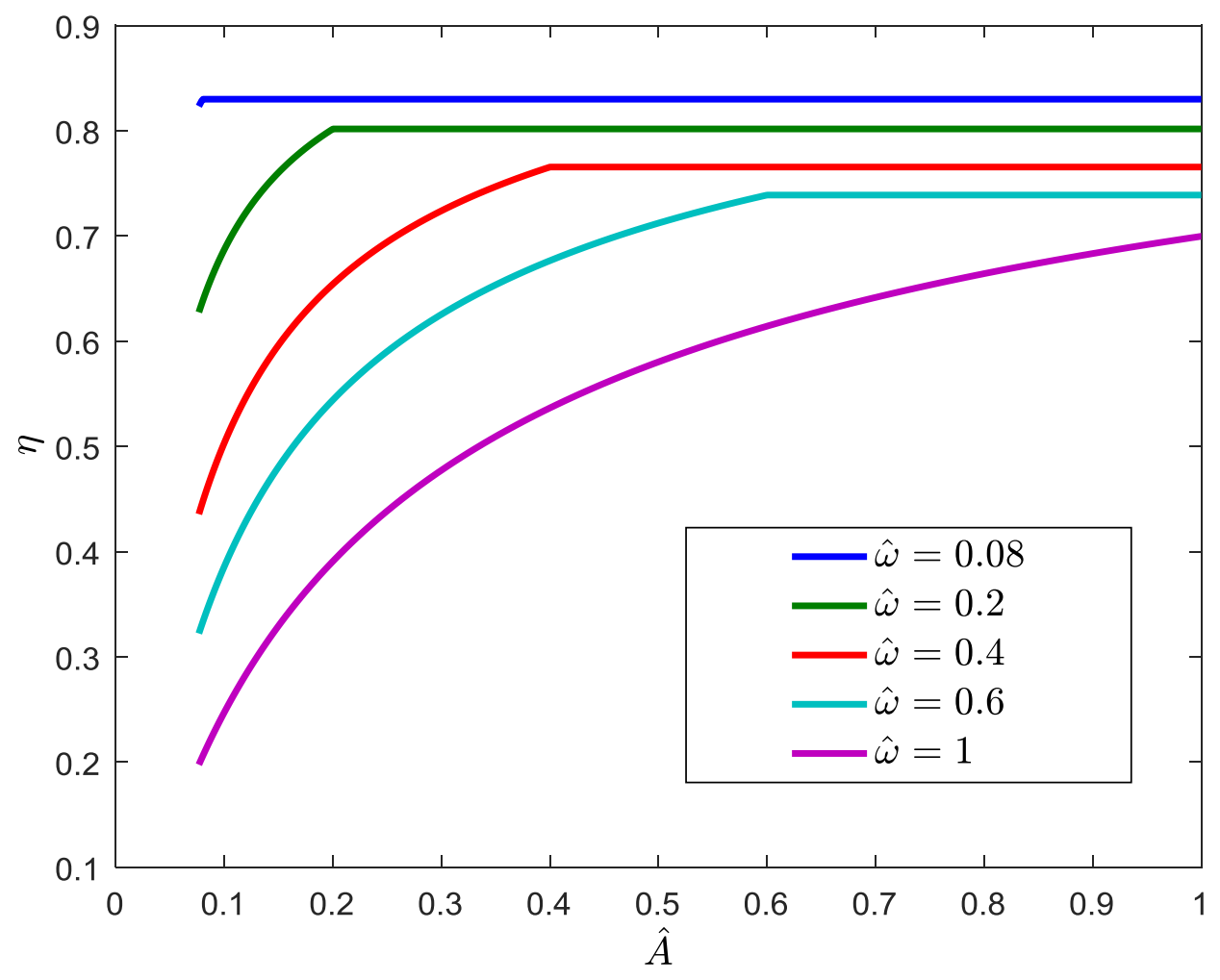

Figure 6.15: Overall pump efficiency vs. valve non-dimensional area for $2 \mathrm{MPa}$ inlet pressure and $25 \mathrm{MPa}$ discharge pressure 


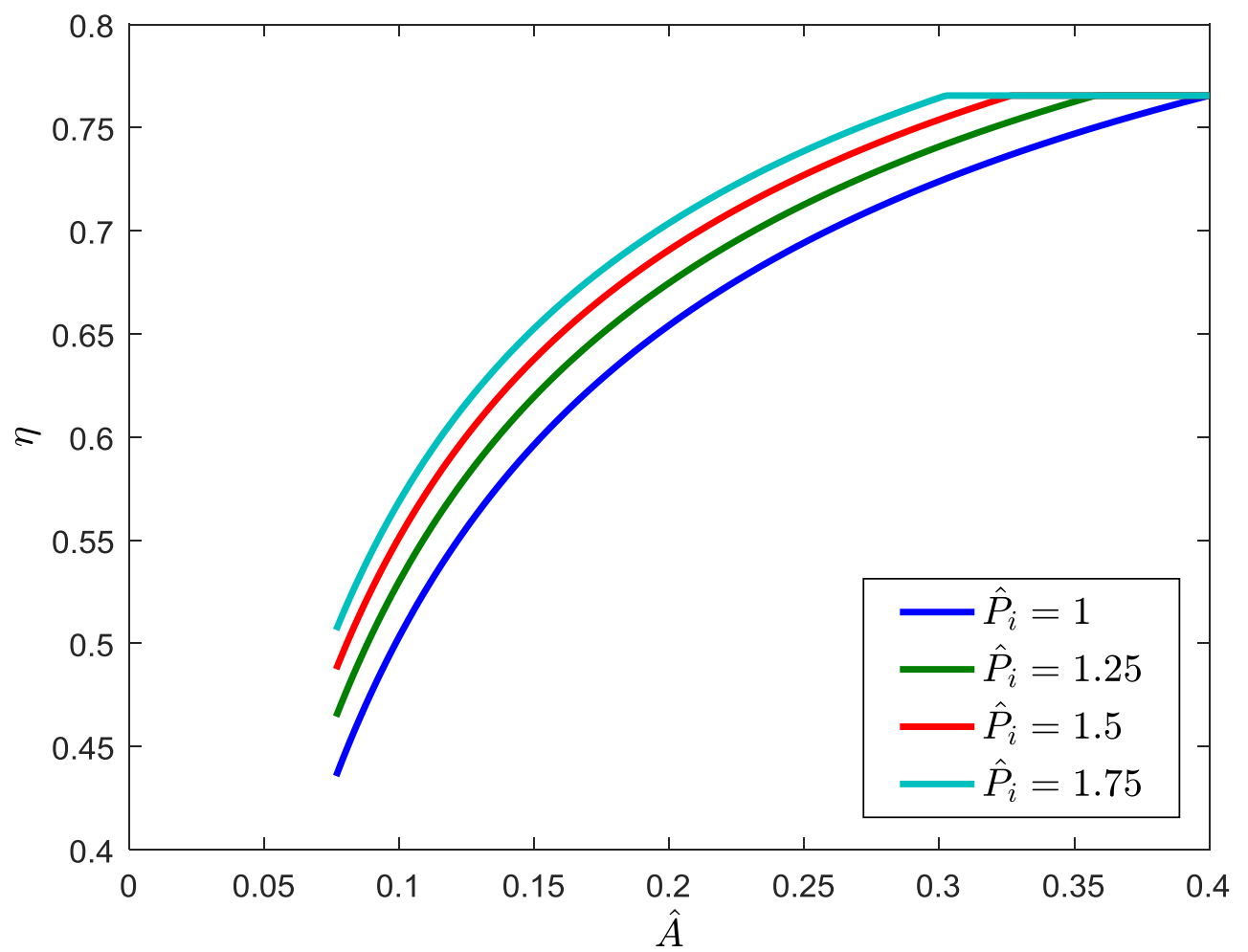

Figure 6.16: Overall pump efficiency vs. non-dimensional valve opening for $25 \mathrm{MPa}$ discharge pressure and 1000 RPM 


\subsection{Velocity Control System Design Results and Discussion}

The results of the velocity controlled system designed in Chapter 5 are presented in this section. In order to explore the dynamic behavior of the system, the system response with and without a controller is examined using MATLAB / SIMULINK ${ }^{\circledR}$ simulations. The results presented in this section are for two cases. In the first case, the valve dynamics is completely ignored and the response of the open-loop and the closed-loop with PD controller were discussed. In the second case, the valve dynamics was included. The controller design and the time response of the system with PID controller and H-infinity controller are discussed.

\subsubsection{No Valve Dynamics Results and Discussion}

Below are some results with controller gains computed as discussed in Chapter 5. For the closed-loop case, a reference non-dimensional velocity of 0.8 is given starting at zero seconds and a nondimensional step disturbance force of 0.75 at five time constants. Figure 6.17 shows the openloop velocity response of the hydraulic cylinder with an input non-dimensional area of 0.8 and a step disturbance force. It can be seen that there is an overshoot of about $100 \%$ with oscillation and a steady state error of $12.5 \%$ with respect to the expected output in the absence of a disturbance. The settling time is four time constants. The pressure corresponding to the open-loop simulation is shown in Fig. 6.18. The pressure response also has overshoot and oscillations.

It can be seen from Fig. 6.19 and Fig. 6.20 that using the PD controller eliminates the overshoot, oscillations and quickens the response. The nondimensional valve opening area versus non-dimensional time is shown in Fig. 6.21. Saturation was used to simulate the real-world constraints. Since the dynamics of both the inlet metering valve and the four-way directional valve have not been studied in this work, the saturation condition is simplified in that the area cannot be negative or greater than the maximum value of 1 . However, the model could be extended to 
include the dynamics of the valve actuators and the ability to switch the direction of the flow. Neglecting these additional characteristics could be justified by assuming that extremely fast acting valve actuators are used.

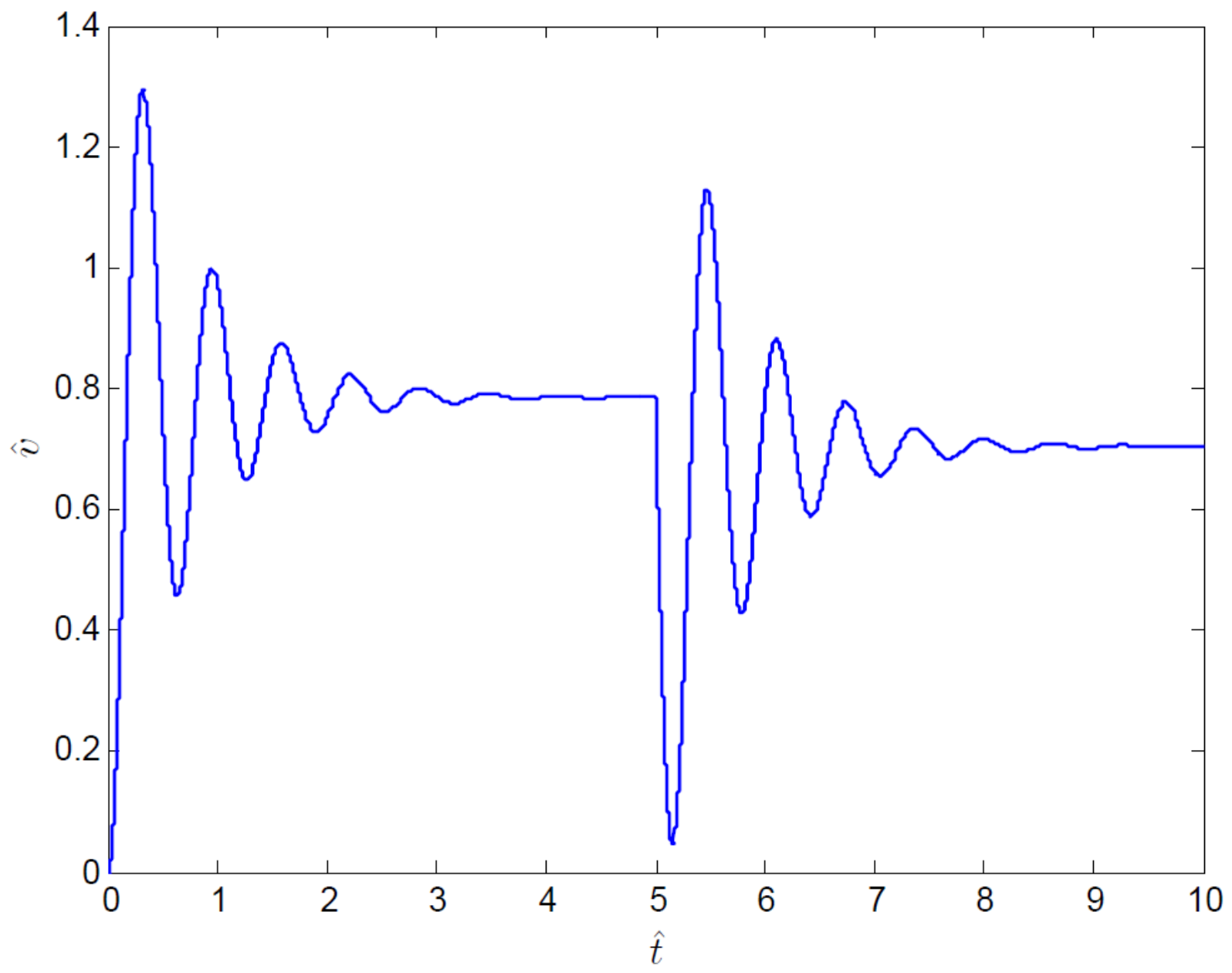

Figure 6.17: Cylinder velocity vs. time with a step disturbance force and no controller 


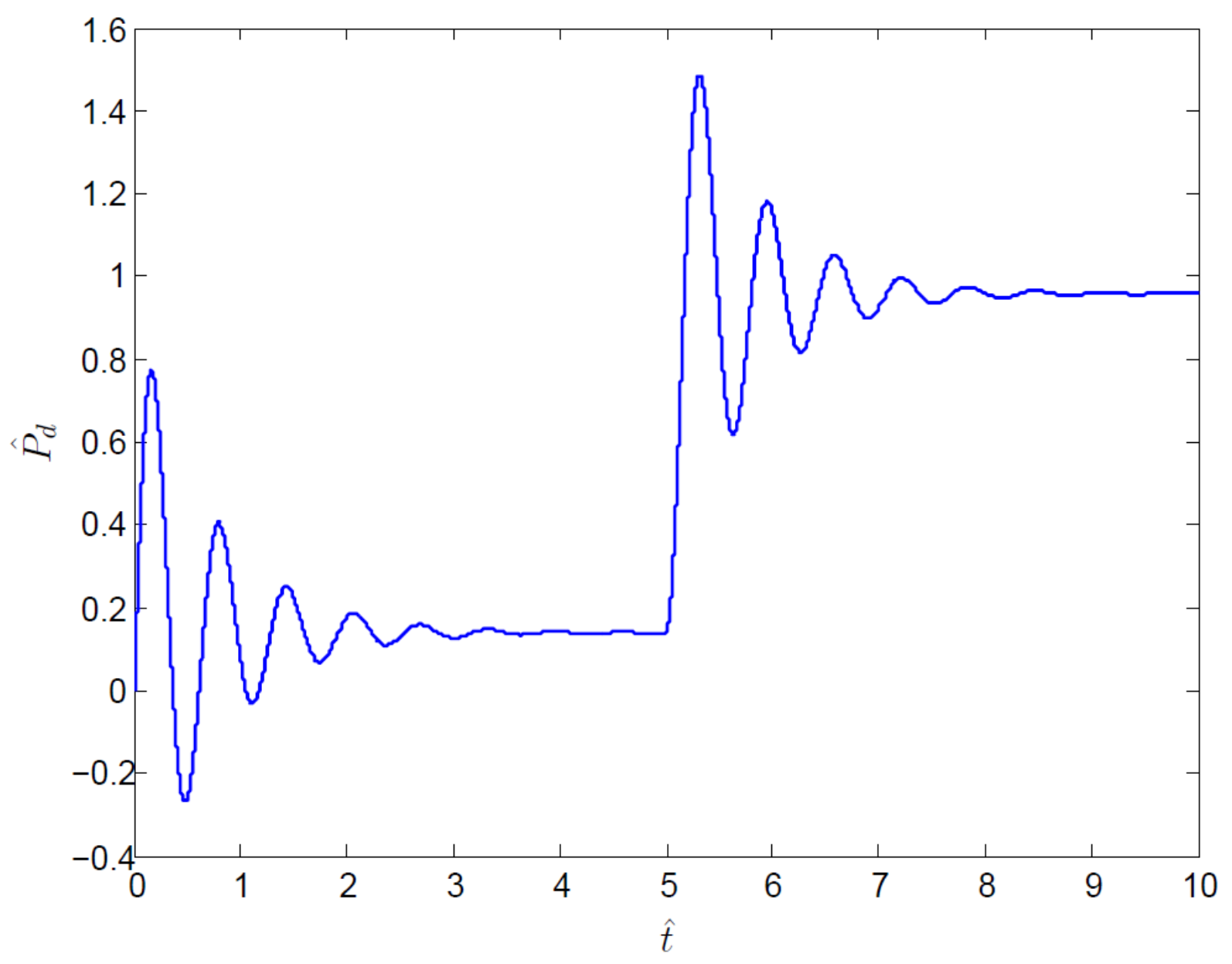

Figure 6.18: Pressure vs. time with a step disturbance force and no controller 


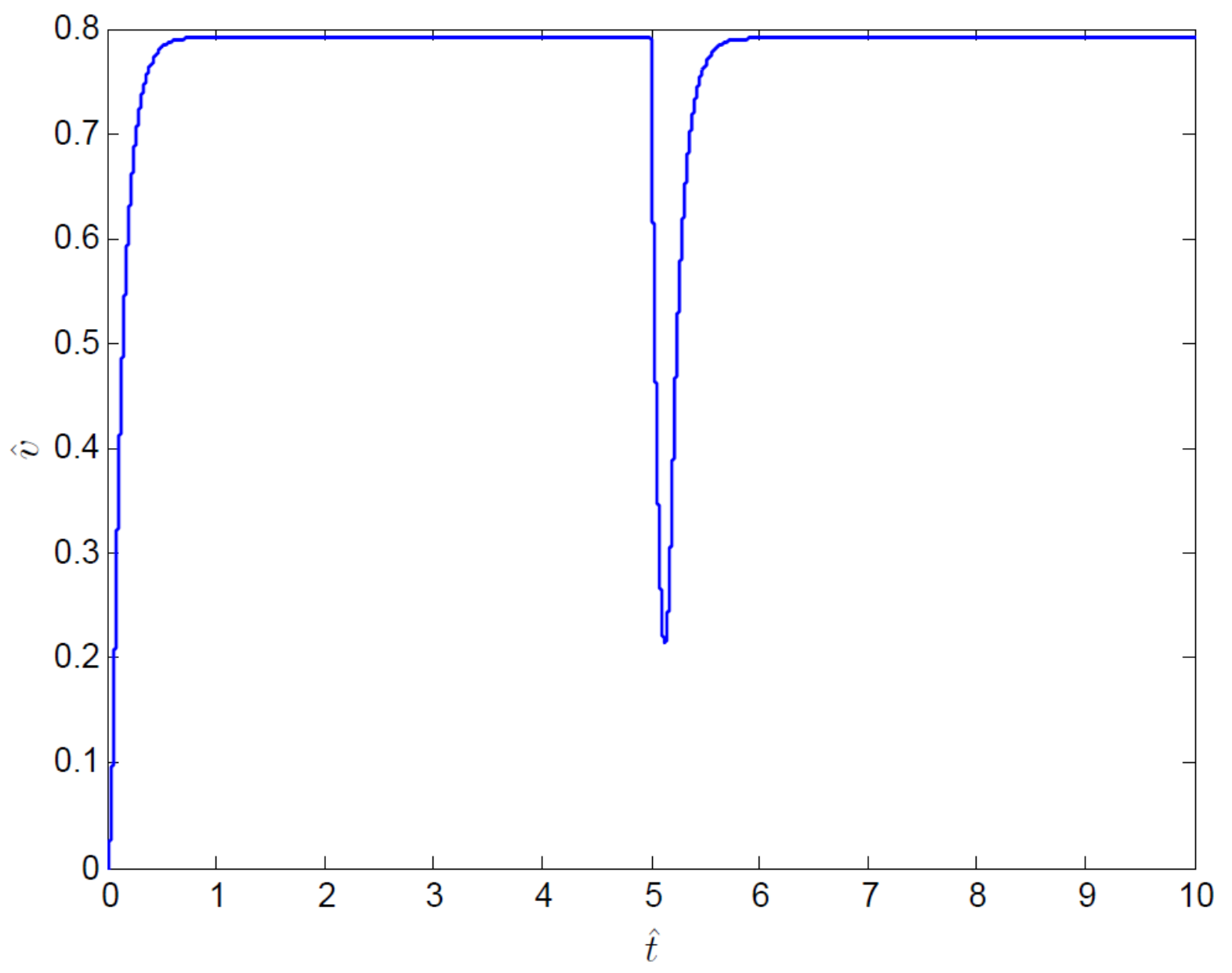

Figure 6.19: Cylinder velocity vs. time with PD controller and a step disturbance force 


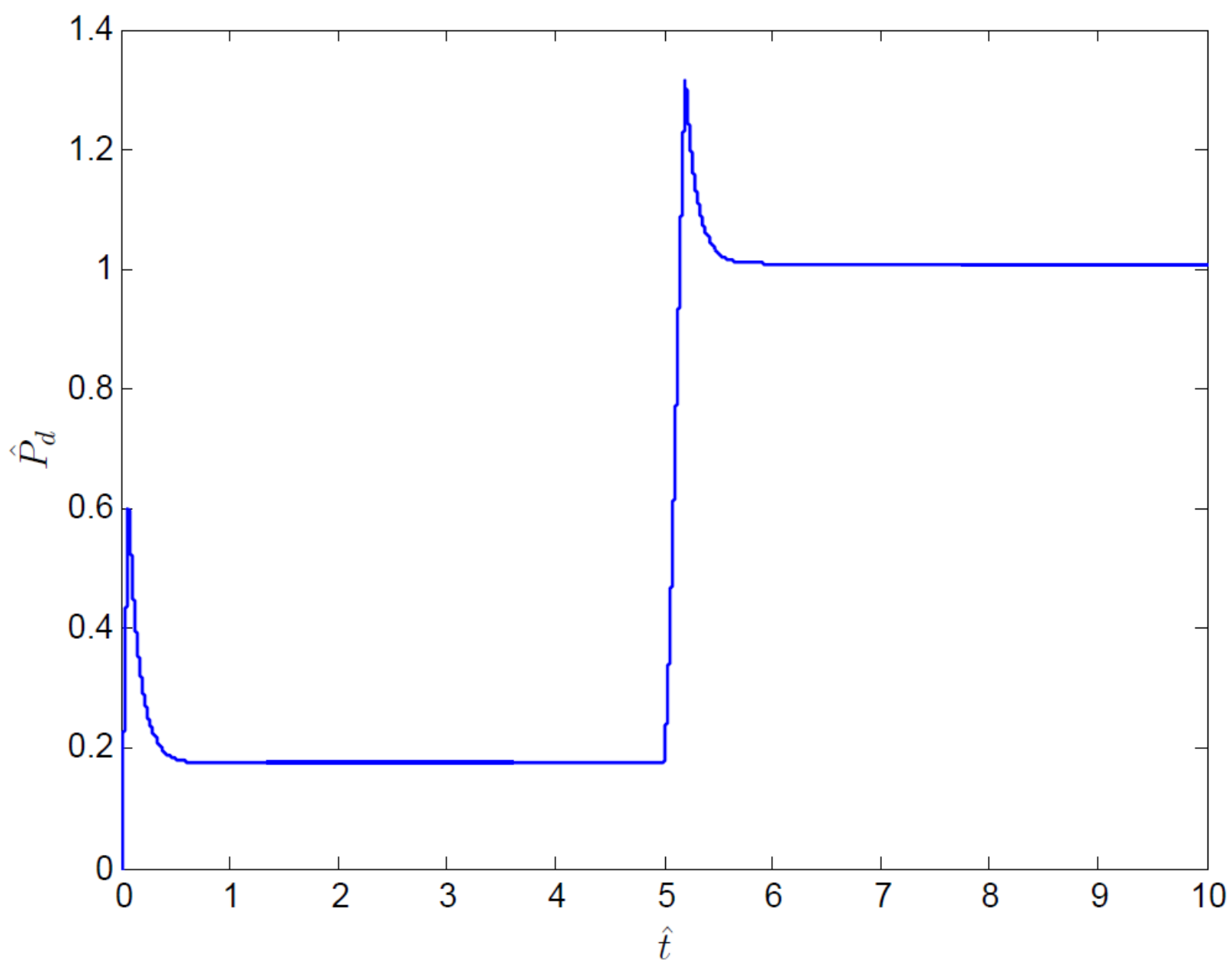

Figure 6.20: Pressure vs. time with PD controller and a step disturbance force 


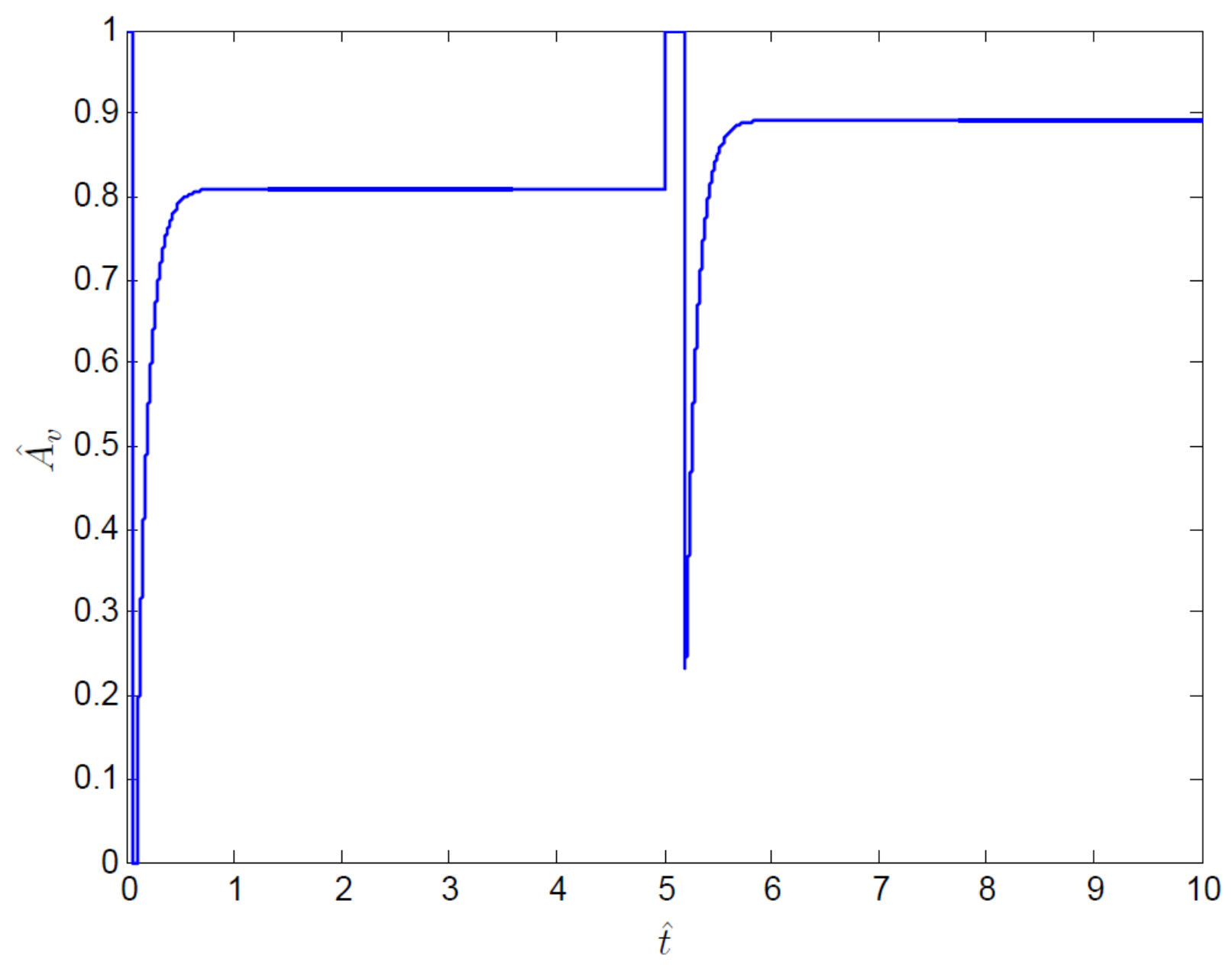

Figure 6.21: Non-dimensional valve opening area vs. time with PD controller and a sinusoidal disturbance force

6.5.2 Including the Valve Dynamics Results and Discussion

Figure 6.22 shows that the response of the system with the extremely fast valve is the same as the case where the valve was neglected (Fig. 6.19) which verifies the assumption of neglecting the valve dynamics if it is much faster than the rest of the system. The next results are for the case of actual valve dynamics. The frequency responses of the PI controller and the $\mathrm{H}_{\infty}$ controller are shown in Fig. 6.23. It can be seen that the PI and the $\mathrm{H}_{\infty}$ frequency responses look the same at medium frequencies. The PI controller has a higher gain at low frequencies which gives a lower 
steady state error. At high frequencies, they are different again which makes the response of the system different. Figure 6.24 shows a comparison of the system velocity time responses for the open-loop case and the closed-loop with PI controller. It can be seen that the open-loop response to both the reference input and the disturbance has an overshoot with oscillation and a large steady state error with respect to the expected output in the absence of a disturbance. Adding the PI controller to the system removes the overshoot and the oscillation from the response to the reference input and eliminates the steady state error. However, the system with the PI controller has a slower response. The response of the system with a PI controller can be made faster by changing the controller gains. For example, if the speed of the response to the reference input is to be doubled, the controller gains need to be changed from $\left(K_{p}=0.122, K_{i}=0.8\right.$, and $\left.K_{d}=0\right)$ to $\left(K_{p}=0.4\right.$, $K_{i}=1.2$, and $\left.K_{d}=0\right)$. A comparison of the responses of the system with the original and new gains is shown in Fig. 6.25. It can be noticed from Fig. 6.25 that increasing the speed of the response results in overshoot and oscillation in the response. The time response of the closed-loop system with the $\mathrm{H}_{\infty}$ controller is shown in Fig. 6.26. Replacing the PI controller with the $\mathrm{H}_{\infty}$ controller reduces the overshoot in the response to the reference input to a very small value while keeping the speed of the system unchanged. The steady state error and the overshoot in the response of the system to the reference input can be completely removed by using a two degrees of freedom controller as shown in Fig. 6.27. 


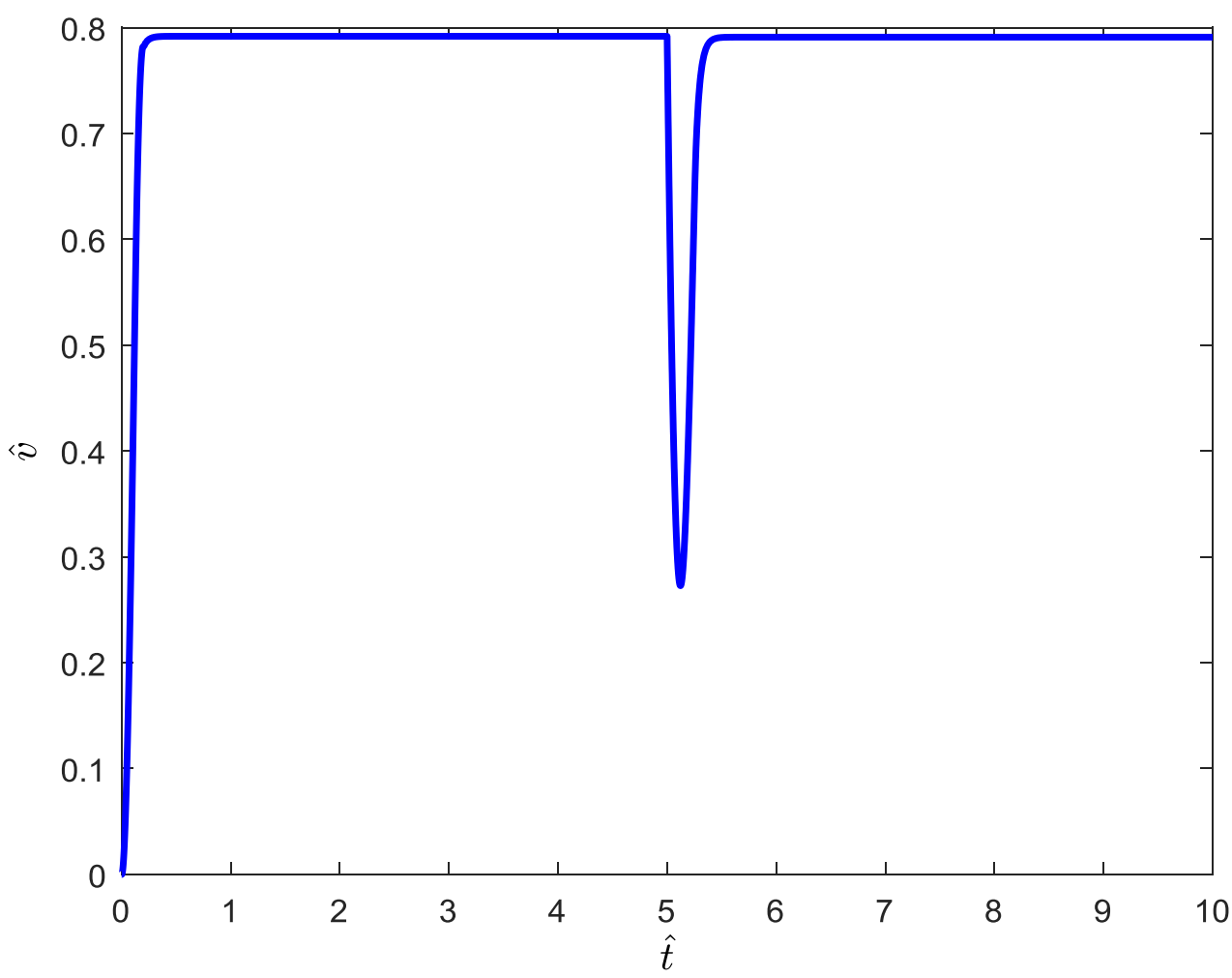

Figure 6.22: Velocity time response for the system with a fast valve with PD controller 


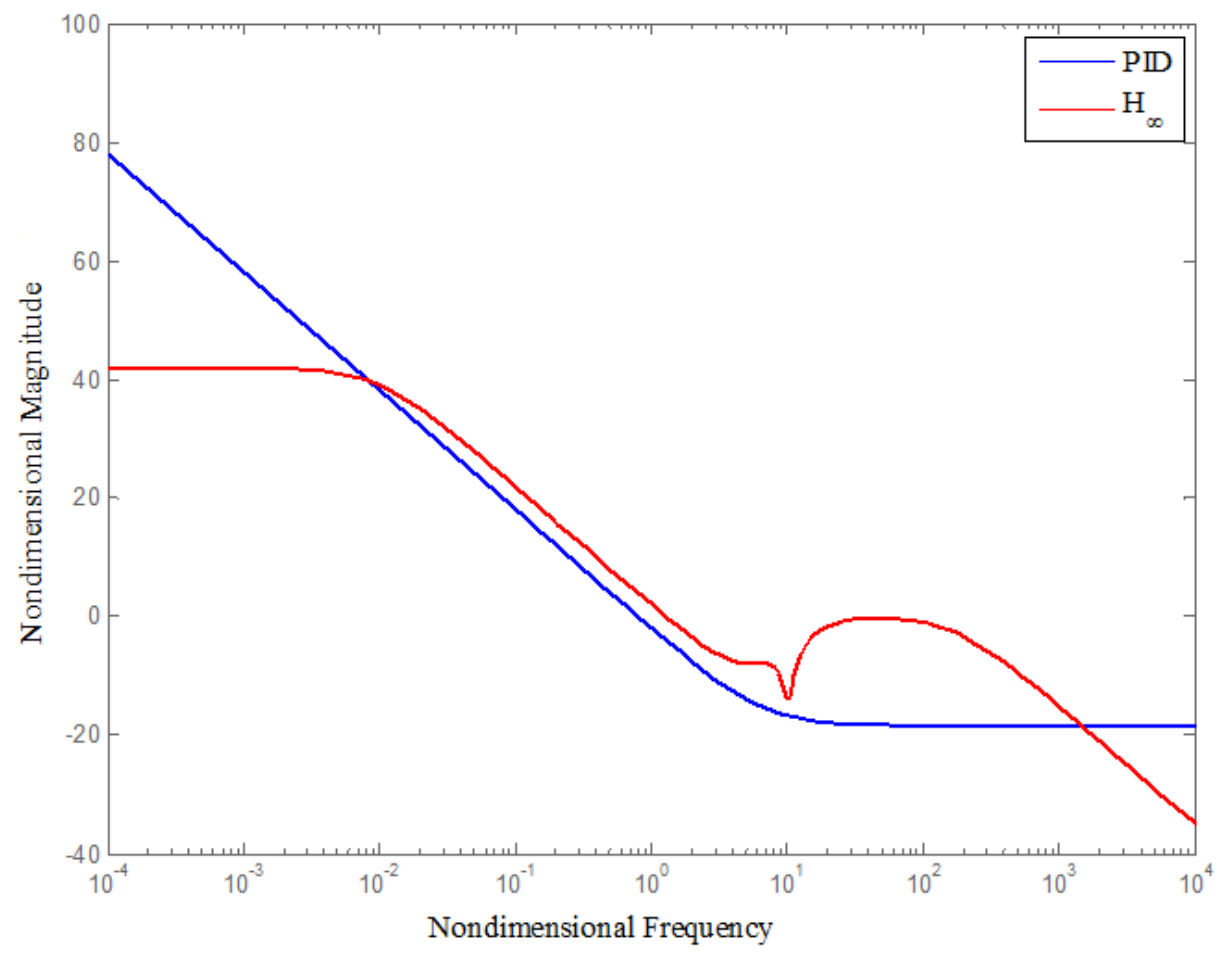

Figure 6.23: The frequency response of the PI and the $\mathrm{H}_{\infty}$ controllers

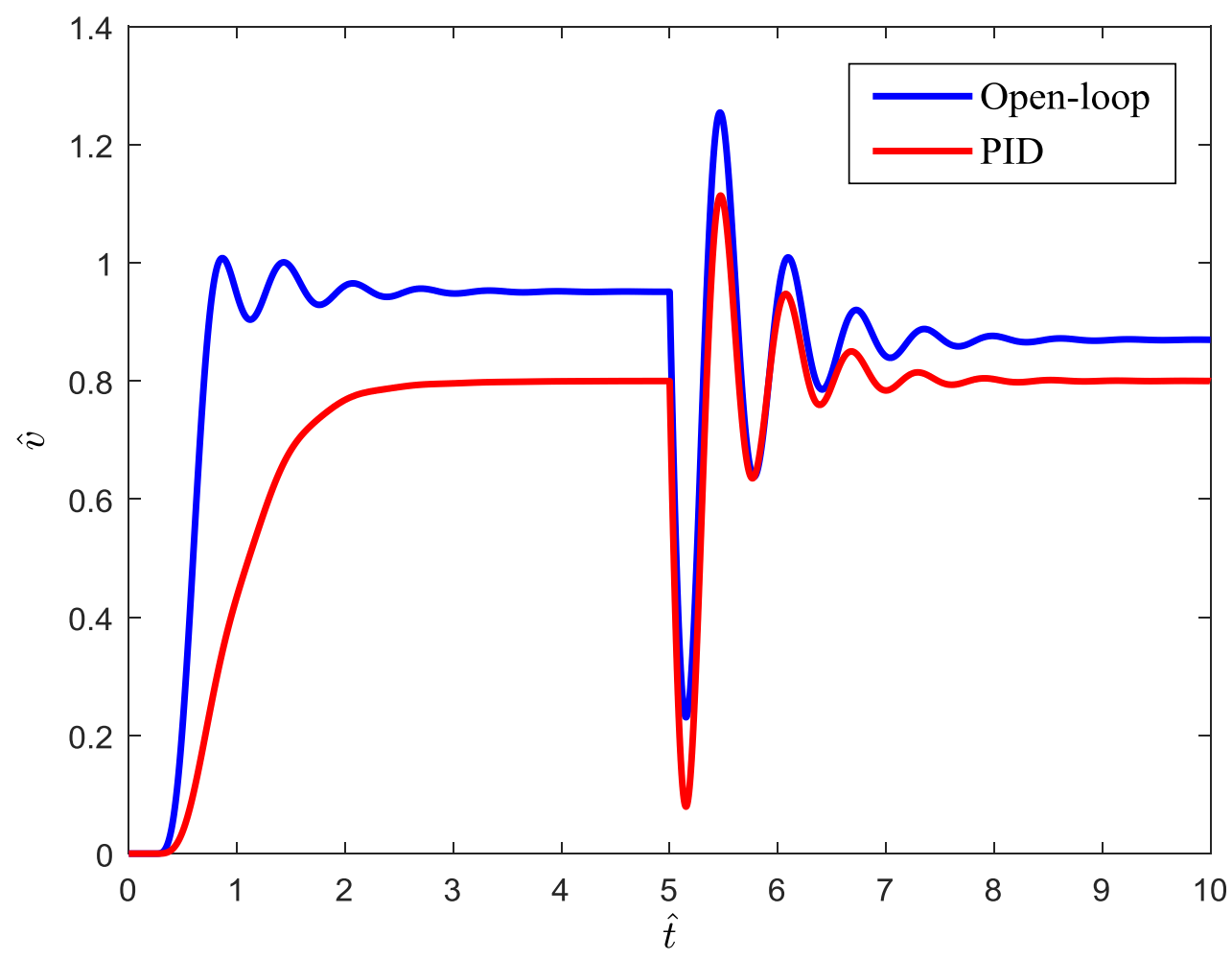

Figure 6.24: The velocity time response for open-loop and closed-loop with PI controller 


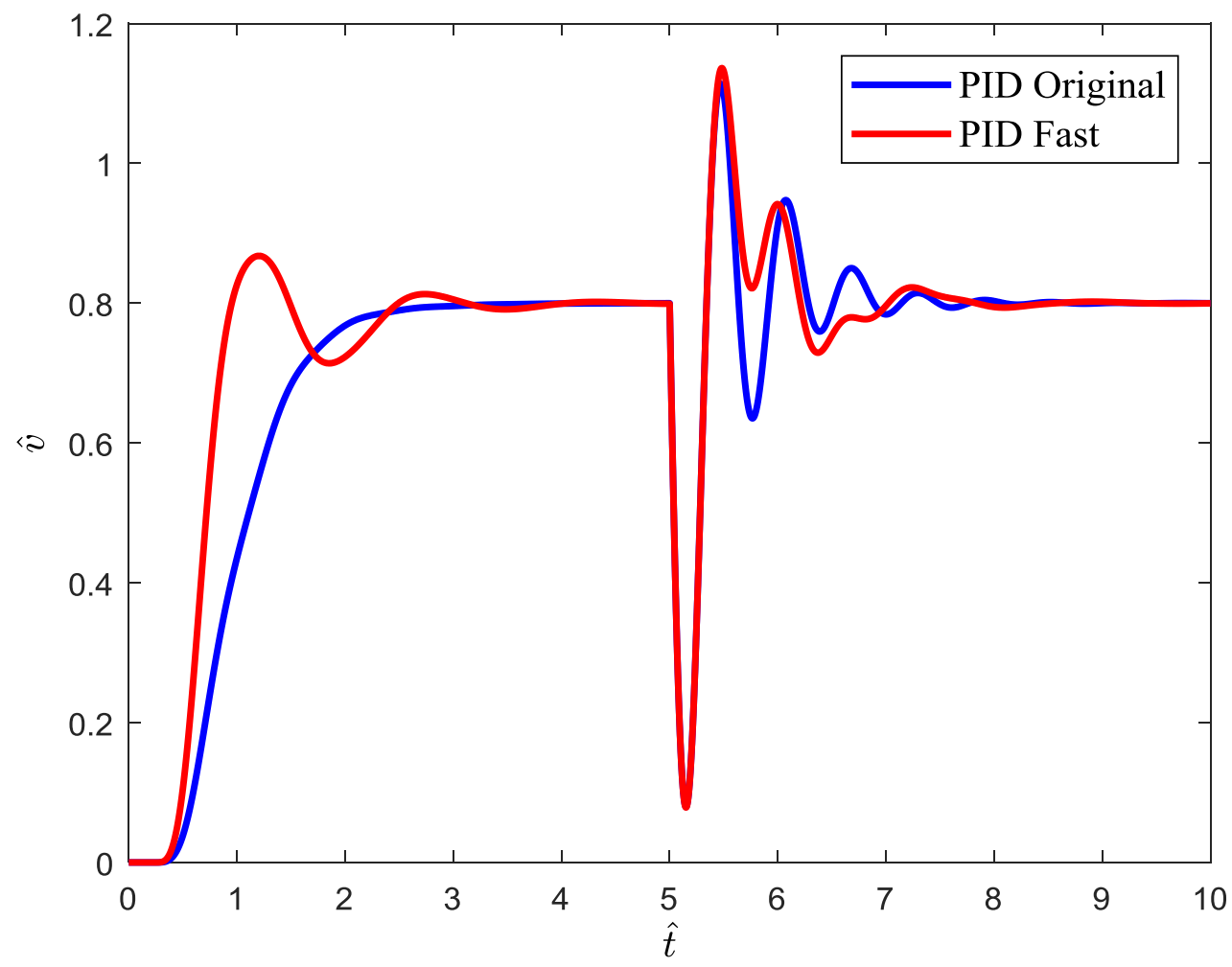

Figure 6.25: The velocity time response with PI controller for different values of the controller gains 


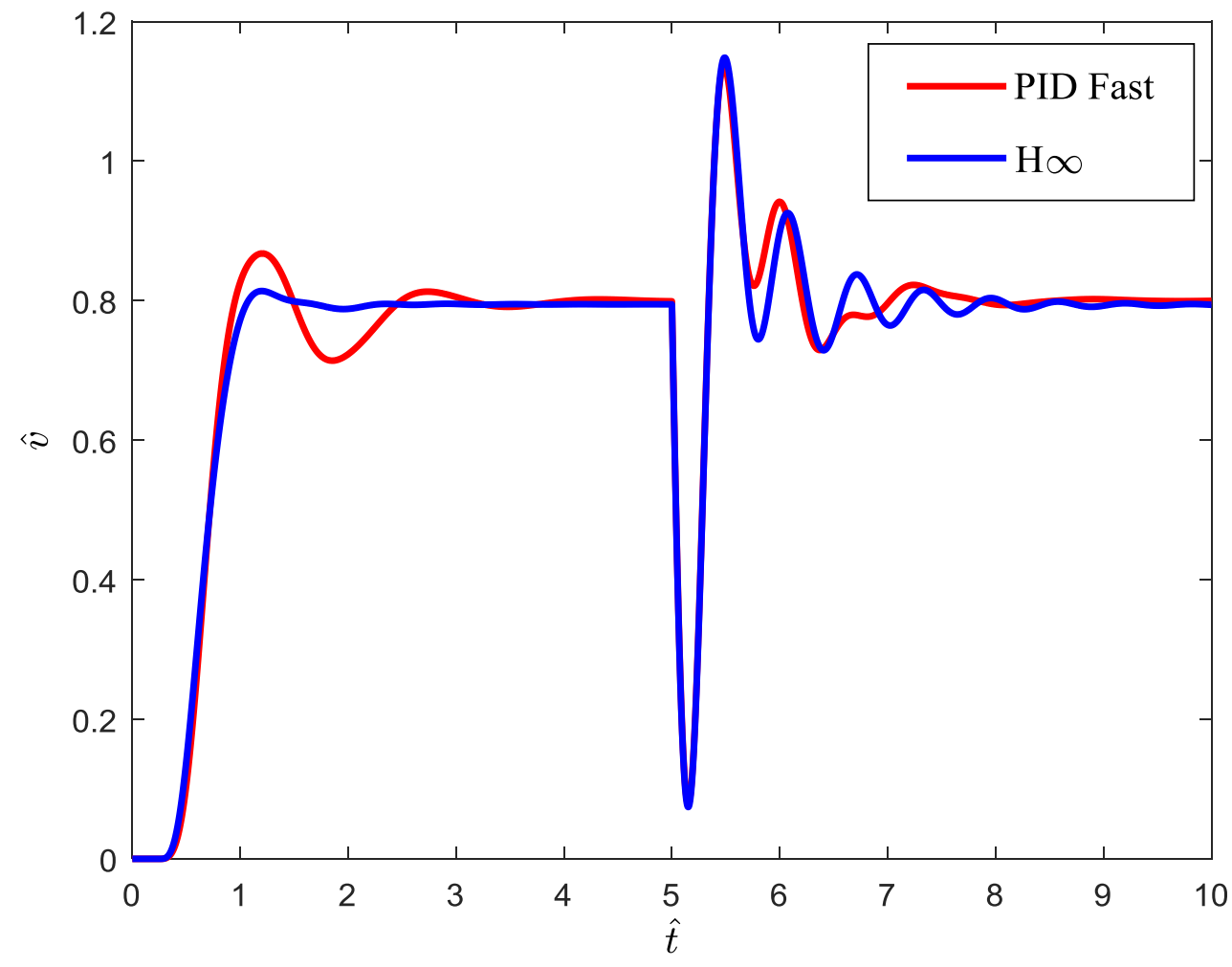

Figure 6.26: The velocity time response with PI and $\mathrm{H}_{\infty}$ controllers 


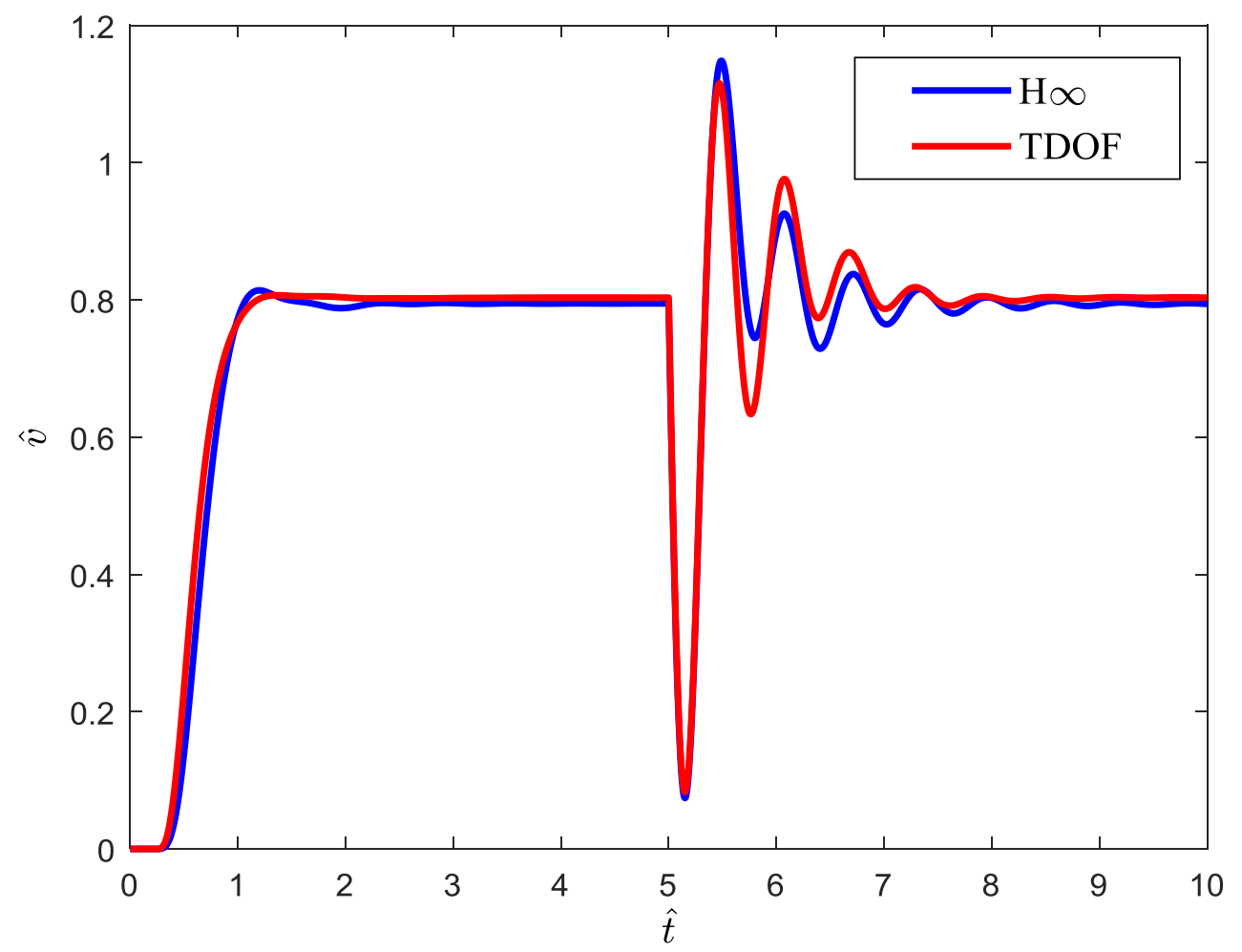

Figure 6.27: The velocity time response with $\mathrm{H}_{\infty}$ controller and TDOF controller 


\section{CHAPTER 7}

\section{CONCLUSIONS AND RECOMMENDATIONS}

\subsection{Background Information}

In this work, a method to control the flow of a fixed displacement pump is presented based on using an inlet-metered pump. The flow, torque, and efficiency are modeled. Experiments have been done and the models are validated against experimental data. The model was shown to agree well with the experimental data. After that, a velocity control system that utilizes the inlet metering system has been designed. The velocity control system is modeled and linearized. Based on the

state space linear model stability analysis is performed. Two cases were considered when the system performance was studied. In the first case, the system designed by assuming extremely fast acting valve actuators, dynamics of valve actuators are ignored. In the second case, the valve dynamics was included. Performance analysis for steady-state disturbance rejection and steady reference signal tracking was done. The simulation results for open-loop, closed-loop with PID controller, closed-loop with $\mathrm{H}_{\infty}$ controller, and closed-loop with two degrees of freedom were presented and discussed. A list of conclusions from the present work is presented in the next section. The last section of this chapter presents some suggestions for future works to be done on the inlet metering system to expand the understanding of the system and its applications. 


\subsection{Conclusions}

The following conclusions are supported by the analysis and experimental results of this paper:

1. A theoretical model for the flow, torque, and efficiency of an inlet metering pump was developed.

2. The theoretical model for the inlet metering pump shows good agreement with experimental results.

3. Both the theoretical model and the experiments prove the inlet metering system can be used as a variable flow source.

4. The ideal discharge flow is not a function of the pump rotational speed unless the maximum flow is reached, which is the product of pump displacement and speed. Instead, the ideal pump flow is a linear function of inlet metering valve area.

5. The torque required by the pump increases as the discharge pressure and the valve area increase.

6. As the rotational speed of the pump increases, the torque decreases when the pump operates in the inlet metering mode. The torque increases with increase in the pump speed when the pump operates at maximum flow.

7. The frictional torque is a function of the valve metering area, pump shaft speed, discharge pressure, and the time during which the fluid is pressurized.

8. The pump efficiency increases as the discharge pressure increases but decreases as the pump rotational speed increases.

9. The inlet pressure was shown to have only a small effect on the pump efficiency. However, if the inlet pressure (and charge pump) were to be included in the computation of the overall 
system efficiency, it would be seen that a high inlet pressure would significantly reduce efficiency due to inlet pressure effect on the charge pump power consumption. The inlet pressure can be made small by selecting a large inlet metering valve area to obtain the required flow.

10. The open-loop velocity control system with inlet metered pump is stable for all realistic (positive) choices of parameters.

11. Without the valve dynamics, the open-loop inlet metering velocity control system has oscillations unless a considerable amount of damping is added.

12. Without the valve dynamics, PD controller can be used to design the inlet metering velocity control system such that the system is stable, there is zero percent overshoot and no oscillations and good disturbance rejection with arbitrarily small steady state error even with the inclusion of saturation nonlinearity.

13. If the valve dynamics model is included in the simulation, the open-loop system is stable but has a large steady state error.

14. With an extremely fast valve actuator, the valve dynamics can be neglected, and a PD controller can be designed based on the dynamics of the rest of the system.

15. The response of the system with the extremely fast valve actuator is the same as the response for the case where the valve dynamics is not included. This verifies the assumption of neglecting the valve dynamics when it is much faster than the rest of the system.

16. If the difference in the speed of the valve dynamics and the dynamics of the rest of the system is not significant, neither the valve dynamics nor the dynamics of the rest of the 
system can be neglected. In this case, a PI controller could be designed so that the system is stable with zero steady state error.

17. $\mathrm{H}_{\infty}$ controller could be designed to improve the system performance. The system response with $\mathrm{H}_{\infty}$ controller is two times faster than the response with the PI controller. However, the response with the $\mathrm{H}_{\infty}$ controller has a small overshoot.

18. Using a two-degrees of freedom controller removes the overshoot associated with the $\mathrm{H}_{\infty}$ controller while keeping the speed of the response unchanged.

\subsection{Recommendations for Future Work}

1. Investigate removal of the charge pump or consider reduction of charge pressures. A large inlet-metering valve would allow for lower charge pressure while allowing the same amount of flow.

2. Investigate potential use in pump-controlled systems. The IMP combines best of valves and pumps in terms of simple low-cost flow control and limited metering losses, especially when charge pressures are reduced. The losses due to the inlet valve restriction can be made arbitrarily low by sizing the valve, especially when compared to valve controlled systems. Experimental data shows that the IMP efficiency is between that of pump controlled and valve controlled systems. The IMP should be considered a low-cost alternative to swash plate control mechanism possibly at the expense of efficiency.

3. Cavitation strength of materials should be investigated - critical components should be designed for cavitation strength.

4. The literature suggests that stainless steel and ceramic are good cavitation resistant materials [63-73]. 
5. To improve the volumetric efficiency, the inlet and discharge check valves should be designed to close faster when using hydraulic fluid. Note that the test pump design is optimized for use with low viscosity fuel and extremely high pressures. A redesign for hydraulic system use would require valves with less damping to speed up closing times which would reduce flow losses from the discharge to the inlet stroke.

6. To improve the torque efficiency, the inlet-metered pump should be designed based on the pressure associated with the typical hydraulic systems. This design will produce smaller parts such as the journal bearing which reduces the friction and eventually improves the torque efficiency of the pump.

7. Investigate different pump configurations such as:

a. Radial piston pumps. This configuration may reduce packaging size.

b. Inline pump configurations with more cylinders to reduce torque, flow, and pressure ripple. 


\section{REFERENCES}

[1] Çalişkan, H., Balkan, T., Platin, B. 2009, "Hydraulic Position Control System with Variable Speed Pump" Proceedings of the ASME 2009 Dynamic Systems and Control Conference DSCC2009, Hollywood, California, USA, October 12-14, pp. 1-8.

[2] "Variable Speed Pumping, A Guide to Successful Applications, Executive Summary," U.S. Department of Energy, Energy Efficiency and Renewable Energy, Industrial Technologies Program.

[3] Williamson, C., and M. Ivantysynova, 2007, "The effect of pump efficiency on displacementcontrolled actuator systems." Proceedings of the Tenth Scandinavian International Conference on Fluid Power, Tampere, Finland. Vol. 2, pp. 301-326.

[4] Wilson, W. E. "Positive Displacement Pumps and Fluid Motors." New York: Pitman Publishing Corporation (1950).

[5] Schlosser, W. M. J. "Mathematical Model for Displacement Pumps and Motors, Hydraulic Power Transmission,” pp. April, 252-257 and 269, and May, (1961), pp.324-328.

[6] Thoma J. "Mathematical Models and Effective Performance of Hydrostatic Machines and Transmissions,” Hydraulic Pneumatic Power, (1969), pp. 642-651.

[7] Aker, A., and Zeiger, G. "Torque on the Swashplate of an Axial Piston Pump" ASME Journal of Dynamic Systems, Measurement, and Control, vol. 107(1985), pp. 220-226.

[8] Aker, A., and Zeiger, G. "The Effect of Oil Entrapment in an Axial Piston Pump". ASME Journal of Dynamic Systems, Measurement, and Control, vol. 107, (1985), pp. 246-251. 
[9] Kaliafetis, P., and Costopoulos, Th. "Modeling and simulation of an axial piston variable displacement pump with pressure control," National Technical University of Athens, Partition 42, (1994)106 82, Athens, Greece.

[10] Manring, N.D. and Johnson, R.E. "Modeling and Designing of a variable Displacement OpenLoop Pump.” Journal of Dynamic Systems, Measurement, and Control, Vol. 118, (1996) pp.267271.

[11] X. Zhang, X., Cho, J., Nair, S.S., and Manring, N. D. "New Swash Plate Damping Model for Hydraulic Axial-Piston Pump.” Journal of Dynamic Systems, Measurement, and Control, Vol. 123(2001), pp.463-470.

[12] Manring, N.D. and Luecke, G.R. "Modeling and Designing a Hydrostatic Transmission with a Fixed-Displacement Motor”. Journal of Dynamic Systems, Measurement, and Control, Vol. 120(1998), pp.45-49.

[13] Manring, N. D. "The Torque on the Input Shaft of an Axial-Piston Swash-Plate Type Hydrostatic Pump". Journal of Dynamic Systems, Measurement, and Control, Vol. 120(1998), pp.57-62.

[14] Manring, N.D. "The Control and Containment Forces on the Swash Plate of an Axial-Piston Pump.” Journal of Dynamic Systems, Measurement, and Control, Vol. 121(1999), pp.599-605.

[15] Manring, N.D. “The Discharge Flow Ripple of an Axial-Piston Swash-Plate Type Hydrostatic Pump.” Journal of Dynamic Systems, Measurement, and Control, Vol. 122(2000), pp.263-268. 
[16] Shi, X. and Manring, N. D., "A Torque Efficiency Model for an Axial-Piston, Swash-Plate Type, Hydrostatic Pump." Bath Workshop on Power Transmission and Motion Control, (2001), pp. 3-20.

[17] Manring N. D. and Zhang, Y. "The Improved Volumetric- Efficiency of an Axial-Piston Pump Utilizing a Trapped-Volume Design.” Journal of Dynamic Systems, Measurement, and Control, Vol. 123(2001), pp.279-487.

[18] Manring, N. D. "Valve-Plate Design for an Axial Piston Pump Operating at Low Displacements". Journal of Dynamic Systems, Measurement, and Control, Vol. 125(2003), pp.200-207.

[19] Seeniraj, G. K. and Ivantysynova, M. "Impact of Valve Plate Design on Noise, Volumetric Efficiency and Control Effort in an Axial Piston Pump”. 2006 ASME International Mechanical Engineering Congress and Exposition November 5-10, 2006, Chicago, Illinois, USA

[20] XU, B., SUN, Y., ZHANG, J., SUN, T., and MAO, Z. "A new design method for the transition region of the valve plate for an axial piston pump." Journal of Zhejiang University-SCIENCE A (Applied Physics \& Engineering), 2015 16(3), pp.229-240

[21] Zhang, S., and Manring N.D. "Numerical Study of Optimal Timing of the Axial Piston Pump.” ASME 2011 Dynamic Systems and Control Conference DSCC2011

October 31 - November 2, 2011, Arlington, VA, USA.

[22] Wang, S. "Improving the Volumetric Efficiency of the Axial Piston Pump". Journal of Mechanical Design, Vol. 134, (2013), pp. 111001/1- 111001/7

[23] Wang, S. "Novel Piston Pressure Carryover for Dynamic Analysis and Designs 
of the Axial Piston Pump". Journal of Dynamic Systems, Measurement, and Control, Vol.135(2013), pp.1-7.

[24] Lee S. Y. and Hong Y. "Effect of CrSiN Thin Film Coating on the Improvement of the LowSpeed Torque Efficiency of a Hydraulic Piston Pump.” Surface \& Coatings Technology 202 (2007) 1129-1134.

[25] Bergada, J.M., Davies, D.L., Xue, Y., Kumar, S. “Experimental Investigation in Axial Piston Pumps Barrel Dynamics" $10^{\text {th }}$ International Conference on Fluid Control, Measurement, and Visualization, August 17-21,2009, Moscow, Russia.

[26] Scott and Andrew, "Dimensionless Design of Variable Displacement Pumps". ASME 2009 Dynamic Systems and Control Conference DSCC2009 October 12-14, 2009, Hollywood, California, USA

[27] Kemmetmuller, W., Fuchshumer, F. and Kugi, A. "Nonlinear Pressure Control of SelfSupplied Variable Displacement Axial Piston Pumps." Control Engineering Practice 18,(2010)pp. 84-93.

[28] Shi, Z., Parker, G., and Granstrom, J., "Kinematic Analysis of a Swash-Plate Controlled Variable Displacement Axial-Piston Pump with a Conical Barrel Assembly”. Journal of Dynamic Systems, Measurement, and Control, Vol.132(2010), pp.18.

[29] Maiti, R and Narayan, P “An Experimental Investigation on Swashplate Control Torque of a Pressure Compensated Variable Displacement Inline Piston Pump” Proceedings of the 8th JFPS International Symposium on Fluid Power, OKINAWA 2011. 
[30] COOMBS, D. 2012, "Hydraulic Efficiency of a Hydrostatic Transmission with a Variable Displacement Pump and Motor". M.S. Thesis, University of Missouri-Columbia.

[31] Xiuye Wei1 and Haiyan Wang 2013 "Dynamics Simulation Study of the Axial Piston Pump." Advanced Materials Research Vols. 706-708 (2013) pp 1323-1326

[32] Manring, N. D. 2013, "Fluid Power Pumps and Motors: Analysis, Design and Control". McGraw-Hill. New York.

[33] Manring, N. D., Mehta, V. S., Nelson, B. E., Graf, K. J., Kuehn, J. L.” Scaling the Speed Limitations for Axial-Piston Swash-Plate Type Hydrostatic Machines". Journal of Dynamic Systems, Measurement, and Control MAY 2014, Vol. 136 / 031004-1.

[34] Busquets, E. and M. Ivantysynova, 2015 “A Multi-Actuator Displacement-Controlled System with Pump Switching - A Study of the Architecture and Actuator-Level Control", JFPS International Journal of Fluid Power System, Vol. 8, No. 2, pp. 66-75.

[35] Manring, N. D. 2016, "Mapping the Efficiency for a Hydrostatic Transmission". Journal of Dynamic Systems, Measurement, and Control May 2016, Vol. 136 / 031004-1.

[36] Tomlinson, S.P. and Burrows, C.R. “Achieving a Variable Flow Supply by Controlled Unloading of a Fixed-Displacement Pump". Journal of Dynamic Systems, Measurement, and Control, Vol. 114, (1992) pp.166-171.

[37] Batdorff, M. A., Lukes, J. H. "Virtually Variable Displacement Hydraulic Pump Including Compressibility and Switching Losses”. Proceedings of IMECE2006, 2006 ASME International Mechanical Engineering Congress and Exposition, November 5-10, 2006, Chicago, Illinois, USA. 
[38] Zhang, Qin., 1999, "Hydraulic Linear Actuator Velocity Control Using a Feedforward-plusPID Control," International Journal of Flexible Automation and Integrated Manufacturing, Vol.7, No. 3, pp. 277-292.

[39] Gibson, I. H., "Variable-Speed Drives as Flow Control Elements," Advances in instrumentation and control, Vol. 48, (1993) pp.1939-1948.

[40] Hu, D., Ding, S., Zhu1, H., Xu, B., and Yang, H., 2011, "Velocity-tracking Control of the Variable-speed Controlled Hydraulic System: Using Compound Algorithm of PD \& Feedforwardfeedback Control" Third International Conference on Measuring Technology and Mechatronics Automation, pp.1109-1115.

[41] Wisch, J.K., N.D. Manring. and R.C. Fales, 2017. "Dynamic Characteristics of a PressureCompensated Inlet-Metered Pump." Journal of Dynamic Systems, Measurement, and Control, 139(6), p.064502.

[42] Brown, F. T., 1984 "The Use of Fluid Inertia for D/A Conversion in Hydraulic PWM Circuits with Seating Valves, Part I: Concepts," ASME Paper No. 84-WA/DSC-4.

[43] Brown, F. T., S. C. Tentarelli and S. Ramachandran, 1988 "A Hydraulic Rotary SwitchedInertasice Servo-Transformer," Transactions of the ASME, Vol. 110, pp. 144-150.

[44] Johnston, Nigel, 2009, “A Switched Inertance Device for Efficient Control of Pressure and Flow," Proceedings of the ASME 2009 Dynamic Systems and Control Conference, DSCC2009, October 12-14, 2009, Hollywood, California, USA.

[45] Pan, Min, James Robertson, N. Johnston, A. Plummer, and Andrew Hillis, 2014, "Experimental Investigation of a Switched Inertance Hydraulic System," Proceedings of the 
ASME/BATH 2014 Symposium on Fluid Power \& Motion Control FPMC2014, September 1012, Bath, United Kingdom.

[46] Pan, Min, N. Johnston, and Andrew Hillis, 2014, "Active control of pressure pulsation in a switched inertance hydraulic system," J Systems and Control Engineering, 227(7), pp. 610-620.

[47] Scheidl R., B. Manhartsgruber, and H. Kogler, 2011, "Mixed time-frequency domain simulation of a hydraulic inductance pipe with a check valve" Proc. IMechE Vol. 225 Part C: J. Mechanical Engineering Science, pp. 2413-2421.

[48] Pan, Min, N. Johnston, A. Plummer, S. Kudzma and A. Hillis, 2013, "Theoretical and experimental studies of a switched inertance hydraulic system" J Systems and Control Engineering, 228(1), pp. 12-25.

[49] Pan, Min, N. Johnston, A. Plummer, S. Kudzma, A. Hillis, 2014, "Theoretical and experimental studies of a switched inertance hydraulic system including switching transition dynamics, nonlinearity and leakage" Proceedings of the Institution of Mechanical Engineers, Part I: Journal of Systems and Control Engineering, Vol 228, Issue 10, pp.802-815.

[50] Ito, H., and T. Miyoshi, "Electronic Fuel Injection System for an internal combustion engine having electromagnetic valves and a fuel damper upstream thereof," U.S.

Patent No. 4,205,637. 3 jun. 1980.

[51] Miyaki, Masahiko, Fullsawa, Hideya, Masuda, Akira, and Yamamoto, Yoshihisa. 1991, "Development of new electronically controlled fuel injection system ECD-U2 for diesel engines" SAE Technical Paper 910252. 
[52] Rinolf R, Imarisio R, and Buratti R 1995, "The potential of a new common rail diesel fuel injection system for the next generation of DI diesel engines," 16 Internationales Wiener Motoren symposium, VDI- Verlag Reihe 12 Nr. 239.

[53] Stumpp, G, and Mario Ricco, M., 1996, “Common Rail - An attractive fuel injection system for Passenger Car DI Diesel Engines,” SAE Technical Paper Series 960870, pp. 183-191.

[54] Guerrassi, N., and Dupraz, P., 1998, “A common rail injection system for high-speed direct injection diesel engines," SAE Technical paper series 980803, pp. 1-8.

[55] Zhu, G., and Reitz, R., "Engine Fuel Droplet High-Pressure Vaporization Modeling" Transactions of the ASME, Vol. 123, APRIL 2001, pp. 412-418.

[56] Balluchi, A., Bicchi, A., Mazzi, E., Vincentelli, A. and Serra, G., "Hybrid modeling and control of the common rail injection system," International Journal of Control, Vol. 80, No. 11, November 2007, pp. 1780-1795.

[57] Balluchi, A., Bicchi, A., Mazzi, E., Vincentelli, A. and Serra, G., "Hybrid multi-rate control of the common-rail," International Journal of Control, Vol. 80, No. 11, November 2007, pp. 17801795.

[58] Ryu,S., Kim, D., Park, T., Kim, B. and Ghal, S., “A study on cavitation damage reduction in fuel injection pumps", Proceedings of the ASME 2010 International Mechanical Engineering Congress \& Exposition IMECE2010, November 12-18, 2010, Vancouver, British Columbia, Canada, pp. 1-7.

[59] Allen, J., Ravenhill, P., Barraclough, S. and Hoolahan, R., "Internal combustion engine with a fuel injection system" US 8,479,708 B2, Jul. 9, 2013. 
[60] Friedrich Schwam: Advanced fuel metering for aero engines[R]. Proceedings of

ASME TURBOEXPO 2000, May 8-11, 2000, Munich Germany.

[61] He, Z., Tao, X., Zhong, W., Leng, X., Wang, Q. and Zhao, p., "Experimental and numerical study of cavitation inception phenomenon in diesel injector nozzles," International Communications in Heat and Mass Transfer 65 (2015), pp.117-124.

[62] Duan, L., Yuan, S., Hu, L., Yang, W., Yu, J. and Xia, X. "Injection performance and cavitation analysis of an advanced $250 \mathrm{MPa}$ common rail diesel injector, International Journal of Heat and Mass Transfer 93 (2016), pp.388-397.

[63] Huan, Zhang, "Cavitation Effect to the Hydraulic Piston Pump Flow Pulsation," Applied Mechanics and Materials, Vols. 599-601 (2014): 230-236.

[64] Eisenberg, Phillip, “On the mechanism and prevention of cavitation," Navy Dept., David W. Taylor Model Basin, 1950.

[65] Matevž Dular, Olivier Coutier-Delgosha, "Numerical modeling of cavitation erosion," 2008 ASME fluid engineering conference, August 10-14, 2008 Jacksonville, Florida USA.

[66] Wang S. 2010, "The Analysis of Cavitation Problems in the Axial Piston Pump," Journal of Fluids Engineering, Vol. 132 pp. 074502/1-074502/6.

[67] Ulrike Litzow, Karl-Heinz Zum Gahr, and Johannes Schneider," Cavitation erosion of advanced ceramics in water" International Journal of Materials Research, 97 (2006), 10, 13721377.

[68] David Niebuhr, "Cavitation erosion behavior of ceramics in aqueous solutions," Wear 263 (2007) 295-300. 
[69] Umanskyi, O., O. Poliarus, M. Ukrainets, M. Antonov. Physical-Chemical Interaction in NiAl-MeB2, Systems Intended for Tribological applications. Welding Journal (2015): 225-230.

[70] Poliarus, Olena, Oleksandr Umanskyi, Irina Boiko and Yevheniia Puhachevska, "New Composite Materials Based on Intermetallics for Protection Details of Hydropower Equipment from Cavitation, Hydroabrasive and Corrosion Wear,” Key Engineering Materials, Vol. 721 (2017): 300-305.

[71] Liang, Jiang, Ge Han, Liu Fengbin, and Chen Darong, "Investigations on dynamics of interacting cavitation bubbles in strong acoustic fields" Ultrasonics Sonochemistry 34 (2017): 9097.

[72] Wang, Yan, Daruta, Geoffrey, Poirierb, Thierry, Stellac, Jorge, Liaoa, Hanlin, and Planche, Marie-Pierre, "Ultrasonic cavitation erosion of as-sprayed and laser-remelted yttria stabilized zirconia coatings,” Journal of the European Ceramic Society, (2017) 1-8.

[73] Bordeasu, I., M. O. Popoviciu, L. C. Salcianu1, C Ghera, L. M. Micu, R Badarau, A. Iosif, L D Pirvulescu and C E Podoleanu, "A new concept for stainless steels ranking upon the resistance to cavitation erosion,” IOP Conf. Series: Materials Science and Engineering, 163 (2017): 1-11.

[74] Wisch, Julie K., "Dynamic and efficiency characteristics of an inlet metering valve controlled fixed displacement pump.” Ph.D. Dissertation, University of Missouri, 2016.

[75] Manring, N. D., "Hydraulic control systems,” Wiley, 2005.

[76] Ogata, K., “System Dynamics,” fourth ed. Upper Saddle River: Pearson Prentice Hall, 2004.

[77] Franklin, Gene F., J. David Powell, Abbas Emami-Naeini, "Feedback Control of Dynamic Systems," Pearson, 2014. 
[78] Carpenter, R. and R. Fales, "Mixed Sensitivity H-Infinity control design with frequency domain uncertainty modeling for a pilot operated proportional control valve," ASME 2012 5th Annual Dynamic Systems and Control Conference joint with the JSME 2012 11th Motion and Vibration Conference October 17-19, 2012, Fort Lauderdale, Florida, USA.

[79] Skogestad, S. and I. Postlethwaite, "Multivariable Feedback Control: Analysis and Design," Second Ed.: John Wiley and Sons, Ltd, 2005.

[80] Fales, Roger, "Uncertainty modeling and predicting the probability of stability and performance in the manufacture of dynamic systems," ISA Transactions 49 (2010) 528_534.

[81] Lundstrom, P., Sigurd, S., and Zi-Qin, W., "Performance weight selection for H-infinity and $\mu$-control method" Trans. Inst. MC, vol.13, No.5, pp.241, 1991. 


\section{Appendices}

Appendix A: Linearization of the Pressure Rise Rate Equation

The pressure rise rate equation is written as:

$\dot{P}_{d}=\frac{\beta}{V_{o}+A_{A} y}\left(Q_{i}-k_{1} P_{d}-A_{A} \dot{y}\right)$

Equation (A1) may be linearized using the following nominal conditions:

$y_{o}=\dot{y}_{o}=Q_{i o}=P_{d o}=0$

The linearized equation takes the form:

$\dot{P_{d}}=\dot{P_{d_{o}}}+\left.\frac{\partial \dot{P_{d}}}{\partial y}\right|_{o}\left(y-y_{o}\right)+\left.\frac{\partial \dot{P}_{d}}{\partial Q_{i}}\right|_{o}\left(Q_{i}-Q_{i o}\right)+\left.\frac{\partial \dot{P}_{d}}{\partial P_{d}}\right|_{o}\left(P_{d}-P_{d o}\right)+\left.\frac{\partial \dot{P}_{d}}{\partial \dot{y}}\right|_{o}\left(\dot{y}-\dot{y}_{o}\right)$

$P_{d o}^{\cdot}=\frac{\beta}{V_{o}+A_{A} y_{o}}\left(Q_{i o}-k_{1} P_{d o}-A_{A} \dot{y}_{o}\right)=0$

$\left.\frac{\partial \dot{P_{d}}}{\partial y}\right|_{o}=\frac{\beta}{\left(V_{o}+A_{A} y_{o}\right)^{2}}\left(Q_{i o}-k_{1} P_{d o}-A_{A} \dot{y}_{o}\right)=0$

$\left.\frac{\partial \dot{P_{d}}}{\partial Q_{i}}\right|_{o}=\frac{\beta}{V_{o}+A_{A} y_{o}}=\frac{\beta}{V_{o}}$

$\left.\frac{\partial \dot{P_{d}}}{\partial P_{d}}\right|_{o}=\frac{-\beta k_{1}}{V_{o}+A y_{o}}=-\frac{\beta k_{1}}{V_{o}}$

$\left.\frac{\partial \dot{P_{d}}}{\partial \dot{y}}\right|_{o}=\frac{-\beta A_{A}}{V_{o}+A y_{o}}=-\frac{\beta A}{V_{o}}$

Substituting Eqs. (A2-A7) into Eq. (A1) gives the linearized form of the pressure rise rate equation. 
$\dot{P}_{d}=\frac{\beta}{V_{o}}\left(Q_{i}-k_{1} P_{d}-A_{A} v\right)$

But

$Q_{i}=C_{d} A_{v} \sqrt{\frac{2 P_{i}}{\rho}}$

Then, Eq. (A8) can be written as:

$\dot{P}_{d}=\frac{\beta}{V_{o}}\left(C_{d} A_{v} \sqrt{\frac{2 P_{i}}{\rho}}-k_{1} P_{d}-A_{A} v\right)$ 
Appendix B: The experimental data

\begin{tabular}{|c|c|c|c|c|c|c|c|c|c|}
\hline $\begin{array}{c}\mathrm{Q}_{\mathrm{i}} \\
{[1 / \mathrm{min}]}\end{array}$ & $\begin{array}{c}\mathrm{Q}_{\mathrm{d}} \\
{[1 / \mathrm{min}]}\end{array}$ & $\begin{array}{c}\mathrm{T} \\
\text { [in-lbs] }\end{array}$ & $\begin{array}{c}\mathrm{P}_{\mathrm{i}} \\
{[\mathrm{Mpa}]}\end{array}$ & $\begin{array}{c}\mathrm{P}_{\mathrm{d}} \\
{[\mathrm{Mpa}]}\end{array}$ & $\begin{array}{c}\text { Voltage } \\
{[\mathrm{V}]}\end{array}$ & $\begin{array}{c}\text { Temp } \\
\text { In } \\
\text { [degC] }\end{array}$ & $\begin{array}{c}\text { Temp } \\
\text { Out } \\
{[\operatorname{deg} C]}\end{array}$ & $\begin{array}{c}\text { Temp } \\
\text { Head } \\
{[\operatorname{deg} C]}\end{array}$ & $\omega[\mathrm{rpm}]$ \\
\hline 2.37 & 0.00 & 41.34 & 2.78 & 1.06 & 0.00 & 32.71 & 33.90 & 47.31 & 1000 \\
\hline 3.75 & 2.38 & 49.56 & 2.74 & 2.12 & 0.50 & 32.80 & 33.96 & 47.26 & 1000 \\
\hline 7.66 & 5.64 & 72.91 & 2.63 & 2.22 & 1.00 & 32.75 & 33.96 & 47.22 & 1000 \\
\hline 11.24 & 8.66 & 72.20 & 2.52 & 2.38 & 2.00 & 32.78 & 33.96 & 47.21 & 1000 \\
\hline 11.18 & 8.78 & 67.24 & 2.53 & 2.38 & 3.00 & 32.80 & 33.95 & 47.20 & 1000 \\
\hline 11.16 & 8.81 & 65.38 & 2.53 & 2.39 & 4.00 & 32.78 & 33.95 & 47.19 & 1000 \\
\hline 11.26 & 8.75 & 65.44 & 2.53 & 2.38 & 5.00 & 32.79 & 33.94 & 47.22 & 1000 \\
\hline 2.43 & 0.00 & 1.48 & 2.77 & 2.08 & 0.00 & 32.73 & 33.85 & 47.69 & 1000 \\
\hline 3.69 & 2.40 & 55.31 & 2.73 & 4.95 & 0.50 & 32.81 & 33.94 & 47.64 & 1000 \\
\hline 7.44 & 5.62 & 96.36 & 2.63 & 5.13 & 1.00 & 32.76 & 33.94 & 47.44 & 1000 \\
\hline 10.91 & 8.65 & 109.82 & 2.52 & 5.30 & 2.00 & 32.77 & 33.93 & 47.56 & 1000 \\
\hline 11.06 & 8.75 & 106.04 & 2.52 & 5.31 & 3.00 & 32.77 & 33.94 & 47.53 & 1000 \\
\hline 11.07 & 8.63 & 103.50 & 2.52 & 5.30 & 400 & 32.80 & 33.93 & 47.66 & 1000 \\
\hline 11.13 & 8.71 & 104.15 & 2.52 & 5.30 & 5.00 & 32.79 & 33.95 & 47.53 & 1000 \\
\hline 2.43 & 0.00 & 41.40 & 2.76 & 2.79 & 0.00 & 32.70 & 33.87 & 46.10 & 1000 \\
\hline 3.78 & 2.35 & 64.67 & 2.73 & 9.49 & 0.50 & 32.79 & 34.00 & 46.06 & 1000 \\
\hline 7.55 & 5.56 & 133.84 & 2.62 & 9.84 & 1.00 & 32.77 & 33.98 & 46.04 & 1000 \\
\hline 10.95 & 8.63 & 171.22 & 2.51 & 10.03 & 2.00 & 32.80 & 33.97 & 46.03 & 1000 \\
\hline 11.00 & 8.75 & 165.87 & 2.52 & 10.03 & 3.00 & 32.78 & 33.98 & 46.02 & 1000 \\
\hline 10.98 & 8.69 & 166.33 & 2.52 & 10.03 & 4.00 & 32.78 & 33.98 & 46.02 & 1000 \\
\hline 10.84 & 8.64 & 162.10 & 2.52 & 10.02 & 5.00 & 32.80 & 33.97 & 46.02 & 1000 \\
\hline 2.36 & 0.00 & 41.34 & 2.72 & 6.02 & 0.00 & 32.72 & 33.91 & 46.20 & 1000 \\
\hline 3.69 & 2.31 & 84.05 & 2.68 & 18.90 & 0.50 & 32.81 & 34.12 & 46.18 & 1000 \\
\hline 7.57 & 5.47 & 210.34 & 2.59 & 19.68 & 1.00 & 32.81 & 34.11 & 46.24 & 1000 \\
\hline 11.05 & 8.45 & 295.16 & 2.49 & 19.93 & 2.00 & 32.80 & 34.11 & 46.14 & 1000 \\
\hline 11.12 & 8.48 & 294.94 & 2.49 & 19.93 & 3.00 & 32.82 & 34.11 & 46.17 & 1000 \\
\hline 11.02 & 8.48 & 289.31 & 2.49 & 19.92 & 4.00 & 32.82 & 34.11 & 46.22 & 1000 \\
\hline 11.09 & 8.49 & 293.16 & 2.49 & 19.92 & 5.00 & 32.83 & 34.13 & 46.21 & 1000 \\
\hline
\end{tabular}




\begin{tabular}{|c|c|c|c|c|c|c|c|c|c|}
\hline 2.42 & 0.00 & 40.85 & 2.71 & 4.92 & 0.00 & 32.77 & 34.02 & 46.06 & 1000 \\
\hline 3.64 & 1.80 & 94.74 & 2.67 & 23.96 & 0.50 & 32.85 & 34.30 & 46.05 & 1000 \\
\hline 7.39 & 5.33 & 241.24 & 2.58 & 25.18 & 1.00 & 32.84 & 34.29 & 46.06 & 1000 \\
\hline 10.72 & 8.29 & 370.23 & 2.49 & 25.48 & 2.00 & 32.85 & 34.27 & 46.07 & 1000 \\
\hline 10.87 & 8.29 & 365.32 & 2.49 & 25.48 & 3.00 & 32.86 & 34.28 & 46.08 & 1000 \\
\hline 10.94 & 8.34 & 354.20 & 2.49 & 25.47 & 4.00 & 32.87 & 34.29 & 46.10 & 1000 \\
\hline 11.06 & 8.35 & 363.52 & 2.49 & 25.48 & 5.00 & 32.90 & 34.29 & 46.12 & 1000 \\
\hline 2.78 & 0.00 & 36.89 & 3.95 & 0.93 & 0.00 & 36.62 & 37.85 & 52.33 & 1000 \\
\hline 4.41 & 2.55 & 46.15 & 3.91 & 1.85 & 0.50 & 36.70 & 37.95 & 52.27 & 1000 \\
\hline 9.02 & 6.57 & 71.12 & 3.79 & 2.01 & 1.00 & 36.68 & 37.94 & 52.24 & 1000 \\
\hline 12.32 & 9.60 & 49.39 & 3.70 & 2.10 & 2.00 & 36.70 & 37.95 & 52.22 & 1000 \\
\hline 13.27 & 10.55 & 44.94 & 3.67 & 2.13 & 3.00 & 36.70 & 37.93 & 52.19 & 1000 \\
\hline 13.30 & 10.57 & 43.47 & 3.67 & 2.13 & 4.00 & 36.71 & 37.91 & 52.16 & 1000 \\
\hline 13.63 & 10.87 & 43.42 & 3.66 & 2.14 & 5.00 & 36.71 & 37.90 & 52.14 & 1000 \\
\hline 2.77 & 0.00 & 36.23 & 3.93 & 1.33 & 0.00 & 36.70 & 37.75 & 52.64 & 1000 \\
\hline 4.42 & 2.19 & 52.45 & 3.89 & 4.58 & 0.50 & 36.80 & 37.86 & 52.61 & 1000 \\
\hline 9.08 & 6.48 & 96.25 & 3.77 & 4.80 & 1.00 & 36.78 & 37.87 & 52.60 & 1000 \\
\hline 11.62 & 8.79 & 86.47 & 3.70 & 4.89 & 2.00 & 36.79 & 37.88 & 52.61 & 1000 \\
\hline 11.70 & 8.78 & 79.27 & 3.69 & 4.88 & 3.00 & 36.83 & 37.88 & 52.61 & 1000 \\
\hline 11.73 & 8.74 & 79.04 & 3.69 & 4.89 & 4.00 & 36.86 & 37.90 & 52.59 & 1000 \\
\hline 11.52 & 8.73 & 78.53 & 3.69 & 4.89 & 5.00 & 36.86 & 37.89 & 52.58 & 1000 \\
\hline 2.94 & 0.00 & 35.73 & 3.91 & 2.34 & 0.00 & 36.49 & 37.28 & 52.54 & 1000 \\
\hline 4.59 & 2.45 & 66.11 & 3.87 & 10.40 & 0.50 & 36.61 & 37.47 & 52.57 & 1000 \\
\hline 9.08 & 6.45 & 154.50 & 3.76 & 10.83 & 1.00 & 36.63 & 37.50 & 52.62 & 1000 \\
\hline 11.48 & 8.65 & 162.34 & 3.70 & 10.97 & 2.00 & 36.66 & 37.53 & 52.63 & 1000 \\
\hline 11.57 & 8.70 & 156.75 & 3.69 & 10.97 & 3.00 & 36.71 & 37.57 & 52.70 & 1000 \\
\hline 11.64 & 8.72 & 157.90 & 3.69 & 10.96 & 4.00 & 36.75 & 37.60 & 52.83 & 1000 \\
\hline 11.44 & 8.68 & 154.68 & 3.68 & 10.97 & 5.00 & 36.81 & 37.64 & 52.88 & 1000 \\
\hline 2.92 & 0.00 & 35.75 & 3.89 & 5.49 & 0.00 & 35.74 & 36.44 & 51.81 & 1000 \\
\hline 4.50 & 2.17 & 87.89 & 3.86 & 19.27 & 0.50 & 35.89 & 36.71 & 51.83 & 1000 \\
\hline 9.12 & 6.39 & 240.61 & 3.75 & 20.09 & 1.00 & 35.90 & 36.75 & 51.88 & 1000 \\
\hline
\end{tabular}




\begin{tabular}{|c|c|c|c|c|c|c|c|c|c|}
\hline 11.47 & 8.50 & 279.90 & 3.69 & 20.28 & 2.00 & 35.94 & 36.78 & 51.91 & 1000 \\
\hline 11.58 & 8.54 & 278.88 & 3.69 & 20.28 & 3.00 & 36.01 & 36.81 & 51.97 & 1000 \\
\hline 11.43 & 8.48 & 274.27 & 3.68 & 20.28 & 4.00 & 36.08 & 36.87 & 52.02 & 1000 \\
\hline 11.54 & 8.46 & 273.53 & 3.68 & 20.28 & 5.00 & 36.15 & 36.91 & 52.06 & 1000 \\
\hline 2.86 & 0.00 & 36.27 & 3.87 & 6.30 & 0.00 & 34.66 & 35.09 & 50.34 & 1000 \\
\hline 4.54 & 2.08 & 100.46 & 3.84 & 24.30 & 0.50 & 34.80 & 35.43 & 50.40 & 1000 \\
\hline 9.20 & 6.28 & 290.76 & 3.73 & 25.42 & 1.00 & 34.86 & 35.49 & 50.47 & 1000 \\
\hline 11.51 & 8.40 & 347.91 & 3.68 & 25.64 & 2.00 & 34.89 & 35.53 & 50.58 & 1000 \\
\hline 11.56 & 8.41 & 347.69 & 3.68 & 25.64 & 3.00 & 34.95 & 35.60 & 50.66 & 1000 \\
\hline 11.45 & 8.47 & 345.72 & 3.67 & 25.64 & 4.00 & 35.02 & 35.67 & 50.71 & 1000 \\
\hline 11.61 & 8.39 & 339.32 & 3.67 & 25.65 & 5.00 & 35.08 & 35.75 & 50.77 & 1000 \\
\hline 2.75 & 0.00 & 36.07 & 3.62 & 0.87 & 0.00 & 36.43 & 37.93 & 52.07 & 1000 \\
\hline 4.26 & 2.18 & 44.88 & 3.53 & 1.82 & 0.50 & 36.53 & 38.01 & 52.04 & 1000 \\
\hline 8.64 & 6.22 & 68.51 & 3.29 & 1.98 & 1.00 & 36.51 & 38.02 & 52.03 & 1000 \\
\hline 11.45 & 8.73 & 52.23 & 3.14 & 2.05 & 2.00 & 36.54 & 38.02 & 52.02 & 1000 \\
\hline 12.30 & 9.71 & 48.54 & 3.09 & 2.08 & 3.00 & 36.63 & 38.03 & 52.02 & 1000 \\
\hline 12.45 & 9.90 & 47.26 & 3.08 & 2.09 & 4.00 & 36.75 & 38.03 & 52.00 & 1000 \\
\hline 12.60 & 10.12 & 46.91 & 3.08 & 2.09 & 5.00 & 36.85 & 38.04 & 52.00 & 1000 \\
\hline 2.73 & 0.00 & 35.94 & 3.62 & 1.42 & 0.00 & 36.21 & 37.75 & 52.10 & 1000 \\
\hline 4.25 & 2.54 & 50.04 & 3.54 & 4.24 & 0.50 & 36.31 & 37.85 & 52.08 & 1000 \\
\hline 8.50 & 6.17 & 90.76 & 3.29 & 4.44 & 1.00 & 36.31 & 37.85 & 52.07 & 1000 \\
\hline 11.45 & 8.72 & 87.26 & 3.14 & 4.55 & 2.00 & 36.30 & 37.87 & 52.07 & 1000 \\
\hline 11.49 & 8.76 & 81.29 & 3.15 & 4.55 & 3.00 & 36.34 & 37.88 & 52.08 & 1000 \\
\hline 11.41 & 8.82 & 80.89 & 3.15 & 4.55 & 4.00 & 36.36 & 37.90 & 52.07 & 1000 \\
\hline 11.29 & 8.79 & 79.47 & 3.15 & 4.55 & 5.00 & 36.36 & 37.90 & 52.07 & 1000 \\
\hline 2.80 & 0.00 & 35.52 & 3.61 & 1.94 & 0.00 & 35.86 & 37.39 & 51.75 & 1000 \\
\hline 4.32 & 2.76 & 61.96 & 3.51 & 9.23 & 0.50 & 35.97 & 37.58 & 51.75 & 1000 \\
\hline 8.57 & 6.13 & 136.22 & 3.27 & 9.62 & 1.00 & 35.98 & 37.58 & 51.77 & 1000 \\
\hline 11.34 & 8.70 & 153.80 & 3.12 & 9.77 & 2.00 & 35.98 & 37.59 & 51.78 & 1000 \\
\hline 11.29 & 8.72 & 150.77 & 3.12 & 9.77 & 3.00 & 36.01 & 37.60 & 51.79 & 1000 \\
\hline 11.38 & 8.73 & 149.44 & 3.12 & 9.77 & 4.00 & 36.04 & 37.64 & 51.81 & 1000 \\
\hline
\end{tabular}




\begin{tabular}{|c|c|c|c|c|c|c|c|c|c|}
\hline 11.52 & 8.68 & 146.41 & 3.13 & 9.77 & 5.00 & 36.07 & 37.66 & 51.83 & 1000 \\
\hline 2.81 & 0.00 & 35.59 & 3.62 & 4.25 & 0.00 & 35.33 & 36.87 & 51.29 & 1000 \\
\hline 4.26 & 2.35 & 85.37 & 3.52 & 18.94 & 0.50 & 35.44 & 37.12 & 51.38 & 1000 \\
\hline 8.37 & 6.03 & 220.95 & 3.27 & 19.79 & 1.00 & 35.44 & 37.14 & 51.43 & 1000 \\
\hline 11.24 & 8.49 & 288.34 & 3.12 & 20.01 & 2.00 & 35.46 & 37.16 & 51.38 & 1000 \\
\hline 11.46 & 8.52 & 282.76 & 3.13 & 20.00 & 3.00 & 35.51 & 37.18 & 51.40 & 1000 \\
\hline 11.39 & 8.50 & 275.94 & 3.13 & 20.00 & 4.00 & 35.55 & 37.22 & 51.41 & 1000 \\
\hline 11.26 & 8.49 & 280.91 & 3.13 & 20.00 & 5.00 & 35.58 & 37.26 & 51.45 & 1000 \\
\hline 2.82 & 0.00 & 35.65 & 3.59 & 4.33 & 0.00 & 34.63 & 36.21 & 50.79 & 1000 \\
\hline 4.24 & 2.37 & 94.66 & 3.50 & 22.94 & 0.50 & 34.74 & 36.53 & 50.66 & 1000 \\
\hline 8.37 & 5.97 & 258.72 & 3.26 & 24.07 & 1.00 & 34.77 & 36.53 & 50.67 & 1000 \\
\hline 11.21 & 8.39 & 343.17 & 3.12 & 24.30 & 2.00 & 34.80 & 36.56 & 50.67 & 1000 \\
\hline 11.44 & 8.40 & 331.84 & 3.12 & 24.30 & 3.00 & 34.85 & 36.58 & 50.69 & 1000 \\
\hline 11.31 & 8.42 & 336.45 & 3.12 & 24.30 & 4.00 & 34.89 & 36.63 & 50.71 & 1000 \\
\hline 11.25 & 8.41 & 335.99 & 3.12 & 24.30 & 5.00 & 34.94 & 36.66 & 50.75 & 1000 \\
\hline 2.18 & 0.00 & 47.45 & 2.37 & 0.74 & 0.00 & 27.32 & 27.23 & 33.12 & 1000 \\
\hline 3.42 & 1.89 & 53.52 & 2.32 & 1.56 & 0.50 & 27.47 & 27.33 & 33.35 & 1000 \\
\hline 6.76 & 5.17 & 71.41 & 2.16 & 1.67 & 1.00 & 27.47 & 27.36 & 33.43 & 1000 \\
\hline 10.55 & 8.70 & 78.63 & 1.97 & 1.83 & 2.00 & 27.51 & 27.38 & 33.74 & 1000 \\
\hline 10.66 & 8.76 & 71.22 & 1.98 & 1.83 & 3.00 & 27.57 & 27.39 & 33.98 & 1000 \\
\hline 10.74 & 8.70 & 71.42 & 1.98 & 1.84 & 4.00 & 27.61 & 27.40 & 34.31 & 1000 \\
\hline 10.78 & 8.77 & 70.66 & 1.97 & 1.83 & 5.00 & 27.62 & 27.45 & 34.64 & 1000 \\
\hline 2.22 & 0.00 & 46.64 & 2.36 & 1.73 & 0.00 & 28.03 & 27.88 & 35.92 & 1000 \\
\hline 3.45 & 1.82 & 58.69 & 2.34 & 4.31 & 0.50 & 28.14 & 28.01 & 36.11 & 1000 \\
\hline 6.87 & 5.09 & 90.77 & 2.17 & 4.47 & 1.00 & 28.16 & 28.05 & 36.11 & 1000 \\
\hline 10.77 & 8.78 & 114.78 & 1.99 & 4.65 & 2.00 & 28.18 & 28.10 & 36.08 & 1000 \\
\hline 10.84 & 8.73 & 108.32 & 2.00 & 4.66 & 3.00 & 28.21 & 28.13 & 36.29 & 1000 \\
\hline 10.83 & 8.70 & 107.94 & 2.00 & 4.66 & 4.00 & 28.25 & 28.15 & 36.50 & 1000 \\
\hline 10.86 & 8.73 & 106.45 & 1.99 & 4.65 & 5.00 & 28.29 & 28.22 & 36.46 & 1000 \\
\hline 2.18 & 0.00 & 45.97 & 2.34 & 3.61 & 0.00 & 28.53 & 28.59 & 38.34 & 1000 \\
\hline 3.46 & 2.49 & 66.84 & 2.32 & 9.13 & 0.50 & 28.63 & 28.75 & 38.09 & 1000 \\
\hline
\end{tabular}




\begin{tabular}{|c|c|c|c|c|c|c|c|c|c|}
\hline 6.91 & 5.05 & 127.47 & 2.17 & 9.44 & 1.00 & 28.65 & 28.79 & 37.95 & 1000 \\
\hline 10.74 & 8.64 & 179.23 & 2.00 & 9.67 & 2.00 & 28.71 & 28.82 & 37.88 & 1000 \\
\hline 10.92 & 8.67 & 171.28 & 2.00 & 9.66 & 3.00 & 28.74 & 28.86 & 38.20 & 1000 \\
\hline 10.89 & 8.63 & 172.43 & 2.00 & 9.66 & 4.00 & 28.76 & 28.90 & 38.68 & 1000 \\
\hline 10.84 & 8.69 & 171.66 & 2.00 & 9.66 & 5.00 & 28.80 & 28.94 & 37.84 & 1000 \\
\hline 2.23 & 0.00 & 44.84 & 2.32 & 7.32 & 0.00 & 29.00 & 29.27 & 37.05 & 1000 \\
\hline 3.48 & 2.23 & 85.27 & 2.30 & 18.59 & 0.50 & 29.15 & 29.50 & 37.11 & 1000 \\
\hline 6.93 & 4.96 & 193.84 & 2.15 & 19.26 & 1.00 & 29.15 & 29.52 & 37.21 & 1000 \\
\hline 10.80 & 8.47 & 304.97 & 1.98 & 19.55 & 2.00 & 29.17 & 29.55 & 37.34 & 1000 \\
\hline 10.81 & 8.47 & 299.92 & 1.99 & 19.55 & 3.00 & 29.18 & 29.61 & 37.38 & 1000 \\
\hline 10.79 & 8.48 & 292.82 & 1.99 & 19.54 & 4.00 & 29.26 & 29.64 & 37.48 & 1000 \\
\hline 10.80 & 8.44 & 297.98 & 1.99 & 19.54 & 5.00 & 29.28 & 29.69 & 37.67 & 1000 \\
\hline 2.23 & 0.00 & 43.98 & 2.34 & 6.70 & 0.00 & 29.46 & 29.94 & 39.12 & 1000 \\
\hline 3.50 & 1.83 & 93.96 & 2.31 & 24.14 & 0.50 & 29.60 & 30.24 & 39.05 & 1000 \\
\hline 6.93 & 4.89 & 239.16 & 2.15 & 25.24 & 1.00 & 29.59 & 30.26 & 39.05 & 1000 \\
\hline 10.75 & 8.31 & 380.10 & 1.98 & 25.57 & 2.00 & 29.61 & 30.28 & 39.31 & 1000 \\
\hline 10.80 & 8.34 & 371.06 & 1.99 & 25.58 & 3.00 & 29.69 & 30.33 & 39.48 & 1000 \\
\hline 10.76 & 8.31 & 373.76 & 1.99 & 25.57 & 4.00 & 29.73 & 30.36 & 39.67 & 1000 \\
\hline 10.71 & 8.30 & 373.60 & 1.99 & 25.57 & 5.00 & 29.75 & 30.42 & 39.54 & 1000 \\
\hline 2.34 & 0.00 & 48.97 & 2.72 & 0.32 & 0.00 & 33.46 & 35.11 & 48.65 & 1500 \\
\hline 3.68 & 1.94 & 53.16 & 2.68 & 0.83 & 0.50 & 33.55 & 35.21 & 48.72 & 1500 \\
\hline 7.49 & 5.65 & 64.64 & 2.58 & 0.85 & 1.00 & 33.55 & 35.30 & 48.86 & 1500 \\
\hline 15.30 & 13.11 & 75.14 & 2.35 & 1.15 & 2.00 & 33.55 & 35.31 & 48.80 & 1500 \\
\hline 15.41 & 12.98 & 63.42 & 2.35 & 1.16 & 3.00 & 33.57 & 35.27 & 48.72 & 1500 \\
\hline 15.59 & 13.33 & 59.92 & 2.35 & 1.16 & 4.00 & 33.59 & 35.26 & 48.67 & 1500 \\
\hline 15.59 & 13.16 & 59.39 & 2.35 & 1.16 & 5.00 & 33.62 & 35.25 & 48.66 & 1500 \\
\hline 2.36 & 0.00 & 49.04 & 2.71 & 1.20 & 0.00 & 33.21 & 34.79 & 48.31 & 1500 \\
\hline 3.68 & 1.87 & 57.73 & 2.67 & 3.92 & 0.50 & 33.30 & 34.89 & 48.32 & 1500 \\
\hline 7.48 & 5.65 & 79.23 & 2.58 & 4.03 & 1.00 & 33.32 & 34.93 & 48.37 & 1500 \\
\hline 15.22 & 13.05 & 119.59 & 2.34 & 4.39 & 2.00 & 33.30 & 34.94 & 48.35 & 1500 \\
\hline 15.37 & 13.10 & 106.40 & 2.34 & 4.39 & 3.00 & 33.35 & 34.96 & 48.36 & 1500 \\
\hline
\end{tabular}




\begin{tabular}{|c|c|c|c|c|c|c|c|c|c|}
\hline 15.47 & 13.10 & 103.30 & 2.34 & 4.39 & 4.00 & 33.38 & 34.97 & 48.37 & 1500 \\
\hline 15.43 & 13.14 & 101.13 & 2.34 & 4.40 & 5.00 & 33.41 & 35.00 & 48.33 & 1500 \\
\hline 2.40 & 0.00 & 49.18 & 2.70 & 2.12 & 0.00 & 32.97 & 34.45 & 47.53 & 1500 \\
\hline 3.65 & 1.93 & 65.08 & 2.66 & 9.06 & 0.50 & 33.06 & 34.63 & 47.57 & 1500 \\
\hline 7.36 & 5.60 & 108.02 & 2.57 & 9.38 & 1.00 & 33.06 & 34.63 & 47.62 & 1500 \\
\hline 15.16 & 12.99 & 190.10 & 2.34 & 9.81 & 2.00 & 33.07 & 34.64 & 47.66 & 1500 \\
\hline 15.27 & 12.99 & 177.42 & 2.34 & 9.81 & 3.00 & 33.10 & 34.66 & 47.69 & 1500 \\
\hline 15.25 & 13.05 & 173.42 & 2.34 & 9.81 & 4.00 & 33.15 & 34.67 & 47.73 & 1500 \\
\hline 15.36 & 12.98 & 171.83 & 2.34 & 9.81 & 5.00 & 33.19 & 34.70 & 47.78 & 1500 \\
\hline 2.43 & 0.00 & 50.33 & 2.69 & 2.56 & 0.00 & 32.82 & 34.22 & 46.89 & 1500 \\
\hline 3.74 & 2.08 & 76.72 & 2.65 & 17.60 & 0.50 & 32.91 & 34.46 & 46.91 & 1500 \\
\hline 7.45 & 5.44 & 155.56 & 2.56 & 18.44 & 1.00 & 32.91 & 34.45 & 46.94 & 1500 \\
\hline 15.04 & 12.75 & 307.91 & 2.34 & 19.02 & 2.00 & 32.90 & 34.44 & 46.98 & 1500 \\
\hline 15.05 & 12.86 & 291.67 & 2.34 & 19.02 & 3.00 & 32.92 & 34.44 & 47.05 & 1500 \\
\hline 15.17 & 12.84 & 288.16 & 2.35 & 19.02 & 4.00 & 32.96 & 34.47 & 47.19 & 1500 \\
\hline 15.11 & 12.77 & 291.36 & 2.35 & 19.02 & 5.00 & 32.99 & 34.48 & 47.32 & 1500 \\
\hline 2.42 & 0.00 & 52.49 & 2.71 & 5.40 & 0.00 & 32.82 & 34.15 & 46.45 & 1500 \\
\hline 3.70 & 2.45 & 87.79 & 2.67 & 23.99 & 0.50 & 32.91 & 34.42 & 46.42 & 1500 \\
\hline 7.51 & 5.35 & 192.08 & 2.58 & 25.18 & 1.00 & 32.90 & 34.40 & 46.39 & 1500 \\
\hline 15.13 & 12.52 & 395.42 & 2.35 & 25.84 & 2.00 & 32.90 & 34.37 & 46.22 & 1500 \\
\hline 15.27 & 12.66 & 377.54 & 2.35 & 25.83 & 3.00 & 32.90 & 34.37 & 46.23 & 1500 \\
\hline 15.22 & 12.63 & 380.20 & 2.36 & 25.83 & 4.00 & 32.92 & 34.36 & 46.46 & 1500 \\
\hline 15.20 & 12.59 & 375.51 & 2.36 & 25.83 & 5.00 & 32.93 & 34.38 & 46.45 & 1500 \\
\hline 2.81 & 0.00 & 49.35 & 3.95 & 0.78 & 0.00 & 36.04 & 37.50 & 51.68 & 1500 \\
\hline 4.47 & 2.18 & 55.81 & 3.91 & 1.87 & 0.50 & 36.05 & 37.56 & 51.61 & 1500 \\
\hline 9.10 & 6.81 & 75.08 & 3.79 & 1.93 & 1.00 & 36.00 & 37.56 & 51.55 & 1500 \\
\hline 15.98 & 13.14 & 75.46 & 3.60 & 2.22 & 2.00 & 35.94 & 37.50 & 51.50 & 1500 \\
\hline 15.95 & 13.12 & 61.80 & 3.59 & 2.22 & 3.00 & 35.90 & 37.45 & 51.45 & 1500 \\
\hline 16.11 & 13.42 & 59.07 & 3.58 & 2.23 & 4.00 & 35.88 & 37.42 & 51.40 & 1500 \\
\hline 16.56 & 13.71 & 57.81 & 3.57 & 2.24 & 5.00 & 35.85 & 37.40 & 51.35 & 1500 \\
\hline 2.80 & 0.00 & 49.66 & 3.95 & 1.44 & 0.00 & 35.18 & 36.97 & 50.86 & 1500 \\
\hline
\end{tabular}




\begin{tabular}{|c|c|c|c|c|c|c|c|c|c|}
\hline 4.44 & 2.15 & 61.30 & 3.91 & 4.69 & 0.50 & 35.24 & 37.04 & 50.79 & 1500 \\
\hline 9.12 & 6.76 & 92.35 & 3.79 & 4.85 & 1.00 & 35.19 & 37.01 & 50.75 & 1500 \\
\hline 16.06 & 13.16 & 115.24 & 3.60 & 5.18 & 2.00 & 35.14 & 36.97 & 50.71 & 1500 \\
\hline 15.88 & 13.17 & 101.36 & 3.59 & 5.18 & 3.00 & 35.13 & 36.93 & 50.68 & 1500 \\
\hline 15.74 & 13.14 & 96.96 & 3.58 & 5.18 & 4.00 & 35.12 & 36.89 & 50.64 & 1500 \\
\hline 15.92 & 13.10 & 97.47 & 3.58 & 5.18 & 5.00 & 35.09 & 36.86 & 50.61 & 1500 \\
\hline 2.82 & 0.00 & 49.55 & 3.95 & 2.11 & 0.00 & 34.64 & 36.50 & 50.33 & 1500 \\
\hline 4.47 & 2.32 & 68.00 & 3.91 & 8.83 & 0.50 & 34.72 & 36.62 & 50.28 & 1500 \\
\hline 9.21 & 6.73 & 115.57 & 3.79 & 9.16 & 1.00 & 34.69 & 36.59 & 50.26 & 1500 \\
\hline 16.05 & 13.03 & 171.50 & 3.60 & 9.52 & 2.00 & 34.65 & 36.56 & 50.24 & 1500 \\
\hline 16.12 & 13.09 & 158.00 & 3.59 & 9.52 & 3.00 & 34.63 & 36.55 & 50.22 & 1500 \\
\hline 15.88 & 13.09 & 150.81 & 3.59 & 9.52 & 4.00 & 34.63 & 36.53 & 50.20 & 1500 \\
\hline 15.80 & 13.03 & 153.88 & 3.58 & 9.52 & 5.00 & 34.64 & 36.51 & 50.19 & 1500 \\
\hline 2.73 & 0.00 & 48.81 & 3.94 & 4.31 & 0.00 & 34.33 & 36.23 & 50.13 & 1500 \\
\hline 4.37 & 2.27 & 83.17 & 3.90 & 19.02 & 0.50 & 34.40 & 36.46 & 50.12 & 1500 \\
\hline 9.01 & 6.57 & 186.80 & 3.79 & 19.85 & 1.00 & 34.39 & 36.42 & 50.12 & 1500 \\
\hline 15.88 & 12.76 & 303.44 & 3.60 & 20.35 & 2.00 & 34.39 & 36.41 & 50.13 & 1500 \\
\hline 15.77 & 12.78 & 295.66 & 3.60 & 20.35 & 3.00 & 34.40 & 36.38 & 50.14 & 1500 \\
\hline 15.70 & 12.80 & 287.41 & 3.59 & 20.35 & 4.00 & 34.41 & 36.38 & 50.15 & 1500 \\
\hline 15.75 & 12.79 & 291.06 & 3.58 & 20.35 & 5.00 & 34.43 & 36.39 & 50.18 & 1500 \\
\hline 2.86 & 0.00 & 47.63 & 3.92 & 4.33 & 0.00 & 34.41 & 36.25 & 50.59 & 1500 \\
\hline 4.47 & 2.05 & 91.36 & 3.88 & 23.88 & 0.50 & 34.51 & 36.55 & 50.62 & 1500 \\
\hline 8.96 & 6.49 & 206.85 & 3.78 & 25.08 & 1.00 & 34.50 & 36.54 & 50.65 & 1500 \\
\hline 15.49 & 12.64 & 374.32 & 3.60 & 25.64 & 2.00 & 34.51 & 36.52 & 50.67 & 1500 \\
\hline 15.49 & 12.60 & 353.13 & 3.60 & 25.64 & 3.00 & 34.55 & 36.52 & 50.70 & 1500 \\
\hline 15.52 & 12.65 & 348.25 & 3.59 & 25.64 & 4.00 & 34.58 & 36.54 & 50.74 & 1500 \\
\hline 15.63 & 12.65 & 357.99 & 3.58 & 25.64 & 5.00 & 34.63 & 36.55 & 50.79 & 1500 \\
\hline 2.73 & 0.00 & 49.96 & 3.69 & 0.36 & 0.00 & 33.59 & 35.19 & 48.56 & 1500 \\
\hline 4.31 & 2.35 & 54.56 & 3.59 & 0.85 & 0.50 & 33.67 & 35.30 & 48.48 & 1500 \\
\hline 8.58 & 6.34 & 66.67 & 3.34 & 0.92 & 1.00 & 33.64 & 35.40 & 48.42 & 1500 \\
\hline 15.69 & 13.11 & 70.26 & 2.96 & 1.17 & 2.00 & 33.63 & 35.39 & 48.40 & 1500 \\
\hline
\end{tabular}




\begin{tabular}{|c|c|c|c|c|c|c|c|c|c|}
\hline 16.10 & 13.47 & 56.19 & 2.94 & 1.19 & 3.00 & 33.64 & 35.31 & 48.38 & 1500 \\
\hline 16.96 & 14.30 & 54.19 & 2.89 & 1.21 & 4.00 & 33.64 & 35.26 & 48.35 & 1500 \\
\hline 17.38 & 14.82 & 54.13 & 2.85 & 1.23 & 5.00 & 33.63 & 35.23 & 48.35 & 1500 \\
\hline 2.73 & 0.00 & 49.96 & 3.69 & 0.36 & 0.00 & 33.59 & 35.19 & 48.56 & 1500 \\
\hline 4.31 & 2.35 & 54.56 & 3.59 & 0.85 & 0.50 & 33.67 & 35.30 & 48.48 & 1500 \\
\hline 8.58 & 6.34 & 66.67 & 3.34 & 0.92 & 1.00 & 33.64 & 35.40 & 48.42 & 1500 \\
\hline 15.69 & 13.11 & 70.26 & 2.96 & 1.17 & 2.00 & 33.63 & 35.39 & 48.40 & 1500 \\
\hline 16.10 & 13.47 & 56.19 & 2.94 & 1.19 & 3.00 & 33.64 & 35.31 & 48.38 & 1500 \\
\hline 16.96 & 14.30 & 54.19 & 2.89 & 1.21 & 4.00 & 33.64 & 35.26 & 48.35 & 1500 \\
\hline 17.38 & 14.82 & 54.13 & 2.85 & 1.23 & 5.00 & 33.63 & 35.23 & 48.35 & 1500 \\
\hline 2.75 & 0.00 & 49.00 & 3.61 & 2.06 & 0.00 & 33.61 & 35.09 & 48.47 & 1500 \\
\hline 4.24 & 2.34 & 68.17 & 3.53 & 9.51 & 0.50 & 33.71 & 35.25 & 48.45 & 1500 \\
\hline 8.57 & 6.29 & 117.93 & 3.29 & 9.85 & 1.00 & 33.68 & 35.23 & 48.46 & 1500 \\
\hline 15.62 & 12.99 & 189.15 & 2.92 & 10.25 & 2.00 & 33.67 & 35.23 & 48.46 & 1500 \\
\hline 15.77 & 12.98 & 175.76 & 2.92 & 10.25 & 3.00 & 33.67 & 35.23 & 48.46 & 1500 \\
\hline 15.74 & 13.09 & 169.33 & 2.92 & 10.24 & 4.00 & 33.68 & 35.22 & 48.48 & 1500 \\
\hline 15.80 & 13.01 & 171.69 & 2.92 & 10.25 & 5.00 & 33.71 & 35.23 & 48.52 & 1500 \\
\hline 2.76 & 0.00 & 48.85 & 3.59 & 4.80 & 0.00 & 33.71 & 35.15 & 48.83 & 1500 \\
\hline 4.20 & 2.30 & 82.31 & 3.51 & 18.77 & 0.50 & 33.79 & 35.38 & 48.84 & 1500 \\
\hline 8.29 & 6.10 & 170.59 & 3.27 & 19.55 & 1.00 & 33.78 & 35.36 & 48.87 & 1500 \\
\hline 15.41 & 12.71 & 312.93 & 2.91 & 20.06 & 2.00 & 33.76 & 35.36 & 48.89 & 1500 \\
\hline 15.56 & 12.82 & 300.16 & 2.92 & 20.06 & 3.00 & 33.78 & 35.35 & 48.91 & 1500 \\
\hline 15.66 & 12.83 & 291.60 & 2.92 & 20.05 & 4.00 & 33.81 & 35.36 & 48.95 & 1500 \\
\hline 15.73 & 12.78 & 296.16 & 2.91 & 20.05 & 5.00 & 33.84 & 35.37 & 48.99 & 1500 \\
\hline 2.70 & 0.00 & 47.00 & 3.59 & 4.18 & 0.00 & 33.97 & 35.45 & 49.69 & 1500 \\
\hline 4.21 & 1.95 & 87.79 & 3.49 & 22.94 & 0.50 & 34.09 & 35.75 & 49.75 & 1500 \\
\hline 8.43 & 6.01 & 198.08 & 3.25 & 24.08 & 1.00 & 34.05 & 35.74 & 49.81 & 1500 \\
\hline 15.69 & 12.59 & 370.17 & 2.90 & 24.66 & 2.00 & 34.06 & 35.75 & 49.84 & 1500 \\
\hline 15.64 & 12.70 & 354.43 & 2.90 & 24.65 & 3.00 & 34.10 & 35.75 & 49.88 & 1500 \\
\hline 15.57 & 12.68 & 354.68 & 2.90 & 24.65 & 4.00 & 34.13 & 35.79 & 49.93 & 1500 \\
\hline 15.56 & 12.62 & 353.65 & 2.89 & 24.65 & 5.00 & 34.17 & 35.81 & 49.99 & 1500 \\
\hline
\end{tabular}




\begin{tabular}{|c|c|c|c|c|c|c|c|c|c|}
\hline 2.27 & 0.00 & 49.67 & 2.50 & 0.34 & 0.00 & 32.10 & 33.65 & 47.12 & 1500 \\
\hline 3.56 & 2.62 & 53.45 & 2.46 & 0.85 & 0.50 & 32.23 & 33.79 & 47.13 & 1500 \\
\hline 7.27 & 5.53 & 65.12 & 2.39 & 0.85 & 1.00 & 32.26 & 33.94 & 47.54 & 1500 \\
\hline 15.13 & 13.07 & 81.64 & 2.01 & 1.19 & 2.00 & 32.24 & 33.98 & 47.56 & 1500 \\
\hline 15.10 & 13.00 & 68.86 & 2.03 & 1.19 & 3.00 & 32.28 & 33.90 & 47.55 & 1500 \\
\hline 15.14 & 13.06 & 65.84 & 2.03 & 1.18 & 4.00 & 32.32 & 33.93 & 47.40 & 1500 \\
\hline 15.26 & 13.03 & 64.01 & 2.03 & 1.18 & 5.00 & 32.37 & 33.97 & 46.90 & 1500 \\
\hline 2.28 & 0.00 & 49.95 & 2.49 & 1.34 & 0.00 & 31.66 & 33.06 & 45.75 & 1500 \\
\hline 3.53 & 2.30 & 58.10 & 2.45 & 3.83 & 0.50 & 31.76 & 33.18 & 45.80 & 1500 \\
\hline 7.24 & 5.46 & 79.83 & 2.38 & 3.91 & 1.00 & 31.81 & 33.22 & 45.82 & 1500 \\
\hline 15.08 & 13.09 & 123.15 & 2.01 & 4.28 & 2.00 & 31.84 & 33.27 & 46.19 & 1500 \\
\hline 15.44 & 13.15 & 109.91 & 2.03 & 4.29 & 3.00 & 31.88 & 33.30 & 46.05 & 1500 \\
\hline 15.41 & 13.17 & 105.51 & 2.02 & 4.29 & 4.00 & 31.95 & 33.35 & 46.14 & 1500 \\
\hline 15.33 & 13.17 & 104.84 & 2.02 & 4.29 & 5.00 & 32.00 & 33.40 & 46.22 & 1500 \\
\hline 2.24 & 0.00 & 49.90 & 2.46 & 2.22 & 0.00 & 31.10 & 32.27 & 45.00 & 1500 \\
\hline 3.53 & 1.79 & 64.89 & 2.43 & 8.60 & 0.50 & 31.25 & 32.44 & 44.96 & 1500 \\
\hline 7.19 & 5.35 & 105.68 & 2.35 & 8.87 & 1.00 & 31.26 & 32.49 & 45.18 & 1500 \\
\hline 15.06 & 12.97 & 185.22 & 1.97 & 9.33 & 2.00 & 31.27 & 32.53 & 45.28 & 1500 \\
\hline 15.16 & 13.00 & 176.50 & 1.99 & 9.34 & 3.00 & 31.33 & 32.58 & 45.16 & 1500 \\
\hline 15.28 & 13.00 & 170.64 & 1.98 & 9.34 & 4.00 & 31.42 & 32.63 & 45.20 & 1500 \\
\hline 15.26 & 13.03 & 172.59 & 1.98 & 9.34 & 5.00 & 31.51 & 32.70 & 45.38 & 1500 \\
\hline 2.22 & 0.00 & 51.94 & 2.46 & 4.77 & 0.00 & 30.53 & 31.47 & 42.76 & 1500 \\
\hline 3.53 & 1.83 & 77.98 & 2.43 & 18.50 & 0.50 & 30.65 & 31.74 & 42.93 & 1500 \\
\hline 7.19 & 5.20 & 159.39 & 2.36 & 19.28 & 1.00 & 30.66 & 31.75 & 43.29 & 1500 \\
\hline 15.12 & 12.65 & 319.39 & 1.97 & 19.89 & 2.00 & 30.69 & 31.80 & 43.37 & 1500 \\
\hline 15.29 & 12.80 & 306.53 & 2.00 & 19.90 & 3.00 & 30.75 & 31.84 & 43.58 & 1500 \\
\hline 15.20 & 12.84 & 308.93 & 1.99 & 19.90 & 4.00 & 30.82 & 31.89 & 43.25 & 1500 \\
\hline 15.14 & 12.75 & 303.83 & 1.99 & 19.90 & 5.00 & 30.89 & 31.93 & 43.26 & 1500 \\
\hline 2.31 & 0.00 & 54.11 & 2.48 & 5.84 & 0.00 & 30.12 & 30.78 & 40.91 & 1500 \\
\hline 3.66 & 2.02 & 89.88 & 2.44 & 24.10 & 0.50 & 30.18 & 31.06 & 41.00 & 1500 \\
\hline 7.28 & 5.21 & 192.86 & 2.38 & 25.22 & 1.00 & 30.19 & 31.09 & 41.15 & 1500 \\
\hline
\end{tabular}




\begin{tabular}{|l|l|l|l|l|l|l|l|l|l|}
\hline 14.82 & 12.57 & 394.99 & 1.99 & 25.91 & 2.00 & 30.20 & 31.10 & 41.27 & 1500 \\
\hline 14.93 & 12.57 & 390.33 & 2.01 & 25.91 & 3.00 & 30.25 & 31.13 & 41.36 & 1500 \\
\hline 14.97 & 12.59 & 387.43 & 2.00 & 25.91 & 4.00 & 30.30 & 31.18 & 41.65 & 1500 \\
\hline 14.95 & 12.63 & 379.72 & 2.00 & 25.91 & 5.00 & 30.37 & 31.23 & 41.79 & 1500 \\
\hline
\end{tabular}




\section{VITA}

Hasan H. Ali received the B.Sc. and M.Sc. degrees in mechanical engineering from University of Tikrit, Tikrit, Iraq, in 2007 and 2011, respectively. His master research was about CFD analysis of convection heat transfer enhancement using wavy channels which can be used in efficient low-cost and compact size heat exchangers. He received the Ph.D. degree in mechanical and aerospace engineering at the University of Missouri-Columbia, USA in 2017. His research interests during $\mathrm{Ph}$. D. study include modeling, design, and control of fluid power systems. 